
ช̊ 




\section{PRACTICAL DOG BREEDING}




\section{OTHER BOOKS BY}

THE SAME AUTHOR

The Airedale

Scotrish and Irish Terriers

The Fox Terrier

The Bull Terrier

Practical Dog Keeping 


\title{
PRACTICAL DOG BREEDING
}

\author{
BY \\ WILLIAMS HAYNES
}

Author of "The Airedale," "Scottish and Irish

Terriers," "The Fox Terrier," "The

Bull Terrier," etc.

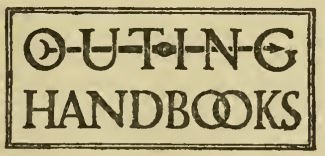

Number 30

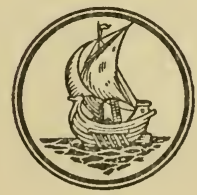

NEW YORK

OUTING PUBLISHING COMPANY MCMXV 


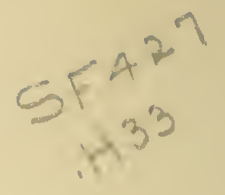

Copyright, 1915, by OUTING PUBLISHING COMPANY All rights reserved.

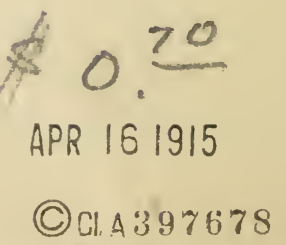


To

THREE FELLOW FANCIERS AND RIVAL BREEDERS, RALPH W. CONDEE

C. G. DARLING

EARLE J. WOODWARD

WITH THE AUTHOR'S THANKS FOR THEIR FRIENDLY

CRITICISMS AND VALUABLE SUGGESTIONS DURING THE WRITING OF THIS BOOK 


$$
=
$$




\section{PREFACE}

7 HIS little book is probably the first attempt to apply modern principles to

the problems of dog breeding. Like
il pioneers, it enjoys certain advantages and labors under peculiar handicaps.

The first object has been to help practical breeders. Clearness has been a prime consideration. Accordingly, everything has been translated into "dog talk." The examples have been drawn from the Stud Book, the kennels, the show ring and the field, and sometimes from the writer's experience as a judge and breeder. In a few instances, it has been necessary to have recourse to imaginary cases, but these too, have been expressed in dog fancier's language.

In the light of our present knowledge of heredity, it is plain that the selection practiced by most dog breeders is crude and haphazard. The breeding "system" advocated in these pages is not new, but it is hoped that the 
readers will close the book with freshened ideals and a better understanding of the fundamentals of dog breeding.

Williams Haynes. 


\section{TABLE OF CONTENTS}

PART ONE

THE PRINCIPLES OF DOG BREEDING

\section{CHAPTER}

PAGE

I Introductory CONSIDERations . . . . . . I3

II REPRODUCTION . . . . . . . . . . 30

III VARIATION . . . . . . . . . . . 48

IV HEREDITY . . . . . . . . . . . . 68

V Selection . . . . . . . . . . . 88

\section{PART TWO}

THE PRACTICE OF DOG BREEDING

VI Pedigree Studies . . . . . . . • • 107

VII BREeding Systems . . . . . • • . . 126

VIII The Stud Dog . . . . . . . . . . 145

IX The BRood Bitch . . . . . . . . . . I6I

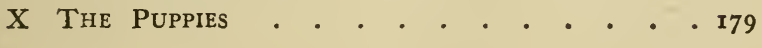

\section{APPENDIX}

Dog Breeding Calculator • . • . • • • 194 BIBLIOGRAPHY • • • • • • • • • • • • • I97 



\section{PART ONE}

\section{THE PRINCIPLES OF DOG BREEDING}

"Heredity and variation - every one knows that somewhere hidden among the phenomena denoted by these terms, there must be principles which, in ways untraced, are ordering the destinies of all living things."-BATESON. 



\section{PRACTICAL DOG BREEDING}

\section{CHAPTER I}

\section{INTRODUCTORY CONSIDERATIONS}

TO doubt, quite the orthodox introduction for this book on dog breeding would be a couple of paragraphs expatiating on the increased interest that we Americans are displaying in thoroughbred dogs for bench shows and field trials and as companions and guards; but I am sure that it is safe to assume that my readers are acquainted with these familiar facts.

Dog fanciers are also informed - at least roughly - of the tremendous advances that have been made the past few years in our new knowledge of the old study of genetics, for articles on the recent scientific developments and practical discoveries in plant and animal 


\section{PRACTICAL DOG BREEDING}

breeding have found their way not only into the popular magazines, but also into the daily papers. When the editors of newspapers in the big cities, whose touch upon the pulse of public interest must be very delicate, find a news value in these items about breeding, it bespeaks a widespread interest from a considerable number of our citizens.

In the midst of much popular interest in all phases of breeding, dog breeders, somewhat curiously, have given but the scantiest attention to the theoretical and practical work being done by trained biologists, the agricultural stations, and careful breeders of various kinds of stock. This is strange, for with certain limitations the knowledge gained in a painstaking study of the sugar content of beets will be valuable to all breeders, not only of plants but also of animals. Experiments in breeding mice and poultry have yielded results that are being practically applied by many horse and cattle breeders. Notwithstanding these good examples, dog fanciers have refused " to take the tips "- to borrow a phrase from the paddock - that fellow breeders and scientific investigators can give them.

This can, however, be reasonably explained. Dog breeding is a sport pure and simple, and, 
as such, it is very largely removed from any immediate economic influences. Scientific workers have devoted themselves to problems of more direct, practical value than the breeding of a dog to win championship points or a derby stakes. They have lent their aid in producing the 200-egg hen, in increasing the weight of cattle and of hogs, in raising the percentage of butter fat in milk. The breeders of economically important stock make breeding their business, and they have the sharp goad of gold to prod them to greater efforts. Their own stock has been the subject of scientific experiment. They have little difficulty in translating into dollars and cents the results of these experiments.

To-day many cattle, horse, sheep, hog, and poultry breeders are alive to the valuable helps that science can give them. Dog breeders have fallen hopelessly behind. A book on breeding that is as plain as A B C to a progressive dairyman will be full of terms that are new and unintelligible to the dog fancier. Every once in a while, one meets a dog breeder who passes among local fanciers as a scientific oreeder. Usually his "science" consists of copies of Darwin's "Origin of Species" and "Animals and Plants under Domestication," 


\section{PRACTICAL DOG BREEDING}

some hazy notions about atavism, telegony, and Mendelian inheritance, combined with a remarkably good knowledge of the points, history, and pedigrees of his breed. It may be stretching the truth to call such a man a scientific breeder, but he is surely making some serious effort along the right way. Most fan. ciers, it is to be feared, do even less than this.

In this day and generation and after all the work that has been done in the study of genetics, it is an outrage that a prominent dog owner should confess that "put two good ones together, and trust to luck" is his idea of successful dog breeding. Nevertheless, I am told by one of his friends that this is the acknowledged "system" of the owner of a certain large kennel. His kennel is filled with the best dogs that money can buy; every modern device to promote good care and good health has been installed in the building; an expert kennelman is in direct charge of the dogs, but is any one surprised to learn that these kennels have never produced a home-bred champion? When we hear such expressions: and when we see such wasted opportunities, it: quite justifies Mr. Muss-Arnolt's forceful statement that " ninety per cent of the so-called dog 
breeding is nothing more nor less than canine prostitution."

Dog fanciers have made a serious mistake in not grasping for their own benefit the important knowledge that has been accumulated in other fields by scientists and breeders. "The principles of scientific breeding" is a pretty good term to put a dog fancier to rout. Before he runs away, however, let him remember that only a few years ago "all these durned high falutin' notions "were scouted by the very farmer who to-day boasts of the blood lines of his cattle and the egg records in his poultry yards.

Let him also recall the many years his breed of dogs has been bred and the number of thoroughbred puppies that are whelped each year. Further let him remember that dogs, excepting field dogs, are bred solely for size, shape, and color, all variations of form, without any regard for the more elusive functional variations of weight, fertility, composition of flesh, and contents and quantity of the milk secretions which are all so vital in the breeding of live stock.

Compared with other breeders, the dog fancier has an easy task. In the first place he 


\section{PRACTICAL DOG BREEDING}

has less for which to breed. Secondly, dog histories and dog pedigrees have been for generations carefully recorded. Lastly, dogs have been bred toward approximately the same ideal for a considerable time - much of the commercial stock and poultry being comparatively recently manufactured varieties, comparable with the Boston Terrier and the Airedale. But are dogs nearer to the ideal, or do they breed closer to type than other domesticated animals?

A good understanding of the principles that have helped other breeders will help the dog breeder. Certainly, they will give him a big handicap over any rival who breeds on the " trust to luck system." Of course, these principles are not infallible rules, else we should long ago have been able to reduce all breeding to a series of mathematical formulæ that would produce champions at will. Just because we must work with such very uncertain tools, it is all the more important that we should learn all we possibly can and from every possible source.

Often dog fanciers mistake the true object of dog breeding. "The longest way round is the shortest way home," but many rush in frantically with the wild hope of breeding a 
champion in their very first litter. Once in a great while this succeeds, but most of the dismal failures are to be accounted for by this hasty, short-cut method. If instead of trying to get a chance winner, the dog breeder would set seriously to work to build up a strain of his own by gradually improving the quality of his stock, he would stand just about one hundred per cent better chance of accomplishing lasting results.

Every breeder should have a knowledge of the principles that underlie all successful breeding, and no breeder can be successful unless he be patient and persevering. Equally important in his equipment is a thorough knowledge of the breed. He must know the Standard that describes the ideal type; he must be able to apply this ideal to the actual dog without having it distorted by the individual application. In other words, he must have in his mind's eye a very definite conception of what sort of a dog he wants to produce, nor should he be easily changed from his ideal. A heavy burden is laid on the breeder's shoulders by every change of type.

The judges are largely responsible for these changes. The incompetent all-rounder, with his imperfect knowledge especially of the finer 
points of many of the breeds he so boldly essays to judge, is the worst offender. There is, however, little doubt that, if the Standards of the different breeds were expressed in more exact language and more liberally illustrated with weights and measures, much confusion would be avoided. Every one knows that a person's fingers should meet when clasped round his own wrist, and that both hands should just be able to encircle the neck. Each penny scale on every railroad platform in the country tells you what you should weigh according to what your height may be.

Similar figures can be worked out for different varieties of dogs and embodied in the S n ntards. One example will suffice: "Back $n \pi: \cdots "$ " is a quotation from one of the prescnt Stai.L. rds. "Length, back of skull to root of tail, $22 \mathrm{~T} / 2$ inches" carefully indicated for a dog, with 2 I inches specified for a bitch. This is also a quotation, taken from the official description of the Skye Terrier Club, drawn by Mr. Duncan Cunningham. There is no material for debate on the comparative clearness of these two definitions.

In addition to knowing the points of his variety, a successful breeder must know as much as possible about its past history. There are 
two phases of canine histories. The one treats of events; the other of dogs. The former is interesting; the latter is invaluable.

It is a standing joke that the origins of all breeds of dogs are shrouded in mystery; but almost always we know something of the conditions that called new breeds into existence and of the uses to which they were originally put. In many cases, we have some pretty reliable information about the materials employed in the "manufacture" of certain varieties. A knowledge of these things is useful. Some idea of the work that was expected of the ancestors of our terriers gives one a wonderful insight into the true meaning of the whys and wherefores of a wire jacket. To know that the Otterhound was a factor in the creation of the Airedale explains where this popular dog got his exceptional nose, his big size, and also his tendency to unattractive ears.

Interesting and suggestive as this part of a breed's history is, it is not nearly so essential to a successful breeder as a sound working knowledge of the good and bad points of the different individual dogs of the past. Without this knowledge a breeder cannot do any real breeding; he will only be mating dogs. No landlubber at sea in an open boat without sail 


\section{PRACTICAL DOG BREEDING}

or rudder could be more completely helpless. James Watson in his work "The Dog Book," a book, by the way, that should be in every fancier's library, gives a vivid illustration of what is the real meaning of a pedigree. $\mathrm{He}$ says:

"We have already said that pedigree is valuable, and it is an essential in the case of purchasing for breeding, but we again repeat that, if the buyer does not know something regard-

\begin{tabular}{|c|c|c|c|}
\hline \multirow{4}{*}{$\begin{array}{l}\text { Sire } \\
\text { King's } \\
\text { Masterpiece }\end{array}$} & \multirow[t]{2}{*}{ King } & Kaiser & $\left\{\begin{array}{l}\text { Red Idol } \\
\text { Kriffel }\end{array}\right.$ \\
\hline & & Kindle & $\left\{\begin{array}{l}\text { Ch. Breda Mixer } \\
\text { Red Inez }\end{array}\right.$ \\
\hline & \multirow[b]{2}{*}{ Killarney Lily } & Balmoral Bill & $\left\{\begin{array}{l}\text { Breda Dan } \\
\text { Balmoral Fan }\end{array}\right.$ \\
\hline & & $\begin{array}{c}\text { Saintfield } \\
\text { Midge }\end{array}$ & $\left\{\begin{array}{l}\text { Red Idol } \\
\text { Shankhill Violet }\end{array}\right.$ \\
\hline \multirow{4}{*}{ im } & & Red Idol & $\left\{\begin{array}{l}\text { Red Ire } \\
\text { Breda Iris }\end{array}\right.$ \\
\hline & Kaiser, пооoc & & $\left\{\begin{array}{l}\text { Ch. Breda Mixer } \\
\text { Knoxonia }\end{array}\right.$ \\
\hline & (Kindle & $\left\{\begin{array}{c}\text { Ch. Breda } \\
\text { Mixer }\end{array}\right.$ & $\left\{\begin{array}{l}\text { The Irish Am- } \\
\text { bassador } \\
\text { Breda Vixen }\end{array}\right.$ \\
\hline & & Red Inez & $\left\{\begin{array}{l}\text { Ch. Bachelor } \\
\text { Breda Florence }\end{array}\right.$ \\
\hline
\end{tabular}


ing the dogs in the pedigree, either personally or from reliable information, one string of names is as good as another to him. Here is a case in point as shown in the following Irish terrier pedigree (see page 22):

"According to the United States government test the Irish terrier that owns that pedigree is practically a mongrel, because in two generations it has but one ancestor with a studbook number. . . . The seeker for champions in the pedigree discards it because he only finds Breda Mixer and Bachelor, and they are too far back. Now we will put it before the man who knows:

" I see a Knox bred one. Knox has done quite a bit of good breeding in his time and they seem to come better right along, but that is to be expected, of course, if the man knows his business; and inbred too, and in the fashionable way. Did you ever notice how many good ones are by a son of a dog that gets good ones out of a daughter?... In this case you have a son of King bred to sister of King.

" "Why, man, you have a wonderful pedigree here. I have never seen anything like it before: full of Breda Muddler blood, or what made him, and not once is he mentioned. Here you have King's sire Kaiser out of 
Kriffel, by Breda Mixer who got Muddler, and Kaiser's sire Red Idol was out of Breda Iris the dam of Muddler. The King's dam Kindle is a full brother in blood to Muddler, for Red Inez was a sister, if not a little sister, to Breda Iris.

" All this is repeated below in the pedigree of Koerchion, King's sister. Do you know how Kriffel's dam Knoxonia was bred? No; well, she was a Knox anyway, and we can take her as all right. King's Masterpiece is a halfbrother of our Celtic Badger, I see, for his dam is Killarney Lily. I met a man the other day who had lately been at Belfast, and he told me of his visiting Mr. Knox and spoke of his dogs very favorably. He likes King very much; and I remember his saying that it was little wonder that Badger and this Masterpiece, which he saw, were good ones, for Killarney Lily was one much above the average. From the way he spoke, she must be a very nice one.

" ' If I remember rightly you won a couple of times with this bitch, but she did not strike as one who would go on much further than she then was. I know, however, that if I owned her nothing would induce me to part with her until I had tried her as a brood bitch. If she 


\section{INTRODUCTORY}

does not prove a good one, then there is no value in a pedigree.'

Formerly dog breeders relied almost exclusively upon what might be called individual selection. They picked out their best bitches and bred them to their best dogs. In the light of modern knowledge, they followed the "trust-to-luck" theory more than they ever would have acknowledged, for they rather prided themselves in their quaint, old-fashioned way on their skill and care as breeders. Most dog fanciers to-day are following right in their footsteps, practicing individual selection, with possibly some efforts to breed out faults by counterbalancing, or mating a bitch to a dog whose strongest points offset her own peculiar weaknesses.

All this is directly in the face of the fact that the ancestors more remote than the immediate parents are being continually shown to be highly important. This places more and more emphasis on the value of a real understanding of a pedigree, which means a real knowledge of the dogs. One of the chief advantages of the foundation of a strain of your own will be the very intimate knowledge that you must of necessity have of the individuals behind your 
breeding stock. The breeder who knows the most about the points of the dogs of the past will be best able to foretell the quality of the puppies of the future.

An example will make even clearer the very great practical value of a knowledge of the real meaning of a pedigree. A certain strain of Airedales has produced a great number of winners, but it inherits from its founder a tendency to light, round eyes and heavy ears. That these defects are buried in the blood is proved not by the shining examples of perfection in these points that this strain has produced, but by the fact that the majority of dogs bred in this strain are more or less "off" in eyes and ears. To be specific, a certain dog of this strain is being extensively used at stud to-day. As an individual he is good in ears and his eye escapes comment except from the hypercritical judge. Without knowing his family tendency to poor eyes and ears, no one would expect his get to be bad in these points. Nevertheless, a breeder would be bitterly disappointed should he use him to improve these points, and many of his puppies are downright faulty in these respects.

To sum up the requirements of a successful breeder and the equipment that he must have: 
He must first of all be a true dog lover and a patient man blessed with that spirit that comes up smiling after many disappointments. These things are inborn in the man himself, and no amount of study can provide him with these necessary characteristics.

A good, sound working knowledge of his breed, however, may be acquired by visits to shows, trials, and kennels, by talks with experienced fanciers, judges, and breeders, by reading historical articles in the kennel papers and by study of the monographs that various authorities have written on different breeds.

The third requirement for success as a dog breeder is a knowledge of the principles that underlie modern scientific breeding. We have seen that, as a class, dog owners are behind other stock breeders in their application of these scientific helps to practical problems. Some fanciers will find in the following pages terms and ideas that may be quite new to them, but within the limits of clearness all that has not a direct practical bearing on breeding operations has been omitted. It is to be hoped that some breeders will be stimulated to pursue further their study, and to this end a short list of the most important and suggestive books is given in the Appendix. 
If a dog owner is a breeder at heart, if he has a good knowledge of his breed and of the principles of breeding, he can make a kennel that will become world famous. Others have done so. The Duchess of Newcastle laid the foundation of her justly celebrated kennels by the purchase of two Fox Terrier bitches, Eber Post, a wire, and Partney Prude, a smooth, for which she paid just ten pounds, fifty dollars. Ask any terrier man about Ch. Collarbone of Notts, or Ch. Cackler of Notts, or Ch. Collar of Notts, or Ch. Corker of Notts, or about that litter of nine all first prize winners and two of them champions. All these terriers were bred by this lady from her own strain.

As a matter of fact, the modest fancier usually has a distinct advantage over the larger kennels. Without a fat purse he is forced, in this day of high priced prize winners, to breed his own good ones. Necessity was ever the mother of invention, and the Stud Books, both in England and this country, show that there have been more champions bred in the "kitchen kennel" than in the wealthy fancier's "show place."

The American dog tancy needs careful, serious breeders. For years we have been importing dogs from England. Far too often it 
has been a case of the last dog over shall be first in the award list. In some breeds we have bred dogs as good as England's best specimens, but in many varieties the retort of a professional at a recent show is true enough to have a sharp sting to it. Two dogs were on the block before the judge, and the handler of one waved the stars and stripes by saying of his entry, "He's an American-bred, sir." The other dog's handler replied, "Yes, and he looks it."

Will a dog fancier be repaid for the time, and the trouble, and the expense, and the work, and the disappointments of breeding? If he is a successful breeder, he most surely will. Financially, because a good dog always commands a good price, and a kennel with the reputation for turning out good dogs will be a Mecca to which bench show and field trial devotees will always flock. Less substantial than dollars and cents, but hardly less satisfying to a true breeder are the personal satisfaction of having accomplished something difficult and worth while and the honor always accorded a breeder of champions among good fanciers. To breed a great dog is a feat that calls for more than time and money. It demands brains and gameness and good faith. 


\section{CHAPTER II}

\section{REPRODUCTION}

HE similarity between the artificial selection of the breeder and the natural selection by means of which Darwin first explained evolution has often been pointed out. By repeated citation it has become very trite, but, like most classic examples, it is a very useful one. We can cover much important preliminary ground by briefly considering this Darwinian theory.

In his "Origin of Species" Darwin brought forward a wealth of evidence to prove that like tends to produce like (that two Beagles will have Beagle puppies) that the offspring always differ from their parents (that no two Beagles were ever identically alike). These are the two fundamental laws of heredity and variation. Darwin said in substance that, granting the truth of these, the fierce struggle for existence always going on in nature would explain the differences in the various species through 
the action of natural selection, or the survival of the fittest.

In order to get this plainly before us, let us take an imaginary case and reduce it to its very simplest form. Let us suppose that by the invasions of some stronger animal a remote ancestor of the dog is driven out of a wooded, mountainous country and forced to live on the bare, open plains. Let us leave out of consideration every factor except the procuring of his food. On the plains he has no cover to aid him in stalking his prey, and he cannot, therefore, approach his victim so closely as before.

It is evident that those wild dogs which can run ever so little more swiftly will stand just so much better chance of "making a living " in the new country. Moreover, skulking through the deep shadows, a dark color would make him less conspicuous, and, whether he was hunting or being hunted, would be a distinct advantage. In the open, however, against the light shades of the rocks and dried grasses, a dark color would be a decided handicap, but a dun or a fawn would be an advantage. Obviously, any dogs that were a bit lighter in coloring would be enabled to creep just so much nearer to a feeding antelope. Any dogs swifter of foot and lighter in color will be bet- 


\section{PRACTICAL DOG BREEDING}

ter able to live on the plains than their slower, darker brothers and sisters. They will have just that slight advantage in getting food and escaping enemies that in the life and death fight for existence will enable them to win out. Natural selection will be working for speed and light coloring.

Those wild dogs, in our example, that are swiftest and lightest will, we have seen, be better able to live on the plains. The chances are in favor of their being the parents of the following generation. Their offspring will contain individuals some lighter and some darker than their parents, and also some swifter and some slower. On the average, however, the second generation will be lighter and swifter than the generation to which their parents belonged. Again the swiftest and the lightest will survive, and these selected individuals will almost certainly be swifter and lighter than their parents, who were in turn the swiftest and lightest of their own generation. And so on for ages.

Eventually the comparatively slow moving, dark colored wild dog that came down to the plains from the mountains has become a fast running, dun colored one. Any dog fancier knows that this will mean that a thick-set dog 
with erect shoulders and straight hocks has become a lithe, racy animal with sloping shoulders and well let down hocks. The demand for increased speed has forced important changes in conformation.

Remember, moreover, that we have only considered the single factor of procuring food. Not only this, but every other condition of his life has been radically changed by the migration from the wooded hills, and each change may have a very direct effect. It is not hard to imagine that, given sufficient time, the dog might be so changed as not to be recognized as belonging to the same species.

This is briefly the explanation of evolution according to the Darwinian theory of natural selection. It is well to note that all biologists agree in their belief in evolution, and the disputes that are engaged in are not over the question of evolution, but over explanations of how evolution has been accomplished and how it is working to-day.

It is plain, for example, that natural selection cannot account for all the phenomena of evolution. It can only act as a sieve, winnowing the fit from the unfit. As Arthur Harris has said, "Natural selection may explain the survival of the fittest; but it cannot explain the 


\section{PRACTICAL DOG BREEDING}

arrival of the fittest." Neither can it account for any useless character, like the tail of the peacock, for example, which is certainly no help to the bird in its struggle for existence. Darwin himself recognized these objections and suggested sexual selection as a supplementary force. Other theories have been advanced, but they do not interest us. The points to be brought out here are that evolution is accepted by all biologists, and natural selection is acknowledged to be one of the most important factors in evolution. The laws of heredity and variation are fundamental beliefs.

Both artificial selection and natural selection rest upon heredity and variation. They differ in that natural selection is passive and usually very slow in its action, but artificial selection, in the hands of a breeder, who is able to work backward through pedigrees and forward by judging his breeding stock not only by their own qualities but also by the qualities of their existing offspring, is more active and yields quicker results.

Fundamentally the breeder's work is selection, and all selection is based upon the workings of heredity and variation. If like did not beget like all would be chaos. What could a breeder do if a Beagle dog bred to a Beagle 
jitch resulted in a litter consisting of a Gordon Setter, a French Bulldog, a dog with undreamed-of characteristics, and maybe a lion cub and a young raccoon thrown in for good neasure? This sounds like extravagant foolshness because the law of heredity is so universal that any exception seems beyond comorehension.

On the other hand, if the mating of two Beagles produced a litter all exactly a mean between the two parents, a perfect combination of all their physical points and mental characteristics, breeding would be absolutely fruitless. In a very short time we should have all Beagles reduced to a dead level average. Every single one would be the same size, have the same conformation and markings, and be identical in voice, speed, nose, and disposition. Thanks to variation a selection is possible, and thanks to heredity a selection is effective.

Plainly, a breeder cannot know too much about these two basic laws upon which all his work depends. Before taking them up, however, we can advantageously look into the mechanical side of reproduction. It has an important bearing upon our work.

Most people know that the whole body of any animal is made up of a great colony of 


\section{PRACTICAL DOG BREEDING}

minute cells. Bone cells and muscle cells, for example, differ in many ways, but all cells have much in common. Every cell is filled with a

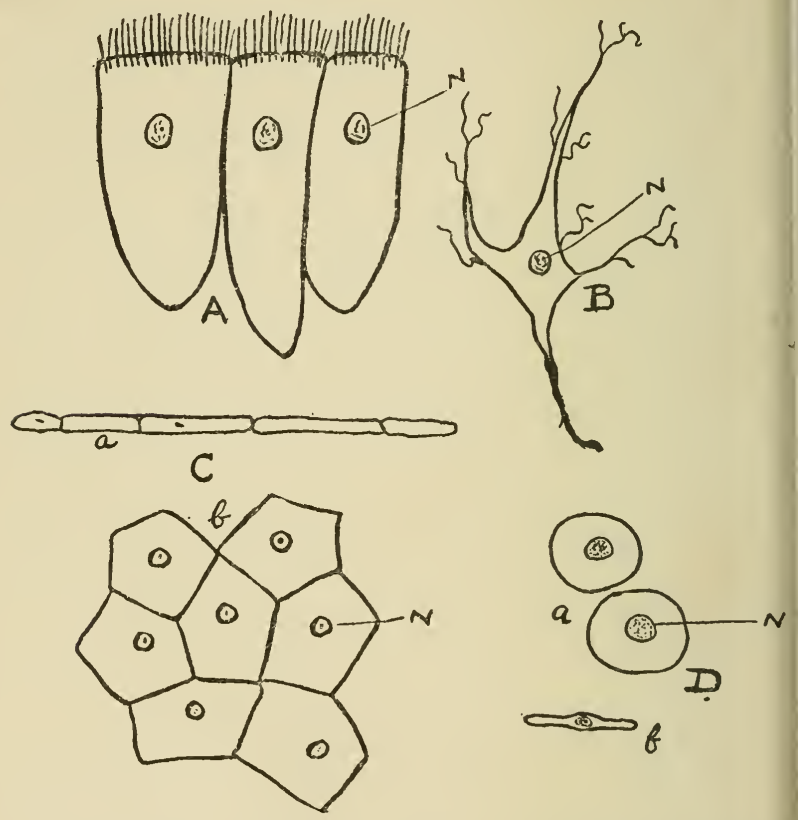

Fig. I.- Typical Cells of the Frog. A, surface of the tongue; $B$, nerve cell; $C$, the top layer of skin, $a$, in cross section, b, surface view; D, blood cells, a, top view, b, cross section. From life; highly magnified, but not to scale.

gelatinous substance called protoplasm in which is a tiny speck, the nucleus. (Fig. I.) All functions of the body are carried on by 
cells, each doing its own work. Moreover, all growth in a body is accomplished by means of cell division, in which the nucleus splits in half and separates, each part carrying with it
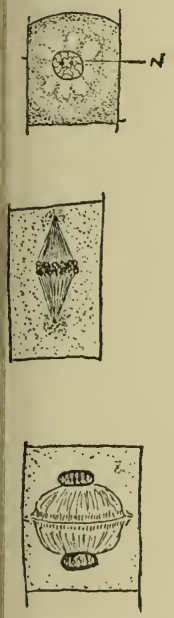
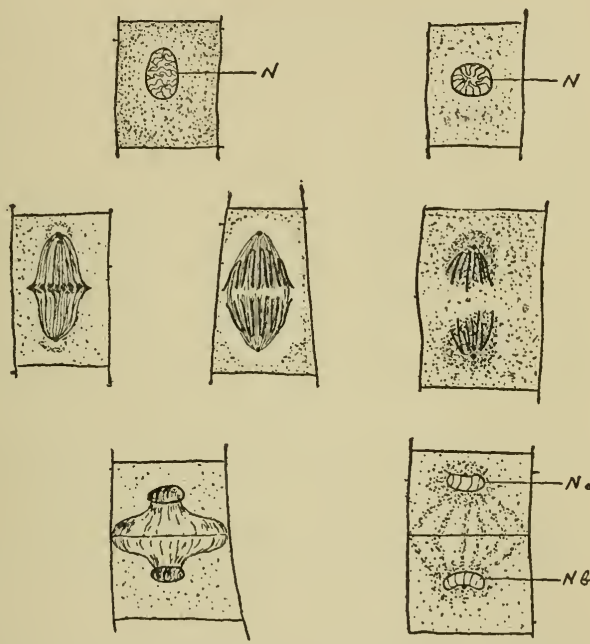

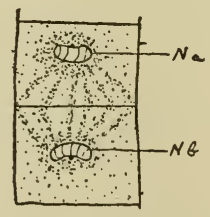

FIG. 2.- Cell division showing splitting of nucleus (N), division of cell contents with each half, and formation of new cell wall. Highly magnified from Root Tip of Onion.

half of the protoplasm. (Fig. 2.) Finally the whole colony of cells that makes up the living organism has arisen from a single cell. In this minute germ cell are hidden away all the secrets of heredity and variation, secrets that man has been trying for years to wrest from it. 
Dogs, like the other higher animals, reproduce sexually. The combination of the male and female germ cells is necessary for the development of a puppy. The sperm, or male germ cell (Fig. 3, A) is even many times smaller than the microscopic female cell. It is a free

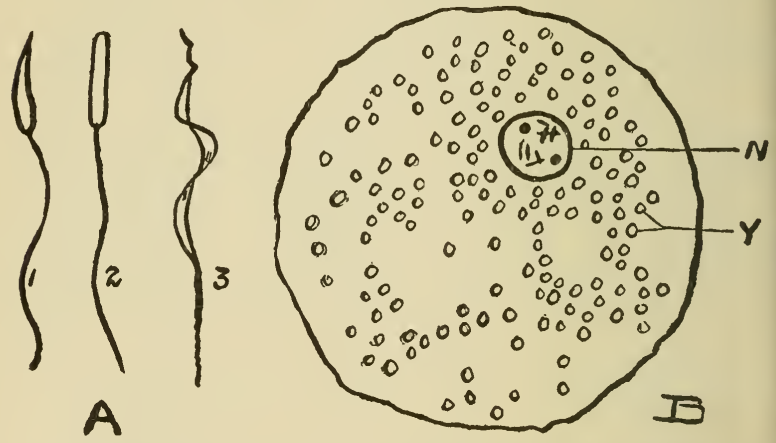

Fig. 3.- Germ Cells. A, Sperms, (1) Snail, (2) Frog, (3) Bird; B, diagram of typical ovum, (N) nucleus, (Y) yolk granules (Food supply). Not drawn to scale.

moving body, shaped like a spear with a roundish head and a whip-like tail, which is used, like a propeller, for locomotion. These sperm cells are produced literally in millions. The ovum, or female cell (Fig. 3, B) is larger, round in shape, and without the power of motion. Like other cells, both the sperm and the ovum contain protoplasm and a nucleus.

Fertilization takes place when the sperm 


\section{REPRODUCTION}

actually unites with the ovum. In some way that is not yet thoroughly understood, the ovum has the power of attracting to itself any sperms that are near it. They move toward the ovum, tails being used as propellers. Finally one - but only one - sperm pushes its spearlike head in through the wall of the ovum, the tail being left behind. The head of the sperm, containing its nucleus and protoplasm, now travels to the nucleus of the ovum. The two nuclei fuse together. Fertilization has taken place. The tiny germ cell is definitely started on its way toward the development of a new individual. It is endowed with tremendous energy and divides repeatedly after a set pattern till in the place of one cell there are many. It grows, fed by the mother to which it fastens itself, and in the course of time it develops into a puppy and is born. The details of the development of the embryo inside its dam are highly interesting, but since a breeder can have no direct influence over that development once fertilization has taken place, it would be out of place for us to follow these studies here.

Let us, however, return a moment to the sperm and the ovum. In the microscopic cells are hidden away all the possibilities of a new dog, a new dog that will be of the same va- 


\section{PRACTICAL DOG BREEDING}

riety as his parents, at the same time differing from them in a thousand ways. For years scientists have been patiently trying to wrest from these tiny specks of life their wonderful secrets of heredity and variation. Much is still a mystery, but many things have been learned that can be of great value to dog breeders.

There have been a number of explanations proposed to account for the well known fact that like tends to produce like. One of the earliest of the theories of heredity assumed that the great number of different parts that make up each adult animal each gave off little buds which were carried by the blood to the reproductive organs and stored away in the germ cells. According to this view, a miniature duplicate of the parent was tucked away in its own germ cells, each sperm and each ovum containing a complete set of buds representing every part of the body of the animal that produced it.

This theory has been discarded. One obvious objection to it is to be found in the case of mutilations. If each part of the body gives off buds to be stored away in the germ cells, it follows that should a certain part be removed in the parent it ought to be lacking in the offspring. All Spaniel puppies would therefore be born with short tails, since the buds for the 
last few joints at the end of the tail should be missing from both parents. Other theories have been advanced, but the one in which we are particularly interested is the germ plasm theory of the great German biologist, August Weismann.

In all its details this germ plasm theory is
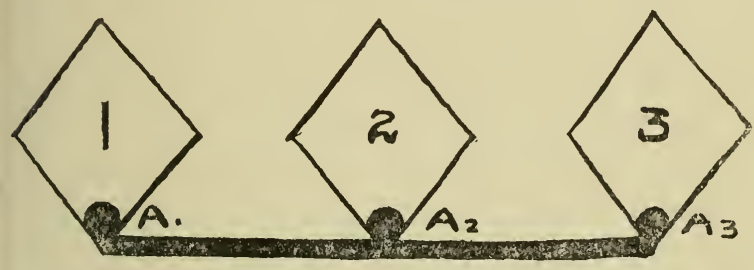

FIG. 4.- Diagram of the Germ Plasm Theory. The Squares ( 1,2 , 3) represent the individuals of succeeding generations; the black dots $\left(\mathrm{A}_{1}, \mathrm{~A}_{2}, \mathrm{~A}_{3}\right)$ are the vital germ cells passed on direct with the bodies (squares) built around them for their protection.

somewhat complicated to one who has not had a scientific training, but it may be briefly explained. According to Weismann's conception the whole of the fertilized ovum is not used up in the development of the new individual. A part of it is put aside and remains unchanged for the special purpose of making the germ cells which this new individual will use to beget the following generation. The accompanying diagram (Fig. 4) will help to make clearer this important idea. The black dots ( $\mathrm{A}_{1}, \mathrm{~A}_{2}$, 


\section{PRACTICAL DOG BREEDING}

etc.) are the germ plasm that is passed along complete and intact from generation to generation. The white squares are the individuals of the different generations, each an elaborated collection of specialized cells developed for the express purpose of protecting and supporting the germ cells. This idea of heredity usually associated with Weismann's name is the most reasonable explanation of the observed phenomena that we have, and other men, notably Haeckel, Owen, Brooks, Rauber, and Galton, have been contributors to this important conception. The setting aside of certain cells at the very beginning of embryonic development and later making reproductive organs out of them has been actually seen under the microscope. There are other important facts supporting the germ plasm theory, and, as we shall see, it offers a sound explanation for most of the observed facts of heredity.

If the germ cells which give rise to the offspring are continuous with those that gave rise to the parent, and this is the generally accepted belief among biologists, breeders will find new ideas of great practical benefit presented to them. It follows that the transmission of the individual characteristics of the sire and the dam is not nearly so direct as dog breeders are 
prone to take for granted. "Like father like son" is not nearly so accurate a saying as "like tends to produce like." This understanding of heredity throws the emphasis off the individual and upon his or her units of inheritance. We are not mating a dog and bitch of certain physical points and peculiar characteristics. We are combining two germ plasms, each bearing certain factors of inheritance. This is a great deal more than a mere difference in terms.

The direct connection from generation to generation is through the germ plasm, and any variation in the offspring lies, not in the development or characteristics of the parents, but only in those things that may affect the nature of their germ plasm. It is as if you had a number of similar balls of soft clay, which will represent the germ plasms. You can put these clay balls into paper bags of different sizes and colors and shapes. By so doing, however, you will not in the least change the clay balls no matter how different they may look in their different bags. Moreover, it would be quite possible to put two identical balls in two like bags, and yet to change the nature of the balls markedly by putting one in a hot oven for a few hours. The two bags will still appear quite alike, but inside of one will be a baked, 
hard ball of brick, and in the other a damp, plastic ball of clay. According to the germ plasm theory of heredity, the germ plasm, the balls of clay in our example, are passed along from generation to generation directly, and the differences in the individuals bearing the germ plasm is not a sure test of differences in their germ plasm.

That there are things, however, that affect the nature of the germ plasm is very evident, or else there would be no variation. As a matter of fact we all appreciate that there is constant and infinite variation. The germ plasm theory must be able to reasonably explain this, or it will not be acceptable.

Naturally the combination of two different germ plasms in the mating of a dog and bitch would cause a variation. There must, however, be other factors, or all the puppies of a litter would be identical, each a mean between its two parents. This certainly does not tally with common observation. There must be other factors at work.

We have seen that the fertilized ovum is a combination of the male sperm and the female ovum, each, according to the accepted theory, carrying its own germ plasm with its individual units of heredity. As has been pointed out, 


\section{REPRODUCTION}

all growth is by cell division in which the nucleus divides, each half taking with it half of the protoplasm. Fertilization is essentially the direct opposite of this, for two cells fuse. It is easy to see that were two cells to combine we should have, in a quantitative way, a double cell with a double nucleus and double the regulation amount of protoplasm. This piling up would continue, and in the next generation we should have a quadruple cell. Without going into the technical details, it may be said that when the sperm cells are maturing in the male reproductive organs they reach a certain stage when they divide into four parts, each containing a fourth of the original nucleus and a fourth of the protoplasm. The ovum also undergoes reduction, as this is called. In this case, however, three-fourths of the original nucleus is extruded from the cells, thrown off, and lost so far as reproduction is concerned. The result of this is that the sperm and the ovum are each, in a quantitative sense of the word, a quarter cell. When they combine and fuse they make a half cell, which amounts to the same thing as a full cell dividing.

This reduction is an actual fact and has been often seen in the germ cells of many different 


\section{PRACTICAL DOG BREEDING}

kinds of animals. Of course, only the main features of reduction have been outlined, and all confusing technical words have been stripped away. Some knowledge of the subject, however, is important to the breeder who would have a better understanding of the nature of heredity.

The reduction of the sperm and ovum is regarded as a factor that introduces a primary cause for variation. The interpretation of the observed facts is as follows. The germ cells are considered as being made up of definite and distinct units of inheritance, called by Weismann determinants. By dividing the germ cell first up and down and then crossways, the determinants are divided in equal numbers but in different combinations. A homely example would be to cut a cherry pie into quarters. Each quarter would contain approximately the same number of cherries - but they will be different cherries. So, reduction of the germ cells is supposed to yield an infinite number of different combinations of the units of inheritance, resulting in infinite variation.

The importance to a practical breeder of these modern conceptions of inheritance will be better appreciated when we come to apply them directly to the specific problems that fanciers 


\section{REPRODUCTION}

nust solve. The dog breeder should get them lear in his mind, for we shall use them later. Weismann's theory of heredity considers the incestral germ plasm as being passed on diectly from generation to generation and reyards the body as a case developed round the jital germ cells for their nourishment and proection. Reduction of the sperm and the ovum $\mathrm{s}$ a well known fact that is interpreted as suplying a fundamental cause for variation, in so nuch that the reduced cells will each contain different combinations of the units of heredity, or determinants. 


\section{CHAPTER III}

\section{VARIATION}

T F like literally produced like, without any variation, there would be neither dog shows nor field trials. Nor would there be any dog breeders, though, of course, some people might raise dogs to supply a demand for a useful animal just as manufacturers turn out tenpenny nails, sugar coated pills, and lead pencils.

Variation is the raison d'etre of the bench show and the field trial. Just imagine a judge confronted by a class of Boston Terriers in which every single entry was absolutely identical in conformation, size, markings, and disposition. It would be like trying to select the best of a paper of pins. Try for a moment to wax enthusiastic over a field trial in which every bird dog not only looked just alike, but was blessed with the same nose, speed, bird sense, and training. It would be about as thrilling as a coursing match on treadmills. 


\section{VARIATION}

Moreover, variation is the backbone of rreeding. Contrast the mingled hopes and ears of the breeder who studies for the first ime the puppies of a new-born litter with what is feelings would be were he absolutely cerain that every last youngster in the lot was an xact reproduction of its sire and dam. For a ime, to be sure, there would be some interest n crossing established varieties. Even this would be quite mechanical, and the results could se foretold with discouraging accuracy. Moreover, our many times great grandfathers would ong, long ago have exhausted the possibilities of such cross-breeding, which, if persisted in under a condition of heredity without variaion, would eventually result in the development of a single breed, the great average dog, the exact mean of all varieties. He might be a very remarkable dog to look at, but he would hardly prove an interesting animal in the breeding kennels.

It is due to variation that the breeder is enabled to make a choice. Only when a choice is presented is there any possibility of improvement. It is very obvious that variation is an important subject for the dog breeder. There are a number of very practical problems that are brought much closer to their correct solu- 
tion by a better understanding of variation

What breeder, for example, would not likı to know the exact limits of variation, anc how much it can be controlled? Whether o1 not variations are correlated, and does a lon head of necessity mean a long back? What kinds of variations are most surely inherited which are hardest to fix in a strain; which are easiest to lose? These questions, and others like them, can be applied by any breeder to his own dogs. It is easy to appreciate their vital importance. A clearer understanding of the nature of variations of all kinds is certain to be a very practical help.

Dog fanciers are fairly brought up on variation: their shows and trials are based upon it, and their breeding would be aimless without it. They have trained their eye to appreciate slight differences in dogs that an ordinary person never notices; but, skilled as our judges and breeders are in recognizing the slightest gradations, they are not in the habit of distinguishing between different kinds of variations and of classifying them. These distinctions are important. Their recognition avoids considerable confusion. They are, moreovis, rather obvious once the attention is directed to them. 
In the first place, there are variations of form and variations of function. The bench show enthusiast is deeply concerned with the former. A Collie breeder, for example, is very anxious to perfect a long, clean skull with a level mouth and filled in foreface, topped off with semi-prick ears (all matters of structure). The follower of the field trials, on the other hand, lays most emphasis on functional variations. A Pointer man is vitally interested in his dog's speed, nose, and endurance (all matters of function). Oft and again the bench show fancier has been charged with utter indifference to vitality, disposition, and intelligence. The unconcern of the field dog owner to the looks of his animals is proverbial. Evidently, both display a lop-sided interest in their dogs, but this is really not so serious as some alarmists would have us believe.

The breeder whose sole object is to produce dogs that will win championship points and silverware knows full well that shyness and viciousness, constitutional weakness, and the tendency to develop certain diseases are all to be religiously avoided. The keenest field trial follower appreciates that speed and endurance are dependent upon good conformation. All breeders are concerned with the functional 
variations of fertility and impotence, of exceptional prepotency as a breeding individual, of the tendency to abortion or to faulty milk supply displayed by some bitches. On the other hand, no breeder wants to breed unsound. cripples.

Again, all variations can be classed as either quantitative or qualitative. They are all either: differences in degree or differences in kind. Of two Toy Spaniels one may grow a very full, profuse coat; the other may always be comparatively short haired. This is a quantitative variation, a degree of difference. The texture of one coat may be fine and silky, without the slightest tendency to curl, and the other coat may be coarse and decidedly wavy. This is a qualitative variation, a difference in kind. All variations in size and shape are quantitative. Variations in substance and material, as texture, coloring, dispositions, etc., are qualitative. It is usually considered that the qualitative variations are easiest to fix and also easiest to lose. It is therefore useful for a breeder to learn to make the distinction between the two and to keep this distinction before him in his breeding operations.

Still a third classification can be made of variations. They are either continuous or dis- 
continuous. The great majority of all variations with which the breeder is concerned are continuous. In fact, it is hard, with the exception of color and markings, to fix on any variations of importance to the dog breeder that are strictly discontinuous. The two different kinds are easily distinguished. A recently proposed English Standard for the Fox Terrier gives the ideal length of head as seven inches measured from the nose to the occiput with calipers. If all Fox Terrier heads in the world were so measured, we should find some longer and many shorter than this ideal. There would, however, be a continuous series of lengths without any sharp breaks. Every possible length from eight to five inches (assuming that these are the limits) would be represented. The length of head is a continuous variation, but the coloring of the head is a discontinuous variation. We should find many were black, white, and tan; some black and white, and also tan and white; fewer would be all black, or all white, or all tan. There would, however, be no intermediate shades of greys, blues, brindles, smuts, or fawns. These colors are not found in pure bred Fox Terriers. They could only be obtained by resorting to cross-breeding. 
A moment's reflection will convince any experienced fancier that continuous variation is the one that almost exclusively enters into his breeding operations. It is probable, however, that some of the fancy points of our highly artificial breeds have originally arisen from discontinuous variations. It seems probable, in lack of any direct proof, that the screw tail of the English Bulldog, for example, first appeared as a mutation, or a sudden discontinuous variation. There is plenty of evidence contributed by the Dutch botanist De Vries to prove that these mutations are continually appearing in various forms of plant and animal life, and that they breed true without reverting to the ancestral form. It is certainly feasible to suppose that the screw tail first appeared as a mutation. Of course, it has been carefully preserved and improved by selection, and even been bred into other varieties, the Boston Terrier and the French Bulldog.

It lies within the range of possibility to breed a Fox Terrier head a hair's breadth longer and another a hair's breadth shorter than seven inches. Obviously in the case of discontinuous variations the opposite is true, and no amount of selection, without any cross-breeding, would produce a gray marked Fox Terrier. 


\section{$V A R I A T I O N$}

It has been boastfully said that, if they would, breeders could produce a dog without a head - the Old English Sheepdog and the Schipperke are living proofs of the ability to produce a dog without a tail - but there are certain very definite limits to what can be accomplished by means of artificial selection. This is particularly true in the case of discontinuous variations. To remember this, and to differentiate between the continuous and discontinuous, may prevent a foolish waste in striving after the unattainable.

We have already seen how bisexual reproduction and the reduction of the male sperm and the female ovum introduce a primary cause for variation. There are other internal causes of variation.

Dog fanciers are generally credited with a pretty firm belief in telegony. Certainly it is not unusual to hear the opinion expressed that, if a bitch is mismated with a mongrel or a dog of a different breed from her own, she is spoiled for breeding purposes. It is supposed that the mesalliance will affect the character of her subsequent puppies. During the past ten years there has been a continually increasing number of fanciers who place no credence in the belief that a previous sire affects subsequent 
litters. The belief, however, lingers, chiefly among "novices" and "old-timers," and every once in a while we hear of a case supposed to prove the contention.

The late F. H. McConnell personally related to me an experience of his, which I offer for what it may be worth. A wire Fox Terrier bitch of his was mismated to an Irish Terrier dog. The resulting puppies were such demons on rats that the experiment was intentionally repeated, but the third time she was bred to a thoroughbred Fox Terrier, a dog, if I remember correctly, of the Warren strain. The pups of this litter were said to show very unmistakable signs of Irish Terrier characteristics.

Be that as it may, the weight of all scientific evidence is against a belief in telegony. The recorded examples are few and far between, and direct experiment has never yielded anything but negative results. Darwin cited the famous case of Lord Morton's thoroughbred mare. She had a hybrid colt sired by a quagga. Afterwards she foaled twice to a thoroughbred stallion, and both of these colts were marked with bars over the shoulders and on the legs, supposed effects of the quagga upon the get of the stallion. However, Pro- 
fessor Ewart of Edinburgh repeatedly performed the same experiment on a large scale and was unable to find any traces of the quagga in any but the direct hybrids of the cross-breeding.

To discard a good bitch because she has thrown puppies to a strange dog seems, in the light of all evidence, to be a bit fanatical. She should certainly be given the benefit of the doubt, and probably most fanciers would be inclined to at least give her a trial. Professor Davenport of the University of Illinois made a canvass among dog fanciers to find out how many believed in the effect of previous matings. He received thirty-seven replies - one from a believer in telegony; two, non-committal; six, uncertain; and twenty-eight denials. These figures, and from my own experience I consider them indicative of the facts, show that the great majority of dog breeders are not believers in telegony.

Another supposed cause of variation is the impression upon the embryo of certain sights, sounds, colors, etc., that affect the dam while carrying the offspring. This very old belief is more widespread among horse and cattle breeders than among dog fanciers. In the Bible we read that Jacob, to increase the number of 
spotted offspring which were to be given to him, set up peeled sticks before the herd. It is, however, generally considered that instances of pre-natal influence through external sources are to be regarded more in the nature of strange coincidences than of any serious cause for variation.

Horse and cattle breeders, however, have gone to rather fantastic extremes in this belief, hanging up colored blankets or holding desirably colored animals in front of females during service. I have heard a few similar cases in dog breeding. The English Bulldog Tidal Bishop, white with brindle markings and bred from white pied stock, invariably got dark brindle puppies, thanks, it was rumored, to the foresight of his owner in holding a brindle dog in front of the bitches he served. Practical breeders, however, disregard these pre-natal influences entirely, or at best regard them with skeptical curiosity.

Reversion to ancestors back of the immediate parents has been often observed in kennels, and it certainly presents a form of variation. It, however, belongs more to the study of heredity. We shall see later that it is capable of a reasonable explanation.

The various external forces and their effect 
upon variation have long been a subject for debate. The trend of biological evidence is more and more against a belief in inheritance of modifications due to environment. Of course, every breeder appreciates that puppies bred from stock that is carefully fed, properly housed, and well exercised will be healthier and stronger than those whelped in kennels where the conditions of life are less ideal. This, however, is more a matter of development than of variation.

It has been frequently observed that the number of puppies in a litter is larger among domesticated dogs than among the wild canida. Abundant food and protection from the extremes of weather have doubtless been the main factors in this increase.

The instances of deterioration in British breeds of dogs introduced into India have been often quoted from Darwin, but since he collected his information additional facts have been brought forward. A strong dog fancy has developed in India, with numerous shows under the jurisdiction of the Indian Kennel Club. Judging from descriptions and photographs, Indian breeders have been able to produce dogs that compare favorably with their direct importations from England, and to-day we hear lit- 


\section{PRACTICAL DOG BREEDING}

tle about the degeneration of dogs in the eastern country. Moreover, the success of the Airedale Terrier in the Philippines and throughout tropical America is further confirmation of the fact that climate does not have such a direct bearing on variation as was formerly supposed.

In America we sometimes hear complaints that the extremes of temperature and the dryness of the air (compared with the climate of Great Britain) ruin the correct texture of a wire coat. Many terrier owners have never been able to find any direct confirmation of this belief. It is certain that dogs brought to a new country have to become acclimated just as people do, but there is only the scantiest evidence that this has any direct bearing upon their offspring with which a practical breeder must reckon.

Many of the external forces affecting dogs are closely allied in their nature to acquired characteristics. These will be discussed later. Some consideration of them, however, belongs to the subject of variation. The best working rule, in view of the disputed importance of these external forces, will be to take no chances. Kennels should be so arranged and so managed as to keep the breeding stock in the very best 
possible condition, so affording the most favorable opportunity for the action of these external forces in the desired direction.

We have now classified the different types of variation and considered briefly the principal causes at work to produce them. We have seen that every variation is either structural or func-

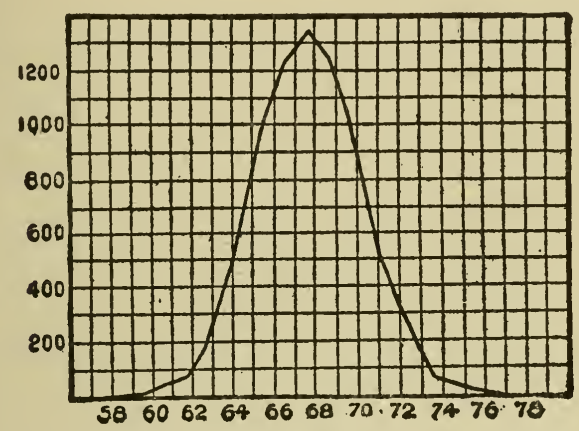

FiG. 5.- Showing the actual variation in height of 8,585 British men.

tional; quantitative or qualitative; continuous or discontinuous. We have taken up the causes of variation in bisexual reproduction; in reduction of the germ cells, in telegony, in pre-natal impressions; in reversion, and in various external forces. Having in our minds a clearer idea of the nature of variation, let us see how variation behaves.

By the very definition of continuous varia- 
tion we expect - and rightly so - to be able to get all possible shades of differences. These differences can be expressed more accurately and clearly by a graph than in any other way. The accompanying figure (Fig. 5), which is taken from J. A. S. Watson's little handbook "Heredity," expresses graphically the variation in the height of 8585 British men.

The vertical lines represent the differences in height in inches and the horizontal lines show the number of men in hundreds. The very top of the curve is at a point between 67 and 68 inches and a little over the line of 1300 individuals. This means that of the 8585 men measured there were over I300 who were roughly $67 \mathrm{I} / 2$ inches tall. There were $\mathrm{I} 200$ men who were something over 66 inches tall, and also 1200 men who were 69 inches tall. The curve expresses graphically the average height and the variation from that average of the men measured. It is merely another way of saying "Most men are an average height"; but it also shows that that average is close to $67 \mathrm{t} / 2$ inches.

Another thing that this curve shows us is that the deviation from the average is quite uniform. There are just about as many men taller than the average as there are men shorter than the 
average. Not only this, but just about as many men are two inches above as there are men two inches below the average height. The curve is remarkably regular on both sides of the apex.

A great amount of similar data has been carefully collected, measuring not only variations in men but also in plants and animals. The figures so collected have been graphically expressed in the same way. The curves thus de rive d have been found to be remarkably similar, all being very close to the normal variability curve, as it is called. This normal curve is

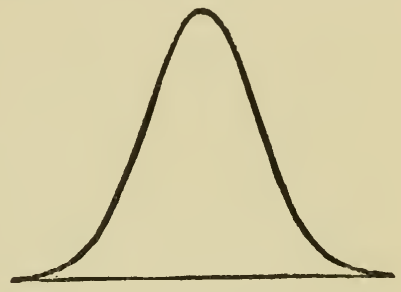

FIG. 6.- Curve showing variations in normal height. Compare with Fig. 5.

shown in Fig. 6, and one can see at a glance how close to it is the curve of the height of the 8585 men. The differences in the height curve from the normal are accounted for by the number of men measured. Had eight million heights been recorded instead of eight thousand, the curve would more closely approach the normal.

All this has a very practical meaning for dog breeders. It proves to us that all continuous variations have a decided average and that the 
falling off in numbers, at first quite fast, very fast in the middle portion, and slower at the extremes, is remarkably even on both sides of the average. Applying this normal variability curve to the ideal length of a Fox Terrier's head, we should find, assuming that the average would be six inches, that just about as many had heads only five inches long as had the ideal length of seven inches. These figures are, of course, purely arbitrary. There is no data available on the length of Fox Terrier heads. It is, however, quite certain that, if the ideal is seven inches, the average would be below this. In real life "an inch on a terrier's head is a good deal," but the even figures were taken for simplicity's sake. The variation would not be so great, but this does not affect our example.

Most dog fanciers will be surprised to find that variation is such a regular and consistent thing. We are quite prone to regard all variations as sudden, freakish, and more or less unreasonable. It is only by studying great numbers that the regular and symmetrical continuity of all variation becomes apparent. Working with individuals, we get the erroneous idea that all variations are sudden and irregular. There are such variations, mutations, but these are not 


\section{VARIATION}

he variations with which dog breeders are comnonly working.

Very gradual variations, both good and bad, re being continually presented to the dog oreeder for his choice. The great difficulty lies $\mathrm{n}$ the fact that the dog is made up of such great number of distinct points. Very selJom does a dog appear which combines any considerable number of variations all in the desired direction. We are, accordingly, forced to sacrifice one point for the advantage of another. In this the dog breeder has the opportunity for displaying his rarest judgment, and in making these choices he will be benefited by knowledge both of variations and of their inheritance.

If the sole and only object of the Fox Terrier breeder were to produce a dog with a head seven inches long, this could be accomplished in a comparatively short time. But besides that seven inch head he wants a well shaped head, nicely balanced, with a flat skull, clean cheeks, and well filled in foreface; a well placed and correctly shaped, dark eye; sound, level teeth, just covered with tight lips; small, Vshaped ears, placed on the corner of the skull and falling forward - and we have not yet gone "behind the collar"! The neck, shoulders, front, ribs, back, loins, hindquarters, feet, 


\section{PRACTICAL DOG BREEIING}

tail, height, weight, bone, coat, and style, eack one must be considered in as careful detail as mere length of head. Not only this, but the relative positions of each part and its proper combination with other points is vitally im. portant.

It is small wonder that the perfect dog of any breed has yet to be bred. The ideal is tremendously improbable, but it is at least conceivably possible. No fancier has ever seen a perfect dog - excepting, of course, one of his own home-bred puppies who died very young! - but we have all seen dogs that in one or two, possibly even in half a dozen different points, were our ideal. That these few points have appeared in accordance with our ideals is a pledge of good faith on the part of variation to supply us with the required material out of which to make absolute perfection.

The variations, both good and bad, which are being continuously presented for our selection are, we have seen, always clustering round the average. Their causes are often mysterious, but we have much knowledge on which to base our breeding operations. We are able to get a clear idea of the nature of the various kinds of variations and to appreciate that they normally swing evenly on each side of the aver- 


\section{VARIATION}

ge. This knowledge will help the breeder vhen he comes to employ the advantageous vaiations, through the agency of heredity, in his :fforts to breed the ideal dog. 


\title{
CHAPTER IV
}

\author{
HEREDITY
}

T TAVING considered variation, whicl makes breeding possible, we are lec naturally to a study of heredity which makes breeding effective. We have already discussed the germ plasm theory of heredity, the most reasonable explanation for the observed facts, and we must now investi. gate these facts to see what practical benefits we can derive from the knowledge gained by careful experiments and painstaking researches.

The very simplest case of heredity is the "pure line," or when reproduction is by means of self-fertilization. Although such reproduction is beyond the scope of the dog breeder's operations, still, because it throws much light on the nature of heredity, it will repay us for a moment's investigation.

Professor Johannsen made the original experiments in the study of pure line heredity with peas and beans, and his results have been 


\section{HEREDITY}

shecked and confirmed by other observers. He took the beans from nineteen plants, each of which had been self-fertilized, as is the usual condition in this variety, and he measured them for variability in weight, breadth, and other details. The whole lot showed a standard variation, and the curve he plotted from his data was close to the normal variability curve. He kept carefully distinct the seeds from each parent plant, and grew each pure line, or in other words, each lot of seeds from each selffertilized plant, separately. The plants raised in each pure line produced seed that had each its own distinct average, differing from the general average of the nineteen original parents. Moreover, he divided each pure line into lots according to size, but the same sized seeds from the same pure line produced seeds that were not of their own size, but nearer to the average size of the pure line from which both they and their parents had sprung.

This means that even within a pure line, when the germ plasm is, of course, unaltered and constant in succeeding generations, there is always variation. Variation is inherent in the germ plasm, even when it in itself is unchanged, for seeds larger than the average produce seeds smaller than themselves and 
closer to the average of the pure line. Is other words, individual characteristics, ever in a pure line when there is asexual reproduc tion, do not reproduce in the offspring.

For the breeder this means that no amoun of selection in a pure line would ever producr a strain that would regularly have larger seed: than the average. In pure line breeding then a very definite limit to what can be accom. plished solely by selection is set. The greal significance of these experiments for the dog breeder is the proof they present that even when the germ plasm is unchanged there is always variation.

In the case of bisexual reproduction, which is the condition under which the dog breeder works, two different germ plasms are united to form the new generation. The germ plasm is no longer a constant, the inheritance is double, from two germ plasms, and the case is obviously more complicated.

In an exhaustive statistical study of the height of 205 parents and their 928 children, Galton was able to analyze the results of bisexual reproduction. He arrived at conclusions that are of inestimable value to breeders. He found that:

I. Like parents beget unlike offspring, and. 
vice versa, like offspring come from unlike parents. Abnormally tall parents, he found, had tall, short, and medium sized children; while of all the tall children studied, some came from tall, others from short, and others from medium sized parents.

2. Offspring are on the average nearer to the average of the race than their parents. The average height of the children of two parents is not the mean between these parents. When the average height of the two parents is above the average of the race, the children's average will be shorter than their parents, and so closer to the race average.

From the first conclusion it follows that two dogs of very different type may be whelped in the same litter, a fact to which any practical breeder will readily testify. Also, that two dogs of remarkably similar type may have been bred from very different parents, another fact that is corroborated by common experience. The general conclusion emphasizes the value of a good working knowledge of the true meaning of a pedigree and shows the utter foolishness of any attempts to judge the offspring by the parents, or the parents by a consideration of the points of the offspring. Almost daily we see dog fanciers attempt these two impos- 


\section{PRACTICAL DOG BREEDING}

sibilities. It is common to hear a man say, "No, I never saw such-and-such a dog, but judging from his pups he must be a shortbacked one with good legs and feet," or something of that sort; while it is even more usual to hear a man say that "So-and-so has the best eyes and ears of any dog at stud, and he certainly ought to get pups good in these points."

The second conclusion of Galton's studies is the principle of regression, or the drag of the race. To the dog breeder it presents vitally the true value of a pedigree. To return again to our example of the Fox Terrier head, which in the last chapter we assumed would average six inches long with an ideal length of seven inches. It would surely result in disappointment to breed together two dogs with ideal seven inch heads, for regression would bring the average of the resulting puppies back closer to the average of the race, which would be closer to six inches. Conversely, a dog and a bitch with five inch heads would, on the average, produce puppies longer headed than themselves, for the average of the offspring would by the same law approach nearer to the average of the race, which in this case is an inch longer than the immediate parents.

Could a complete refutation of the ideas 
usually followed by dog breeders be more forcibly expressed? We are so very prone to cant about "like produces like," and so very willing to accept a pedigree, which at best is only a guaranty of purity of blood, as proof positive of uniformity in type.

Plainly, there is but one way to cut loose from the drag of the race. Bring the general race average as close as possible to the ideal expressed in the Standard. In this way, and only in this way, can regression be won over from an enemy to an ally. If a Fox Terrier breeder should by continued and careful selection raise the average of his own strain from the general race average of six inches to the ideal average of seven inches, he would not have to worry about length of heads so long as he exercised enough selection to hold the very great advantage he had gained.

Besides the pure line inheritance and the bisexual inheritance there is another, named after the man who discovered it, Mendelian inheritance. Mendel, an Austrian monk, studying the crossing of different varieties of garden peas, made important discoveries that were quite unappreciated for thirty-five years. In I 900 his work was rediscovered and confirmed by De Vries, Tschermak, and Correns, each 


\section{PRACTICAL DOG BREEDING}

working independently. The garden pea shows sharply differentiated characters in its different varieties. Mendel crossed these and observed the way that these different characters were inherited in the hybrids. Mendelian inheritance then is primarily the inheritance of hybrids, or cross-breds, but subsequent study has shown that many individual characters in straight bred animals follow this same law.

It is beyond our needs to go into all the technical details of Mendel's experiments, or to know how he succeeded in being sure that he was crossing certain plants. We will confine ourselves to the results obtained in one particular case. Crossing the tall variety, which is about six feet high, and the dwarf, which is about a foot and a half high, Mendel got a generation of plants, every one of which was just as tall as the tall parent. This is certainly not what one would naturally expect, for we generally look upon cross-breds as a combination of their parents, and we would think the offspring of the tall and short varieties would be about four feet tall. These tall cross-breds were allowed to fertilize themselves, which is the usual method of reproduction, and from the resulting seeds a second generation was raised next year. 
This second hybrid generation behaved in a truly extraordinary manner. Many plants were just as tall as their tall parents and the tall half of their grandparents; others, however, were just as short as their dwarf grandparents. There were absolutely no plants of intermediate height. What is even more remarkable, the dwarfs bore a constant numerical proportion to the talls. There was one dwarf to three tall, or twenty-five per cent. of the second hybrid generation were dwarf. In the next and in all succeeding generations, these dwarfs continued to produce only dwarf plants. Here was a hybrid, breeding absolutely true, a perfect dwarf produced from tall parents, produced in turn from crossed tall and dwarf.

The seventy-five per cent. talls in the second hybrid generation behaved very differently. Self-fertilized, some produced both tall and dwarf plants, while others produced only talls. It was found that twenty-five per cent. of the apparent talls of the second hybrid generation were true talls and continued to produce talls indefinitely. Those seeming talls, half of the whole second generation, continued to produce both talls and shorts, in the ratio of twenty-five per cent. true dwarfs, twenty-five per cent. true 


\section{PRACTICAL DOG BREEDING}

talls, and fifty per cent. seeming talls, but in reality hybrids in inheritance.

To sum up the results of this important discovery: the first cross between tall and dwarf produced all talls. Mendel expressed this by saying that tallness is in this cross dominant and dwarfness recessive. This hybrid, talldwarf, but tall looking generation, produced twenty-five per cent. true dwarfs, twenty-five per cent. true talls, and fifty per cent. hybrids with tallness dominant. This is known as segregation, or the sifting out of the offspring in definite proportions of the characters employed in the cross. This proportion is $I: 2$ : I. These same results can be expressed in a chart:

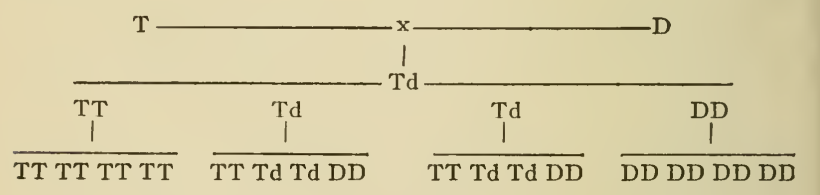

The first cross is represented by the letters $T$ (tall) and D (dwarf). The fact that tallness is dominant and dwarfness is recessive is represented by the symbol $\mathrm{Td}$, a tall looking plant in which dwarfness lies recessive or hidden. The true talls (TT) and the true dwarfs 
(DD), which are later segregated, continue, as is shown, to breed true.

This principle of segregation, or the splitting up of the off-spring into the Mendelian ratio of $\mathrm{I}: 2: \mathrm{I}$ is a fundamental part of this type of inheritance. Dominance of one character over another does not invariably occur. Sometimes there is a blending. In such cases the symbols in the chart would be changed from $\mathrm{Td}$ to $\mathrm{TD}$, representing in this particular case a plant of intermediate height. The subsequent splitting off into true talls and true dwarfs would be the same in each case.

Beyond all further doubt Mendel's law has been demonstrated to hold in its mathematical relations. The breeder, however, must remember it applies only to one character or set of characters, not to the entire individual. Judged as individuals, the Mendelian nature of a hybrid cross might not be at all apparent, though each character be following strict Mendelian inheritance. Some characters would be dominant in one parent, others in the other parent, and still others might be a blend. In this way, the different characters, viewed as a whole, would seem a hopeless muddle. For this reason the true nature of such inheritance 
was so long obscured, only to be discovered by the careful isolation and study of each character by itself.

The dog breeder can make no use of Mendel's law until he establishes what characters in dogs, if any, follow it. That there are such characters is highly probable. Color in chickens, pigeons, rabbits, guinea pigs, and cattle; hair and eye colors in man; presence or absence of horns in cattle; the shape of the comb in chickens, and many other similar characters have been found to follow Mendelian inheritance.

A. L. Hagedoorn has done some work on color inheritance in Dachshundes, and C. C. Little has made a statistical study of coat colors in Pointers from data in the A. K. C. Stud Book. Their work, which supplements the rather scanty data of Professor A. Lang, indicates that black and brown (liver) follows the same Mendelian inheritance observed in these colors in mice, guinea pigs, and rabbits. Dr. C. G. Darling believes eye coloring in Airedale Terriers is Mendelian, the light color being dominant. He acknowledges that he has not sufficient data to either prove or discredit this hypothesis, but, as an eye specialist and a terrier breeder, his opinion bears weight. If 
he is correct, it is probable that all eye coloring in dogs follows Mendelian inheritance.

It is also probable that the smooth and broken coats in Fox Terriers, a form of cross breeding that is common, is Mendelian, the broken coat being, in this case, dominant. The red and black coloring in Chow Chows and self colored spaniels is also probably according to Mendelian inheritance. However, before a positive statement can be made in any of these cases, more evidence is required. Such evidence would be a valuable contribution to the equipment of breeders, and it is to be hoped that some day it will be collected. To be of practical value, it must be determined by a careful study of a great number of individuals from all possible combinations, for large numbers are necessary to establish the true ratio, and of course, the greater the number of cases the less the probable error.

In view of the great likelihood of different characters in dogs being subject to Mendelian inheritance there is a practical value in knowing what are the average numerical results to be obtained from crossing characters following this ratio. Let us take a simple case when black and red colors are crossed, the black being dominant. The symbols used are the same 
as before, i.e., $\mathrm{BB}$, a true black; $\mathrm{RR}$, a true red; and $\mathrm{Br}$, a seeming black with red recessive. A hundred offspring will in every possible cross give the following approximate results :

Sire and Dam

$\begin{array}{lccc} & \mathrm{BB} & \mathrm{Br} & \mathrm{RR} \\ \mathrm{BB} \times \mathrm{BB} & \mathrm{r} & \ldots & \ldots \\ \mathrm{RR} \times \mathrm{RR} & \ldots & \ldots & 100 \\ \mathrm{BB} \times \mathrm{RR} & \ldots & 100 & \ldots \\ \mathrm{Br} \times \mathrm{Br} & 25 & 50 & 25 \\ \mathrm{BB} \times \mathrm{Br} & 50 & 50 & \ldots \\ \mathrm{RR} \times \mathrm{Br} & \ldots & 50 & 50\end{array}$

Mendelian inheritance is particularly applied to crosses of certain sharply defined characters. But quite aside from this practical application of this type of inheritance, in a peculiar manner it throws a strong light on the nature of the germ plasm and the whole subject of heredity.

From the action of characters under Mendelian inheritance we can see that the units of heredity in the germ plasm remain, even when crossed, true and pure in respect to any given character. To return to Mendel's original experiment, the unit for tallness is carried by one plant and the unit for dwarfness by another. On combining the two germ plasms these two units remain distinct, or all offspring 


\section{HEREDITY}

of the cross would forever afterwards be a blend, and there could never be separating of the offspring back to the original sizes. The tallness and the dwarfness remain distinct, though they may blend.

Each hybrid germ plasm contains heredity units represented by $T$ and $D$. When crossed the T's of one plasm combine with the T's of the other plasm, giving TT or true tall, or they may combine with a $\mathrm{D}$, resulting in TD which may be either a blend or one factor may dominate the other. The D's act in the same way, they may combine with other D's giving $\mathrm{DD}$, or true dwarfs, or with T's giving DT, or TD, which is the same thing.

Each germ plasm of every individual has two determinants as they are called. These may be TT, or DD, or TD. On crossing these couples in each individual act independently, and one determinant of one parent will combine with one determinant of the other parent. Accordingly in crossing TT $\mathrm{x}$ DD the only possible result will be TD. This is exactly what happens in the first hybrid cross. But on crossing TD $\mathrm{x}$ TD we can get either $\mathrm{TT}$, or $\mathrm{DD}$, or TD, and it is a mathematical certainty that the chance of TD combining is just twice as great as TT or DD, hence the 
establishment of the Mendelian ratio of ITT: 2TD : IDD.

It is just as if you tossed two coins in the air. The only possible combinations for you to get would be two heads, one head and one tail, or two tails. If you did this five times, it might happen that you got two heads every time; but if you did it a thousand times and kept count, you would find that you would get very close to 250 two heads, 500 heads and tails, and 250 two tails - the Mendelian ratio of $\mathrm{I}: 2$ : I.

The practical application of this is the lesson it teaches that in Mendelian inheritance it is useless to try to establish in a strain a blend between two characters. Such a blend will never breed true. The characters will continually be splitting up into the two original forms.

Another very practical lesson is that very evidently the germ cells of both parents each contain a complete set of hereditary units. Every possible character is represented in both male and female, which applies to all inheritance whether Mendelian or otherwise. This upsets the idea that the sire is more important than the dam so far as the physical appearance of the offspring is concerned. This is a 
ime honored belief that dies hard, but the ooner it is buried the better it will be for all ireeders.

The question of whether or not acquired haracteristics are inherited has been long deated by biologists. The tendency is to place ess and less credence in this once popular beief. Practical breeders ought to be able to listinguish true acquired characteristics, so as o appreciate their relation to his operations. First, such a character is only acquired durng the lifetime of the individual. Those charicters that have been acquired by the whole ace are beyond the scope of this definition. The retrieving habit, which must be taught to a bird dog, is an acquired characteristic: the oointing habit, which they have inherited, is 10t.

Second, a factor outside the dog, something in his habits, training, or environment, must have brought about the change. Cutting off a terrier's tail is an acquired character: the endency displayed by many terriers to go thick in skull, though this happens in the dog's lifetime, is not.

Third, and this is the most difficult point to establish in the individual case, the acquired character must affect only the body of the dog 


\section{PRACTICAL DOG BREEDING}

and not his germ plasm. Bad raising during puppyhood may result in rickets and other. weaknesses. If these weaknesses go further and affect his fertility they cannot be strictly considered as acquired so far as that dog's heritage is concerned.

In this strict, scientific sense, acquired characteristics are obviously non-inheritable, else long ago our Terriers and Spaniels would have been born with short tails and no training would be necessary for bird dogs and hounds. Diseases, as such, are not inherited strictly, though, of course, communicable diseases may be transmitted by the dam to the pups. This is not inheritance but infection. The tendency to develop certain diseases is, however, passed on from one generation to another. Use and disuse of certain faculties or organs probably act much in this same way. The fact that Pointers and Setters have for generations been broken to the field makes Pointer and Setter puppies easier to train. Exercise of certain muscles develops them and makes them stronger. Effects from use and disuse must, however, be very slow in their action. They are felt more in transmission of the capability for further development than in a direct inheritance. 
In practice the breeder need not worry over he inheritance of acquired characters, proided he is assured they are acquired in the trict meaning of this term. This is not so in he case of care and treatment of his breeding tock and puppies. Environment is a very lifferent thing, and poorly housed, dirty, unler-fed stock are not good breeding stock. Environment has a very direct action on deelopment, and the breeder must maintain his iennels under favorable conditions that will inure strength and health among his dogs.

In our conceptions of heredity we dog breedrs have made two mistakes. These are natural ones, and it is some consolation to know hat other breeders, and even trained biologists, have fallen into the same errors. In the first place, we have paid too much attention to the exceptional individual, the dog that is a "stormer," way above the average of his race. Secondly, and this sounds somewhat paradoxical, we have not paid enough attention to the individual points that go to make up the whole dog.

In our almost fetish worship of the Champion of Record, we have been led astray in formulating any sound systems of breeding. We have overlooked the great average of the 


\section{6}

\section{PRACTICAL DOG BREEDING}

race and the drag that this average always ex erts. This has been very strikingly demon strated in the statistical studies of inheritanc which were pointed out earlier in this chapter

Although as breeders we are continuall: working for the development or effacement 0 certain points, we have overlooked the fact tha these different characters behave differently ir transmission. Some blend, others never do Some are correlated, others are quite inde pendent.

The fact that heredity is from the whole race more directly than from the individual is for. cibly impressed on us, and the fact that hered. ity keeps all variations close to the race aver. age, together with the fact that many characters combine in definite proportions, bring out the mathematical nature of all inheritance. We are working with tremendously complicated material. It is little wonder that this mathematical relation of variation and heredity should be obscured. But picking out individual characters and working with them in large numbers give new ideas and fresh inspiration to the careful breeder. We can now appreciate the real significance of scientific: breeding, and understand that it is not merely fine spun theory. 
The principles of variation and heredity in the light of modern biological knowledge enable us to make our selection in matings with a fuller understanding of the problem before us and with a more reasonable expectation of success. It is very much more effective than the old hit and miss methods. 


\section{CHAPTER V}

\section{SELECTION}

$1 \mathrm{HE}$ dog breeder is merely a spectator of variation and heredity. However much he may know of the causes of these highly important factors in his breeding operations: however deeply he may be interested in the results, his direct control over either cause or result is nil. $\mathrm{He}$ is quite powerless to exert the least bit of influence over the combination of the heredity units in the germ plasm of the stud dog or of the brood bitch he breeds to him.

He can, however, select which two germ plasms are to be combined. In doing this, as he does every time he mates two dogs, he ceases to be a mere passive on-looker. He becomes the active, directing force. His will, in a measure, replaces natural selection. Obviously, his selection will have a most vital influence on the breed with which he is dealing. His skill and knowledge, or his carelessness and 


\section{SELECTION}

his ignorance, as the case may be, have effects much more far reaching than the immediate success or failure of his own kennels. Many breeders do not seem to realize the great responsibility that rests upon their shoulders.

The principles of variation and of heredity, those two important laws governing all breeding, must always be remembered during a consideration of the very practical problems of selection. Bearing this in mind, the solution of the problems of selection will be discovered in the answers to the following questions: What is the true object of selection? What can and what cannot be accomplished by selection? How can the results possible through selection be best accomplished?

What is the true object of selection?

We have already seen that all variations swing close to the race average, and heredity always tends to keep them there. These variations may be on one side of the average of the race, or they may be on the other - they may be, from a fancier's point of view, either favorable or unfavorable. But, excepting sudden mutations, all cluster about the race average, and just as many will be on one side as the other. The curve of normal variability illustrates this graphically. The principle 


\section{PRACTICAL DOG BREEDING}

of regression in heredity is always exerting its drag to keep the get of exceptional parents, which may be exceptionally good or exceptionally bad from the breeder's standards, closer to the average of the race than were the individual parents.

It is very evident that the only way the breeder can make any important, permanent headway is to bring the average of his own strain closer to the ideal expressed in the Standard than it is to the average of the race. In this way, and only in this way, can the drag of the race be lessened, and this drag is the breeder's worst enemy. Until he can overcome it, his breeding can only be partially successful. To overcome it, by raising the average of his own strain, is the true object of all selection.

Just what this drag of the race means to a breeder is expressed in mathematical form by Galton's law of ancestral heredity. This law was first derived from statistics. It has subsequently proved to be substantially correct. Pearson, by taking into consideration the individual variation in each generation, has worked out a more complete mathematical expression of the same principle, but for practical purposes Galton's figures are sufficiently accurate. It is very obvious, from what we know of vari- 
ation and heredity, that inheritance is not alone from the immediate parents, but also from the parent's parents " even to the third and fourth generation." Galton's law, as stated in the following table, expresses in per cent. the effective heritage contributed by each of the first six generations and by every individual in those generations.

$\begin{array}{cccc}\text { Generation } & \begin{array}{c}\text { Number of } \\ \text { Ancestors }\end{array} & \begin{array}{c}\text { Influence of } \\ \text { Generation }\end{array} & \begin{array}{c}\text { Influence of } \\ \text { Individual }\end{array} \\ \text { I } & 2 & 50 . & 25 . \\ 2 & 4 & 25 . & 6.25 \\ 3 & 8 & 12.5 & 1.56 \\ 4 & 16 & 6.25 & 0.39 \\ 5 & 32 & 3.125 & 0.10 \\ 6 & 64 & 1.5625 & 0.024\end{array}$

These figures give true meaning to the drag of the race. They put before us vitally the advantages of lessening this drag, which should be the true object of all selection. Yet how very few keep this object before them. Most are trying, by hook or crook, to breed a champion. They rush cross lots, forgetting that "the longest way round is the shortest way home." Instead of trying to breed a chance champion, they should strive to bring their own strain gradually closer to the ideal. In other words, they should work to purify the ancestry of their strain, so that the inheritance 


\section{PRACTICAL DOG BREEDING}

from all ancestors may not only be similar in type, but also as close as possible to the ideal. Such a strain would be invaluable. To be sure, every puppy bred would not be a complete expression of the ideal - in fact the ideal dog had never been seen, and probably never will be - but that every litter would contain pups close enough to that ideal to win is beyond cavil.

Can this be accomplished by selection?

Theoretically it can. Practically, there are great difficulties to be overcome. In several strains, if not all the points that make up the modern dog, at least some of them have been brought to high and uniform perfection. The underjaws of Bulldogs bred in Mr. Walter Jefferies' Stone Kennels are famous the world over. "For legs and feet go to Redmond" is a byword among English Fox Terrier breeders. Llewellyn bred English Setters are universally accredited with dash and speed. A few other instances might be cited, but it is sad they are so few.

The great difficulty in dog breeding lies in the very great number of points that make up the dog. It would not be difficult to pick out one or two points and to establish a strain that would average close to the Standard. It is, 
however, a very different matter to bring all the multitudinous points of the modern show or field trial dog to the ideal. Nevertheless, it is possible, for variations are always being presented for selection. In working for the ideal dog a breeder sometimes feels as if he were trying to drain the sea dry with a sieve. This is not so, though it is almost as if he were attempting this task with an after dinner coffee spoon. It is theoretically possible to establish a strain that would turn out champions to order, even if the practical difficulties are great.

A glance at the table of Galton's law of ancestral heredity gives a foundation for this statement. It will be noticed that the influence of the individual ancestor becomes less with astounding rapidity. The individual contribution of a dog in the sixth generation is only 0.024 per cent. A somewhat involved mathematical proof has been worked out to show that after six generations of careful and continued selection a certain character will invariably breed true. No further selection for that point is necessary, provided no dogs which will deteriorate the inheritance for that point are introduced into the strain. In other words, six generations of selection in the case of our old example of the length of a Fox Terrier's 


\section{PRACTICAL DOG BREEDING}

head would raise the average from six to seven inches, and that new length would be indefinitely maintained so long as adverse selection was not brought to bear. The very practical advantages of possessing a strain of Fox Terriers whose length of head was fluctuating about the ideal average rather than an inch below it needs no comment.

The mathematical study of variation and heredity is of inestimable value, and serious breeders should acquaint themselves with the formulæ which, however, have no place in a little handbook. Without going into the mathematics involved, it may be said that it has been established that any character consistently bred for can be fixed in six generations, but that there will be but a very slight reduction in the variation. We could increase the length of Fox Terrier heads in a strain from six to seven inches, but when the new average was established the number of dogs varying about this new point would be the same as formerly varied about the old average.

This seems a refutation of the common belief that a strain will die out. Except for adverse selection, either intentional or unintentional, there is no reason why, if fertility can be maintained, any family or strain should 


\section{SELECTION}

vear out, deteriorate, or become extinct. In ictual practice there have been many cases where, in spite of all that could be done, a ;train has degenerated. What has happened $\mathrm{n}$ most such cases is that the breeder has been forced to have recourse to outside blood to zeep up the stamina and fertility of his strain. Adverse selection has been forced upon him willy-nilly.

Furthermore, it seems at first sight that if variability is not materially reduced by continued selection, a type once established should not only breed true, but be capable of indefinite further improvement. Raise the average length of head in a strain of Fox Terriers to seven inches, then set a new ideal of eight inches and repeat the process. It sounds reasonable, if it is true that variation is not reduced. The figures show that this cannot be done below 85 per cent. of the original variation, but there are other limits set to what can be done by selection. There is a definite mechanical limit, for example, to the length of leg and the weight it will support. There is a physiological limit to the work that can be done by the vital organs, such as the size of the heart and the amount of blood it can pump. These mechanical and physiological limits 
make it impossible to breed a Great Dane ur to the size of a shire horse.

The breeder can expect that intelligent, continued selection will change type in any desirec direction, and that new type will breed true after six generations of continued selection. He cannot, however, expect to accomplish any material reduction in the amount of variation. So far as the opportunity that variation always presents for further selection is concerned, the breeder will always have material available, but there are mechanical and physiological limits beyond which no amount of selection can ever be carried. However, in all probability, these limits have not been reached, except possibly in the size of the very large and the very small breeds.

If the true object of selection is to lessen the drag of the race and if careful continued selection can change type, but not reduce variation, how can the dog breeder most quickly and effectively accomplish his results? What are the principles involved in rational selection?

First and foremost, the breeder must know the points of the dog he is breeding. "An eye for livestock" is a common phrase. Some people are blessed with it: others seem to lack it. Several years ago, two friends visited my 


\section{SELECTION}

kennels to pick a Scottish Terrier puppy. Neither visitor knew the points of the breed, and color and markings were in this case little help in distinguishing between the youngsters. The elder could not tell one puppy from another: the younger could invariably pick out any one of the dozen odd with ease. The one had no "eye for livestock." The other, provided she learned the points of the breed, was a born judge. If a breeder has an "eye" for a dog he is indeed blessed. If he has not this desirable faculty, he should do all in his power to cultivate it.

Once a breeder has thoroughly learned the points of his breed, he must "keep his eye in," as the saying is, by attending shows. It is suicidal for a breeder to bury himself in his own kennels. He must visit shows, see and study good dogs, distinguish their excellencies and their defects. Otherwise, he will be unable to tell which of his puppies are ducklings and which are swans. The homebred puppy very often appears to be a worldbeater in his own run. In the show ring, however, his proud owner often discovers faults that he never before dreamed existed.

But the breeder who returns to his kennels with a new ideal of perfection after every 
bench show that he visits will never accomplish a thing. Once the points of the breed are learned, a breeder must set up before him an ideal toward which he must always work. To change that ideal every six weeks is to insure failure. True, the type that wins at the bench show to-day is often very different from the type that was winning five years ago. This places a great burden on the already overloaded shoulders of the breeder. It is hard work to establish any given type or any given set of characters. To be continually shifting that type and changing the characters makes lasting improvement impossible. From all that has been said of the true object of selection and from what we know of ancestral heredity, it is plain that to be forever tinkering with the ideal and at the same time to expect to fix that ideal in a strain are two things as incompatible as oil and water.

Besides knowing the points of his breed and having a fixed and definite ideal to breed for, the breeder must know the history of his variety. He should know what they were originally used for, and, if a manufactured variety, what breeds were employed in their manufacture. Even more important is a knowledge of the good and bad points of the different indi- 
vidual aogs of the past. He must appreciate the prevailing faults of his breed. He must know just what certain bloodlines stand for and what they mean in good and bad points. He must realize what strains are predominant and in what ways their predominance will be beneficial or harmful to his own stock. This knowledge is absolutely essential to a successful, intelligent selection. The practical application of the principles of variation and heredity, so essential to a breeder's success, can only be made by means of this knowledge. Yet how very often do we see men and women attempting to breed from dogs whose very sire and dam are absolutely unknown to them save in name only.

The sire and the dam are, so far as heredity is concerned, equipotent. The germ cells of each carry a complete set of all heredity units, as is evidenced by the nature of Mendelian inheritance. Either sire or dam may transmit to any puppy of either sex any or all of their own characteristics. The parent, however, whose heredity units for any particular point are purest will, in general, predominate over the parent whose inheritance for this same point is mixed. This explains the prepotency of an in-bred dog. A Bulldog, for example, 


\section{PRACTICAL DOG BREEDING}

in-bred to a strain noted for wonderful underjaws and layback, big flat skull, but with bad ears and a long tail can naturally be expected not only to possess these peculiar excellencies and faults himself, but also to pass them on to his get. The figures in Galton's law of ancestral heredity will prove to be a rough guide by which to judge the prepotency of an in-bred dog or bitch. Since they express this in figures, they are easy of application. Breeders must always remember that in-breeding is a double-edged sword. The faults or defects in any in-bred dog or strain will be intensified and passed on just as surely as any good points.

Quite aside from in-breeding, there is another feature of predominance that is highly important. In most breeds of thoroughbred dogs the most casual study of pedigrees impresses one with the great importance of certain dogs and certain families. In all breeds that I have studied, including Airedales, Scottish Terriers, Chow Chows, and field trial Pointers, I have found that most of the great dogs have been bred either in or close up to certain families. Wheeler in the Show Collie traces the main line of Collie blood through the various important dogs, each a direct descendant of Old Cockie. Mr. Ralph W. Con- 


\section{SELECTION}

dee has traced out the line of the main line of blood in Airedale Terriers, which has come down to us from old Champion Brush.

These interesting family trees are not works of the imagination, and any one can readily convince himself of the great importance of these main lines by selecting at random any important show winner of these breeds and seeing how very quickly his pedigree runs into the main line of blood. In fact, if his sire is not directly in the main line, the chances are that his sire's or his dam's sire will be. In the chapter on Pedigree Studies these two charts, and others, are given in full.

In most breeds it is safe to assume that there is a prepotent strain. A few phenomenal dogs and their get have been responsible for most of the improvement that has been made. It is impossible for a breeder to tell offhand whether or not any given dog is really a great sire, or merely a popular show dog being used extensively at stud. It will be well worth while to study the pedigrees of his own breed to determine what family has produced the great dogs. If a stud dog is bred in the right strain it is safe to assume that he stands just so much better chance of being a truly valuable stud dog than one outside of this line. 


\section{PRACTICAL DOG BREEDING}

Although the influence of sire and dam are equal and prepotency may be displayed by either sex, still in a numerical sense the sire is more important. An average dog at stud will be the sire of fifty puppies to any one whelped by a bitch. His influence on the future generations of the breed is obviously the greater in direct proportion to the number of pups he gets. This must not, however, be taken in any way as an excuse for the old fallacy that "any old bitch with a pedigree is a good brood bitch." Quite the reverse is the truth. For the breeder, his own brood bitches are every bit as important as the stud dogs to which he breeds them. Both sire and dam are equal in any individual mating. The greater importance of the sire only applies broadly to the whole breed, but both for the advantage of the individual breeder and the good of the whole breed it would be well if it could be determined whether or not a certain $\mathrm{dog}$ is an exceptionally good sire during his lifetime, and not, as is so often the case, after he is dead. Sires should always be selected on their records as producers of good puppies, not on their records as bench show specimens or field trial winners.

In selecting the individuals for breeding 


\section{SELECTION}

stock a distinction should be made between faults and defects. A fault is positive: a defect is negative, though the difference is often mainly one of degree. Never breed to a dog that is downright faulty in any one point no matter how great may be his other excellencies is an old-time rule that is sound and sensible. Among the faults specially to be eschewed in any breed are those of conformation and soundness. Bad pasterns, cow hocks, deafness, blindness. - except when any of these are caused by overwork or accident - should be shunned. Over-shot or under-shot, except, of course, in breeds where these formations of the jaws and teeth are required; or bad shoulders must be viewed with keen suspicion. Such positive faults, once they are introduced into a strain are hard to eradicate.

In studying pedigrees so that they may be made a practical aid to selection, the breeder must remember that while the importance of back blood is very great, still this importance lies mainly in the early generations. To go back five or six generations before finding a good dog in a pedigree is foolish. Take the very extreme example of when a good dog appears so many as ten times in the sixth generation. Even then his influence would only be 


\section{PRACTICAL DOG BREEDING}

0.24 , or less than one quarter of one per cent. If the individuals between the first and this sixth generation are inferior or commonplace or doubtful, such a pedigree, however beautiful it may look, is not a good one for breeding purposes.

To sum up: the real purpose of selection is to bring the type of the breed as close as possible to the ideal as set forth in the Standard. To do this for any length of time raises the quality of the inheritance of every pup since all ancestors are closer to the average of the ideal than to the average of the race. The drag of the race in this way becomes a help and ceases to be a hindrance. Selection will fix a character or type in six generations, but no amount of selection can materially reduce variation. There are, however, limits, mechanical and physiological, to what can be accomplished by selection, but in dog breeding these limits have not yet been reached. In order to make a wise selection, the breeder must know his breed, its points, its characteristics, its history, and, that his selections may be cumulatively effective, he must set up before him an ideal and always breed toward it. 


\section{PART TWO}

\section{THE PRACTICE OF DOG BREEDING}

Praestanisimi canes in suo quique genera sunt, id est, ex unius generis parentibus prognati.

The best dogs are bred each in their own race, that is, from parents of the same breed.

- Conrad Gesner in "Historiae Animalum." 



\section{CHAPTER VI}

PEDIGREE STUDIES

HE practical dog breeder, striving to produce a bench show winner or a phe-

nomenal field trial performer, often
hrugs his shoulders skeptically at the experishrugs his shoulders skeptically at the experience and precepts of breeders of other kinds of thoroughbred stock, and he is inclined to pooh-pooh the theoretical work of scientists. If the principles of variation, heredity, and selection do not apply to dogs as they do to other animals, then scientific dog breeding, in the accepted meaning of the words, is chimerical. The dog breeders' indifference to these things is, in this case, thoroughly reasonable and well justified. If, however, the reverse is true, then dog breeders merely handicap themselves by their failure to understand and apply the principles of genetics to their problems.

"The proof of the pudding," says the old saw, "is in the eating." The proof of the dog breeder's pudding is in the puppies. The kennel that consistently turns out home-bred 


\section{PRACTICAL DOG BREEDING}

winners, either on the bench or in the field, is avowedly successful. The dog show fancier's ideal is the bench champion: the hunting dog enthusiast's ideal is the field trial champion. This furnishes a definite standard of accomplishment of the object at which all serious dog breeders are aiming. Moreover, the records of the wins at shows and trials are available for reference. The records of wins plus the pedigree records of the stud books furnish us with a handy gauge by means of which we can either prove or disprove the efficiency of scientific principles applied to practical breeding problems and also, a good medium by means of which the work of the biologist can be translated into the everyday terms of the breeder.

I know very well the objections that can be raised against the stud books as a source of material for studies of this kind. In the first place, there is no guarantee that the pedigrees recorded are correct. There have been, of course, some cases of deliberate fraud in the registering of dogs, but ninety-nine dog fanciers out of a hundred would, I am sure, as soon steal pennies from a beggar as fake a pedigree record. Calamity howlers to the contrary, the men and women who breed dogs are at heart sportsmen and sportswomen, and for every 
story of crooked dealing one hears gossiped at the ringside, one can hear ten of such scrupulous honesty that it puts to shame the " butcher, the baker, and the candlestick maker." The deliberate errors in the pedigree records are so infrequent that for practical purposes they can be discounted.

More common is a distortion of the records through personal fancies or prejudice. For example, the stud books would be but a poor place from which to collect data on Boston Terrier colorings. Many dogs must be entered as "dark brindle, evenly marked with white," which are not, strictly speaking, this very popular color and much desired markings. Such errors are impossible of detection, and the sole solution lies in the selection for study of subjects that do not bear any taint of this kind. Most common of all are the typographical errors. These creep into any book, and, it is to be regretted, they are specially frequent in records of this kind, made up, as they are, from blanks filled in by many different persons writing in all degrees of legibility. Nor do the fantastic names bestowed on some dogs help this trouble. These most common errors, however, are seldom such that they affect the results of statistical studies. 
Granting the weight of these objections, there is, however, much that a breeder can learn from studies of pedigrees. Nor is this, especially if one be working with his own favorite variety, the dry-as-dust work it might be supposed to be. The main objects of the studies I have made here have been to throw light upon the direct connection existing between the scientific work of the biologist and the practical work of the breeder, and to suggest studies that serious breeders can make with advantage each in his own breed.

Whenever two or three dog fanciers go hobby horse riding together the old question about in-breeding is sooner or later almost sure to be discussed. We have all heard some careful breeders praise such a system of breeding to the skies, and others, equally competent and successful, denounce it bitterly. The general public has the idea that thoroughbred stock, and most especially thoroughbred dogs, have been weakened in constitution and dulled in intellect by continued in-breeding. Many dog owners, while they will stoutly deny the ill effects of such mating, will almost in the same breath exclaim that there is altogether too much in-breeding. The whole subject has been badly muddled by a loose use of the term 
in-breeding, and by very hazy notions on the part of every one concerned as to just how common true in-breeding is among dogs.

In-breeding means nothing more nor less than the crossing of the blood of one individual. There are only three possible ways in which this can be accomplished.

I. By breeding a sire to his own daughter, as expressed in a pedigree of the following general type:

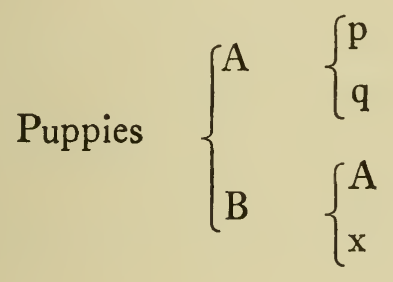

2. By breeding a dam to her own son:

$$
\text { Puppies } \begin{cases}A & \left\{\begin{array}{l}
x \\
B
\end{array}\right. \\
B & \left\{\begin{array}{l}
p \\
q
\end{array}\right.\end{cases}
$$

3. By breeding together full brother and full sister: 


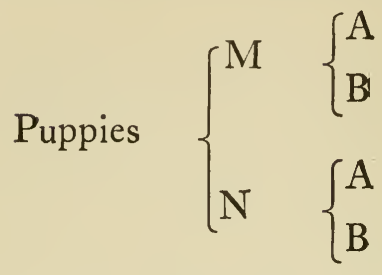

These, and only these, are true in-breeding. Bearing this in mind, any dog breeder will at once recognize that a great deal of what is really line breeding passes in current talk as true in-breeding. Such inaccuracy in the use of simple terms is decidedly unfortunate. The perfectly true statement that continued inbreeding results in degeneration of both physical and mental powers is transformed into a foolish bugaboo if every line bred dog is to be considered in-bred.

Just what proportion of thoroughbred dogs are in-bred and what proportion are line bred? Here is a question to which the stud book can furnish the answer. For the purpose I have selected two terrier breeds, the Scottish and the Airedale Terriers. These belong to the same general family, but the Scottie is one of the oldest breeds in this division, while the Airedale is a comparatively recently manufactured variety. In each breed one hundred average dogs were selected, fifty of each sex 


\section{PEDIGREE STUDIES}

nd ten from each stud book for the past ten 'ears, so as to get a fair general average of he whole breed. In like manner, a hundred hampions were picked out at random from ach variety. The results were as follows:

Average dogs. Champions.

;COTTISH TeRriers

Inbred

Line-bred

$\begin{array}{rr}3 & 1 \\ 4 & 9 \\ 93 & 90\end{array}$

Airedale Terriers

Inbred

7
6

Line-bred

87

I

9

Out-bred

$87-88$

NOTE.-The "Line-bred" in the above only includes dogs bred from the primary cross of half brother to half sister, and there are certainly dogs in the "Out-bred" that are truly inbred.

Including both in-breeding and the primary cross of line breeding only 7 per cent. of the Scottish terriers are closely bred, and but I3 per cent. of the Airedales. Plainly, there must be a great deal of exaggerated talk about in-breeding. I will say frankly that, although I am tolerably familiar with Scottish Terrier breeding, I expected to find more than seven among one hundred average dogs closely bred; and an experienced and successful Airedale breeder to whom I put the question thought " about a third ( 33 per cent.) of the Airedales are close bred." 


\section{PRACTICAL DOG BREEDING}

Those who advocate in-breeding as the solution of the dog breeder's problems are wont to claim that the majority of the champions and great dogs have been produced by this system of breeding. The records do not confirm this belief. Of the Scottish terrier champions only one in ten is close bred (including inbreeding and the primary cross of line breeding), and only one in eight of the Airedales. It is interesting to note that in both breeds the number of line bred champions greatly exceeds those that are truly in-bred.

In accomplishing the result desired by dog breeders, i.e., the winning of the honorable title, line breeding has proved to be, at least in the case of these two representative breeds of Terriers, tremendously more effective. It is also interesting for a breeder to note that inbred dogs winning their championships have been only half as numerous as in-bred dogs in the average lot. In other words, an in-bred dog has only half the chance of becoming a champion that is enjoyed by an out-bred animal. In the case of the line bred dogs, however, the chances of winning the right to the prefix "Ch." seem to be double those of an average out-bred dog. Very evidently line breeding is the best friend of the Scottie and 
Airedale fancier. This is, of course, exactly what one might have foretold by a broad application of the principles of inheritance, remembering especially the behavior of all variations and the law of ancestral heredity.

One remarks at once in this table that the Airedales are more closely bred throughout than are the Scottish Terriers. I will hazard a guess, without dignifying it by calling it even a probable explanation, and suppose that this is the result of close breeding being forced on the Airedale fanciers because theirs is a recently manufactured variety and has therefore less variety in blood lines.

The very general recognition afforded to families and strains by dog fanciers, and the very commonness of such expressions as "the winning strain" and "bred in the purple" show that the prepotency of certain blood lines has been so great as to be apparent without any serious statistical study of pedigrees. In several varieties, the line of descent has been traced out through the strain that has proved to be preëminently successful in the show ring or the field. H. E. Packwood in his admirable monograph, "The Show Collie" goes to considerable pains to show that the vast majority of the finest specimens of this breed have 


\section{PRACTICAL DOG BREEDING}

been closely bred to the strain started by Old Cockie. The chart of the family he gives is as follows:

Old Cockie (pedigree unknown)

Ch. Charlemagne (grandson)

Ch. Metchley Wonder (grandson)

Ch. Christopher

Edgbaston Marvel

Ch. Wellesbourne Conqueror

Ch. Parbold Piccolo

Ch. Portington Bar None

Edgbaston Plasmon (inbred) Ch. Anfield Model Ch. Ormskirk Olympian Ch. Ormskirk Emerald

Ch. Wishaw Leader Heacham Galopin

Ch. Squire of Tytton

Somewhat similar tables have been worked out for other breeds, notably wire Fox Terriers, Airedales, Scottish Terriers, and Pomeranians. More elaborate records were analyzed by the late Major Taylor in his valuable work on the performances and pedigrees of the Setters and Pointers. Professor Davenport of the University of Illinois has made an exhaustive statistical study of the ancestry and track records of American trotting horse sires and their get. These studies demonstrate strikingly that the greatest improvement in speed has come through a few exceptional sires, all more or less closely related in blood.

Adapting Davenport's methods to a study 
of dogs, substituting for the time record of the trotter the winning of a championship as a standard of accomplishment, I have analyzed the ancestry and get of all Airedale Terrier dogs who have won the honorable title either in Great Britain or the United States. This data, when analyzed, bears out the general conclusion that most of the improvement in a breed of dogs, as in the case of a breed of horses, has been due to a few exceptional sires, all of the same family. It is interesting to note that the line of descent worked out by me from stud book statistics is identical with the family tree prepared empirically by Messrs. Ralph W. Condee and Earle J. Woodward. Statistical study coincides in results with the practical experience of breeders.

To January, I9I3, eighty Airedale dogs and sixty-nine bitches had won their championship in England and this country. Of these eighty dog champions, who any fancier knows will have better-than-average opportunities at stud, fifty-three never sired a championship winner of either sex. Despite the exceptional stud opportunities of all champions, only twenty-seven of them sired champions. Moreover, of these twenty-seven champion sires of champions but thirteen were the sire of more than one cham- 


\section{PRACTICAL DOG BREEDING}

pion. But, and this is significant, these thirteen champions sired forty-nine of the hundred and forty-nine championship winners. In other words, one-third of the total number of champions of the breed were sired by one-third of the dog champions, while only a half of all champions were sired by any champion. The thirteen exceptional champion sires got 33 per cent. of the champions, while the sixty-seven other dog champions between them sired only 22 per cent. of all champions. These figures are only roughly approximate, but they show impressively the tremendous influence for good of these thirteen exceptional breeding individuals.

In the second generation, of the eighty dog champions only twenty-four appear as grandsires of champions, and of this twenty-four, only ten are grand-sires of four or more champions. The fact that almost without exception the thirteen champions who sired two or more champions are also among those who were grand-sire of four or more champions is confirmatory evidence of their prepotency. The exceptional sires are also the exceptional grandsires. The following table shows the champions in the ancestry and get of these exceptional breeding individuals: 
PEDIGREE STUDIES

119

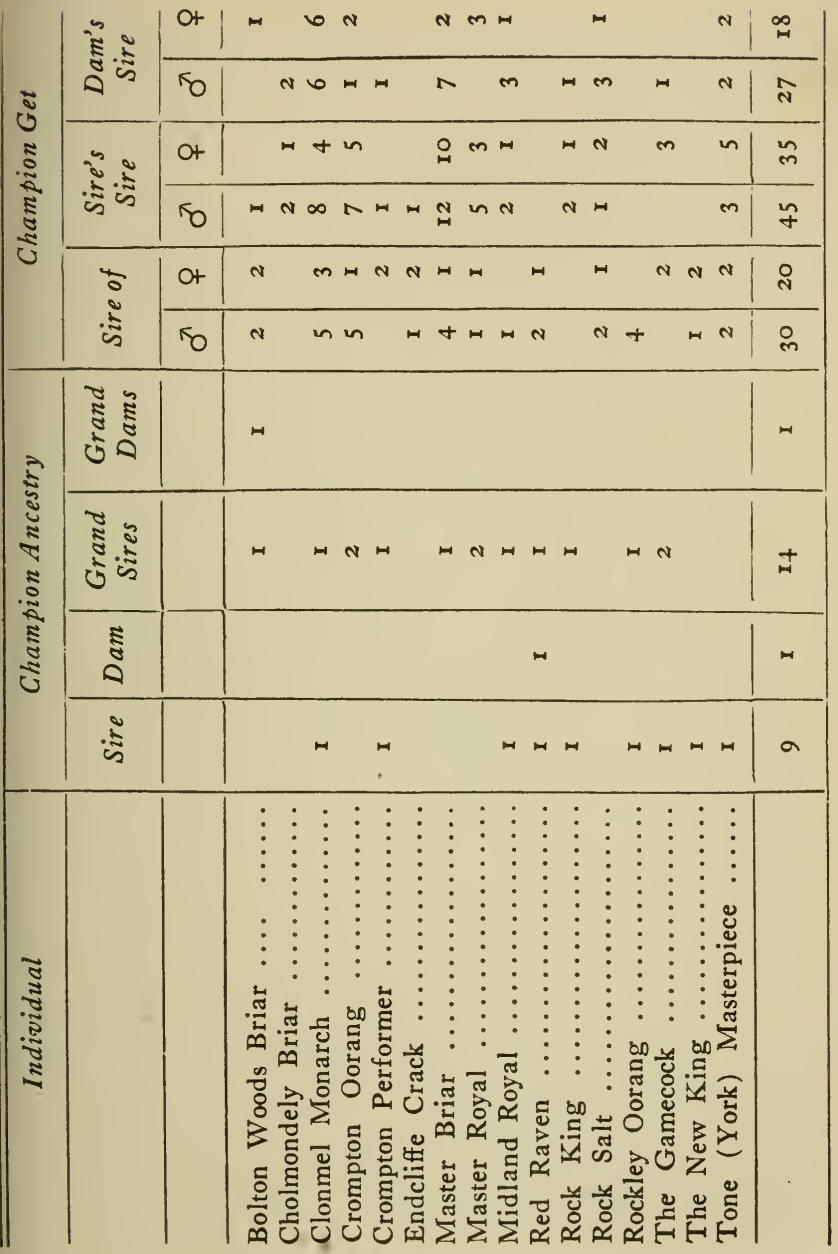




\section{PRACTICAL DOG BREEDING}

Without tracing out all the relationships and every dog in this table is related - it is worth while to point out that all are descendants of Cholmondely Briar. The three greatest producers of the lot are Master Briar, grandson of Cholmondely Briar, his son Clonmel Marvel, and Crompton Oorang, who is by a son of Master Briar out of a daughter of Clonmel Monarch.

This same table is very useful in checking certain beliefs more or less popular among dog breeders. For example, there is the old kennel proverb that "a great sire is famous for his daughters." The table does not bear this out. The great Airedale sires have produced thirty championship winning sons to twenty championship winning daughters, or half again as many. Since the proportion of dog to bitch champions in the whole breed is only eight to seven, the great sires have been distinctly above the breed average in their male get who have won championships.

In the second generation, the proportion of grandsons winning their championships is even greater. The exceptional grand-sires produced seventy-two grandsons and fifty-three grand-daughters who were able to annex the title. Moreover, sons of champions pro- 
duced eighty champions of both sexes, fortyfive dogs and thirty-five bitches, while the daughters of champions produced forty-five champions, twenty-seven dogs, and eighteen bitches. Except that both sons and daughters of champions produced more champion sons this is not a fair comparison, since the opportunities of the dogs are vastly greater than those of the bitches. In fact, when we consider the comparatively few number of puppies that any bitch can produce during her lifetime, the daughters of exceptional sires have made a wonderful showing and, compared with the average progeny of the average brood bitch, they surely fall under the class of the exceptional breeding individual. Theoretically, an ideal matron would be one whose sire and two grandsires were among the exceptional sires. Such a bitch could be very reasonably expected to prove the dam of puppies above the average class of the breed.

Certain characteristics in cattle, poultry, rabbits, guinea-pigs, and human beings have been proved to follow Mendelian inheritance, and it is a very natural hypothesis that certain points in thoroughbred dogs do likewise. Eye color, wire and smooth coats, and coat color are those characters that, from what has been 
discovered to be true in other animals, we should most naturally expect to behave in the typically Mendelian ratio when contrasting factors are crossed in dogs.

That black and brown coloring do in fact exhibit the same behavior in transmission among dogs as among mice and guinea pigs was forecast by the experiments of Profess̄or A. Lang and Dr. A. L. Hagendoorn. This has recently been corroborated by the pedigree studies of coat color in Pointers by C. C. Little of the Bussey Institution. The Pointer was chosen because the breed is well established and exhibits at the same time marked and easily recognized differences in color, and yet there is no fancy, placing a premium on any particular shade. The results of Little's studies, which were first published in The Journal of Heredity, are set forth in the following table:

\begin{tabular}{l|r|r|r|r}
\hline \hline \multirow{2}{*}{ Nature of Mating } & \multirow{2}{*}{$\begin{array}{c}\text { Number } \\
\text { of } \\
\text { Matings }\end{array}$} & \multicolumn{3}{|c}{ Color of Offspring } \\
\cline { 3 - 5 } & Black & Yellow & Liver \\
\hline Liver x Liver & 97 & 0 & 21 & 305 \\
Black x Black & 8 & 23 & 0 & 5 \\
Yellow x Yellow & $\mathrm{I}$ & 0 & 4 & 0 \\
Black x Liver & 56 & 77 & 9 & 95 \\
Yellow x Liver & 15 & 8 & 10 & 46 \\
Yellow x Black & 9 & 6 & 10 & 2 \\
\multicolumn{1}{c}{ Totals } & 186 & 114 & 54 & 453 \\
\hline
\end{tabular}


Little concludes from his study of these matings and the results obtained that there are two factors at work producing the colors in Pointers: "I. B. The factor for black pigment which is absent in brown (liver) animals. E. The factor for the extension of the brown and black pigment in the hair. In the presence of this factor, animals have spots of brown or black pigment on a white ground. In its absence the colored spots are yellow of various shade." This allows the following combinations, resulting in the four different visible types:

I. $\mathrm{BE}=$ Black.

2. $\mathrm{bE}=$ Brown (liver).

3. $\mathrm{Be}=$ Yellow with black nose.

4. be $=$ Yellow with flesh nose.

Little makes practical application of this analysis of coloring in the following suggestions to Pointer breeders: "In order to purify a strain from black individuals it is only necessary to go on breeding liver to yellow or yellow to yellow indefinitely. As long as this is carefully done there should be no blacks produced. Yellows from two liver parents may safely be crossed with liver-colored animals. If, however, any other yellows are used, the breeder may expect a certain number of black 


\section{PRACTICAL DOG BREEDING}

young among the progeny. To obtain a pure black strain is not so simple, requiring for its certain completion a separate breeding test for each black individual by crossing it with yellows coming from two liver parents. If among the progeny any liver or yellow young are found, it is certain that the black in question is not of the formula BBEE and will, therefore, not breed true."

This is a splendid example of the help that the practical dog breeder can get from the scientific work of the trained biologist. In the past, dog breeders have regarded such work as purely theoretical and of little or no use to them, largely because the data and experiments of these investigators of breeding problems have not been made with dogs. On the other hand, because the material is expensive and the time required for practical experimentation comparatively long, biologists have not employed dogs in their work on the principles of genetics. Recently there have been indications of a change in this condition. Dog breeders are beginning to awaken to the opportunities they have neglected in shutting their eyes to scientific help for their practical work. Biologists are extending their studies to include analysis of the statistical data of the kennel 


\section{PEDIGREE STUDIES 125}

club stud books and direct experiments with thoroughbred dogs. Both breeders and biologists must profit by such a movement. 


\section{CHAPTER VII}

BREEDING SYSTEMS

PHREE things every dog fancier has: a private formula for a sure cure for distemper; a pet method of feeding and conditioning; and a system of breeding. These three vary almost as infinitely as the total number of those riding the doggy hobby. Nevertheless, each personal variation can usually be placed under a general classification.

There have been, so I have read, something over three thousand distinct and infallible systems for breaking the bank at Monte Carlo; but all of these are founded upon four basic principles. It is much the same with all the different systems of breeding a champion. All these systems can be reduced either to a single one, or at best a combination of two or three, of six different basic systems. Strange to relate, three of these six are no systems at all.

The use of the word system applied to a plan or method of dog breeding is unfortunate. 
The word implies scientific order, a definite rule. It connotes infallibility, a sort of guaranteed success. No breeder should ever become so infatuated with a particular scheme of mating as to follow it blindly, and any breeding system that sets itself up to be a set of fixed and unchanging rules can at the very outset be regarded with suspicion. Such advice as "Always breed a bitch to her sire's sire" is wickedly foolish. The breeder who attempts to follow it is courting failure. The principles of genetics cannot be expressed in mathematical formulæ that will invariably work out a correct solution for any breeding problem. Other breeding systems are guesses founded upon practical observation, but misinterpreted by lack of experience or insufficient knowledge. Others are merely excuses for ignorance, or more often laziness. Neither a guess nor an excuse can rightly be called a system.

The best of the so-called systems are those that neither attempt to lay down fixed rules, nor to bolster up weakness, nor to offer short cuts to success. At best, they are merely guide posts pointing out the way to sound breeding practice, and even to call them systems is twisting the meaning of that word. 


\section{PRACTICAL DOG BREEDING}

Because some breeding systems are good, others are bad, and still others are indifferent, it is well worth the serious breeder's while to consider them somewhat in detail. After so doing he will be better able to map out for himself a course that he is to follow in his breeding operations. Let us first consider those systems that are no systems at all.

The greatest of these is the trust-to-luck system. It is to be feared that a majority of fanciers breed their dogs on this basis. "Put two good ones together, and trust to luck." That sums up the idea of these men. It is this famous system that, as H. E. Packwood puts it, "floods the whole world with well bred bad dogs," for a dog can have a pedigree full of champions and yet be not only a poor specimen but also be downright badly bred. Some strains of blood mix about as well as oil and water, and to attempt to cross them results in positive retrogression. Selection is the only direct force in breeding that is at the breeder's command, and when he fails to employ it he ceases to be a breeder at all.

Next to the trust-to-luck breeding, and just about as popular and just about as pernicious, is the fashionable breeding system. By this method a bitch is invariably mated to the lat- 
est sensational winner. Pedigree, and all that it means in heredity, individual points, and all that they mean in variation, - both are blissfully ignored. Only the number of first and special prizes won count, and it is very well known that, given a certain amount of quality, the number of prizes won is almost always in direct ratio to the opportunities given a dog. A reasonably typical dog in the hands of a professional visiting every show in the circuit, or a reasonably good performer run through all the field trials from Connecticut to Mississippi, either will have a bigger list of wins to his credit at the end of the season, than a truly superior dog, the property of a fancier who only supports his own local fixtures. Trust-toluck makes no pretense of serious selection. Fashionable breeding deliberately bases its selection on a gauge as stable as a weather vane.

It is not to be supposed that there have been no valuable sires who have also been popular winners, but a breeder who sends his brood bitches to the latest sensation is very apt to produce dogs like the one a fair fancier showed under George Raper at a show in the Midlands several years ago. The dean of the English judges gave the entry the gate and his owner later came up and complained bitterly 


\section{PRACTICAL DOG BREEDING}

that such things should not be because, forsooth her entry was sired by Champion Soand-so and his dam was Champion Such-a-one. Raper's answer was, "Next time, Madam, show the pedigree and leave the dog at home."

A third so-called breeding system is the egotistical system. A fancier breeds to his own dogs because it is cheaper, because it gives them greater opportunity as sires, or because it supplies the puppies with pedigrees that look as if he had established a strain of his own. Often he is absolutely honest in his belief that his stud dog is the greatest living sire, but this blind prejudice, even though it be innocent, is none the less at fault because it is blind and innocent. This egotistical breeding is the breeding vice of little minds.

These three systems, the trust-to-luck, the fashionable, and the egotistical are all actively bad. By a lucky fluke some few good dogs may have been bred according to them, but any one of the three followed consistently is sure to result in great waste of time, effort, and good breeding material, without having made the least progress. They are the ones that are no systems at all, and together they are undoubtedly responsible for that vast army of 


\section{BREEDING SYSTEMS}

thoroughbred dogs whelped every year that are never good enough to be anything more than a yard dog or a companion.

The three systems that remain are much more serious attempts at careful selection based upon definite principles. If they were no more, they would be great improvements over those we have discussed. Properly employed, each is a valuable aid. Their abuse has lessened their usefulness. Not one of them can be considered an infallible rule of sound breeding, for any one persistently employed will bring a breeder upon the rocks. These systems are in-breeding, line breeding, and outbreeding.

There are, we must remember, but three forms of true in-breeding. In-breeding necessitates the direct crossing of one individual's blood. This is only possible when a sire is mated to his own daughter; when a dam is bred to her own son; or when full brother and sister are crossed. Probably nine fanciers out of ten consider the mating of half brother and sister (dogs with either the same sire or else the same dam) as in-breeding. This is the primary cross of line-breeding. In fact, as we discovered in our pedigree studies, most of the 


\section{PRACTICAL DOG BREEDING}

ideas about the prevalency of in-breeding results from a confusion of these two terms and what each really means.

The mating of a sire to his own daughter obviously results in a tremendous intensification of his own blood. Using the figures of the numerical expression of the law of ancestral heredity, there will be 3 I per cent. of his blood in the puppies. Plainly, such a cross is the most effective means of perpetuating the qualities of a certain dog. The same is true in the case of a bitch bred to her son. These two are the closest forms of breeding, though, of course, if the individuals employed be themselves in-bred, or even line bred, the intensification of blood will be even greater.

The breeding together of full brother and sister is the most effective means of preserving and magnifying a certain cross. A bitch bred to a certain dog has produced a litter of very exceptional quality. To repeat the cross will be an uncertain experiment at best, but to breed together the best dog and the best bitch of the exceptional litter will fix the nick of blood firmly.

In-breeding for generation after generation will result in degeneration of physical and mental powers, and, if persisted in, will eventually 
mean sterility and the production of monstrosities. Blind puppies, and ones with malformations, especially of the legs, feet, ears, and tail, are the goal of continued in- and in-breeding. How soon the deterioration will appear depends upon the ruggedness of the variety experimented with and the conditions of kenneling, exercise, and feeding under which the breeding stock lives. It is, however, perfectly safe to say that to-day no breed of dogs is in-bred to anywhere near an injurious point. The total number of in-bred dogs certainly does not exceed Io per cent., and in most breeds probably not 5 per cent. These figures show that there is much exaggeration in the belief in the commonness of in-breeding.

The danger of in-breeding lies not, as so many suppose, in deterioration, but in the magnification of the heredity of a single individual. This is, of course, the very object of all inbreeding, but since the good and bad points are both intensified, in-breeding is a double edged sword. It is just as difficult, if not more so, to remove faults as to improve excellencies. The removal of in-bred faults is a "bad job." For this reason, in-breeding can only be judiciously used. However, the fact remains that in-breeding, properly understood and wisely 


\section{PRACTICAL DOG BREEDING}

applied, is a most directly effective weapon in the hands of the breeder. Much of the improvement in our blooded stock - this is particularly true of cattle and poultry - has been the direct result of skilful and prudent inbreeding.

Judged by the results produced, however, line breeding, although its results have been slower and are less sensational, has been even more effective. In our pedigree studies we saw that line breeding has, in the case of two typical Terriers, produced more than five times as many champions as in-breeding, and the breeding of a champion is the object of the dog fancier's breeding operations. Line breeding may be considered as a slower, safer, surer method of close breeding.

Line breeding can be defined as the combining of the blood of a certain individual without the direct use of that same individual. It is fairly represented by the marriage of cousins in whose children the blood of the grand-parents is again combined. It is possible - in fact, fanciers often use the term in this way to have a dog line bred to a certain great individual without that individual's name actually appearing in the pedigree at all. Such a line bred dog offers all sorts of opportunities for 
the use of certain blood in various combinations, since he can be mated directly to the exceptional individual in question without the attendant dangers, both active and passive, of direct in-breeding.

The primary or closest cross of line-breeding is the mating of half brother and half sister. This, like in-breeding, offers a means of concentration of one individual's blood. The outer limits of line-breeding shade off into out breeding. It is not always possible to determine just when the one begins and the other ends, but for practical purposes a rough and ready rule can be based on the law of ancestral heredity by disregarding as line-breeding anything beyond the fourth generation.

Two subordinate modifications of line-breeding principles are the figure system and the alternate generation system. The former was originally worked out for race horses and was first presented to dog fanciers by C. J. Davies in his book on breeding. In his monograph on Scottish Terriers he traces out the system in the pedigrees of this breed. The distinguishing feature of the figure system is the transfer of the emphasis from the sire to the dam. Instead of studying the sires in a pedigree, the dams are analysed, and all dogs are 


\section{PRACTICAL DOG BREEDING}

placed in families traced back through their dams to the original females of the breed. The system has one very obvious advantage. The fact that a sire usually has many more progeny than a dam makes the determination of his true worth as a breeding individual a much more complicated and difficult task. With his many opportunities, a dog at public stud may sire several winners and yet not be a truly exceptional sire. On the other hand, if a bitch produces the same number of good offspring she is almost surely an exceptional breeder.

The figure system traces back the different families through the bitch line, and by this means discovers the strains that have been specially prepotent. As an example, Davies, in tracing out the Scottish Terrier blood lines, discovered that the vast majority of the champions of the breed have come through their dams from the bitch Splinter II. Bitches who trace in tail female to this bitch and their sons are members of the Splinter II family, and, as such, are peculiarly desirable breeding stock. The figure system has never gained any general popularity among dog fanciers, probably because of the labor necessary to trace out the female lines of the different breeds. Few dog 


\section{BREEDING SYSTEMS}

fanciers have the patience and the industry of the chief supporter of this system, which, moreover, has no very apparent advantage over the method adapted from Davenport in discovering the prepotent strains through the better known and more easily traced sires.

The alternate generation system of breeding is based upon the belief that exceptional quality is accustomed to skip a generation. A famous dog is noted for his bitch puppies, or a dog never gets a son as good as himself, are two very common and very dogmatic statements. Their support rests upon the fact that several great dogs have failed at stud, and that their sons have often been markedly successful sires. We have seen, however, that this does not hold as generally true. The shining exceptions have led fanciers astray. The principles of genetics would certainly not bear out any belief in certain characters skipping a generation, except in the case of reversions which are, however, very irregular in their action and quite uncommon. The drag of the race would be at work to make the get of exceptional individuals less exceptional, i.e., closer to the average of the race, but there is no biological evidence to support the idea that it is better to breed to the progeny of an excep- 


\section{PRACTICAL DOG BREEDING}

tional dog or bitch, if the parent is available.

Straight out-breeding, the scrupulous avoidance of all close breeding of any type, is a child of the super-fear of the noxious effects of continued close breeding. From what has been said, it is plain that this is foolish and unprofitable. Moreover, from a practical point of view, it is almost impossible. The line of descent of most breeds has come to be concentrated in certain families which have proved to be overwhelmingly prepotent and from which most champions and exceptional breeding individuals have been bred. Quite naturally, sometimes consciously and often unconsciously, this has resulted in more or less consanguinity throughout the variety. Any breeder, whose breeding operations were extensive and extended over any considerable period of time, would find it difficult to live up religiously to a system of complete out-breeding. If he succeeded in so doing, his dogs would be such a jumble of mixed strains and contrasting heredities that any success that he might achieve would surely be sporadic and fleeting.

Destructive criticism is not nearly so valuable as constructive. It is a fruitless and thankless task to pull apart the various breeding systems without piecing together a substi- 
tute to take their place. "Piecing together" is the correct verb, for the breeding system I am going to recommend is not an original production, though I am sure that in the form I offer it, it has never been presented to dog fanciers. I have borrowed freely from the work of other dog owners, from the practice of other breeders, and from practical application of the principles of genetics, always working upon the foundation of my own experience.

First the dog breeder who seriously intends to make every effort to guarantee his own success will learn all he can from the history of his breed, and next, after thoroughly understanding their points, he will draw up for himself a very definite ideal. His actual breeding operations will be directed towards the establishment of a strain that will as closely as possible approximate this ideal.

Remembering always that until the drag of the race can be transformed into an ally, it is the breeder's worst enemy, he should strive to accomplish this, rather than to attempt any chance success in the production of a flyer or two. How can this be done, and how can it be done most quickly and with the least expense?

Even a casual study of any breed will re- 


\section{PRACTICAL DOG BREEDING}

veal the fact that certain points "come good" in the majority of the dogs. Other points are commonly bad. If in the selection of the brood bitches of his kennels, a breeder get two or three of sound average type, but excelling particularly in those points in which their breed, as a breed, is weak, he will have made the best possible start toward the establishment of that ideal strain. Naturally, these bitches should not only excel in these weak points of their breed, but should, so much as possible, be bred from stock strong in these same characters. Bred to dogs excelling in these same points, and better in others, the foundation of the strain is well laid.

In every subsequent mating that takes place a breeder should always strive to hold every good point possessed by his bitch, and to add to them something extra from the stud dog. The dangerous pitfall that trips hundreds of thoughtful breeders is an attempt to balance points, good and bad, against each other. A bitch excelling in eyes, skull, and ears but lamentably bad in foreface will be bred to a dog with a capital foreface, but shocking in eyes, ears, and skull. Or a bitch with speed and hunting sense, but lacking in bottom, will be mated to a solid dog with substance to spare, 
but little else to recommend him. As an example of glorious optimism such matings are splendid, but as breeding operations they are pathetic. The result is more than apt to be a spoiling of whatever good points were possessed by both parents, for these points were probably above the average of the race, and the principle of regression would tend to pull the average of the puppies back closer to the breed mean. Always hold then whatever good points we have, endeavoring in each successive mating to add to these other good points.

The advantage of starting at the weakest points of a breed and working up toward those points that are commonly good in the variety with which one is dealing is almost self-evident. It tremendously simplifies the problems of selection. The more generally a certain desirable point is possessed by a breed, the easier it will be to find a suitable mate possessing it. Sooner or later every breeder is forced to compromise. He must sacrifice one point for another, but the longer he can postpone this compromise, the firmer will be the foundation of his strain. Moreover, a dog excelling in points notably weak in his variety will never fail to catch a judge's eye. This very prac- 


\section{PRACTICAL DOG BREEDING}

tical, almost mercenary, consideration cannot be overlooked in these days of keen competition.

Working to found a strain from weakness through to strength, and always scrupulously holding all the good points and trying to add other excellencies to them is a broad policy that will be found to be eminently practical and valuable. Working on this basis, there are two things useful in narrowing the selection of the individual dogs in any particular mating. Always judge a dog as a breeding unit not by its own points, but on its ancestry and progeny.

To form a right estimate of the ancestry of a dog a knowledge of the points, both good and bad, of the dogs of the past is absolutely necessary, and a wide acquaintance with the dogs of the present is imperative if one is to judge a dog by its progeny. There are great practical difficulties in the way of doing this. It is, however, the best and surest means of arriving at a correct conclusion of the true worth of any individual as a breeding unit. Every scrap of definite knowledge of this kind can be regarded as a valuable asset, but breeders are fortunate in having another alternative that gives valuable assistance in selection. If 


\section{BREEDING SYSTEMS}

an accurate tracing out of the winning strain cannot supplant knowledge of the points of the dogs of a breed, at least it can ably supplement it. In the Airedale and Scottish Terriers we found, and the same is probably true of every breed, that a few exceptional sires had been responsible for the vast majority of the improvement. It is very much worth while for a fancier to trace out the winning strain in his own variety. An indifferent dog bred in this strain will almost surely be a better sire than an exceptional winner in whose veins this desirable blood does not flow.

The elimination of all guess work and the willingness to accept considerable length of time before success comes should be the first resolution made by a breeder. This means study, first, of the principles of genetics; next, of the breed with which one is dealing; and lastly, of the individuals employed in every mating. Working upon a foundation of excellence in the weak points of his breed and always retaining good points gained and adding others to these, the breeder, provided he judges his breeding stock by their puppies rather than by their own points, is sure to establish a strain upon which he can count for 


\section{PRACTICAL DOG BREEDING}

results. This, however, cannot be done in a season. The breeder must possess those qualities we all admire in our dogs, patience, gameness, and faithfulness. 


\section{CHAPTER VIII}

\section{THE STUD DOG}

O ninety-nine fanciers out of a hundred it is the soundest and kindest advice to warn against keeping a stud dog. Since it is human nature for each of us to consider himself " the hundredth man," and as the temptations, especially financial temptations so hard to overcome, are strong, it is right and proper that this advice should be supported with hard facts.

The conscientious breeder always finds that the selection of a suitable sire to whom to breed his matrons is his most serious problem. The more thoroughly he understands the principles underlying sound breeding practice, the more serious this problem becomes. He will look further than to the latest winner, either at the bench shows or in the field trials, as the case may be. He will not necessarily be satisfied with a champion son of champion parents. $\mathrm{He}$ will never breed to a dog just because he is convenient, or because he is owned by some 


\section{PRACTICAL DOG BREEDING}

friend, or by a prominent fancier, or by a popular judge.

He must find a dog that is better than his bitch in as many of her best points as possible: a dog, moreover, that has desirable features not possessed by his bitch. This dog must be from parents and grand-parents of the correct type; a dog bred, if possible, in the "winning strain"; a dog who has been proved by his puppies to be a desirable sire. Any experienced breeder will say that it is perfectly impossible to discover a dog combining all these qualities. Granted, some of these points will always have to be sacrificed, but the chance of finding the greatest possible number of them lies in having every dog at public stud available. For any one fancier to hope to keep a single dog combining them is to hope for the "impossibly impossible." No fancier, be he ever so wise and ever so wealthy, could possibly expect to own such a collection of sires that he would be sure of having just the best possible mate for each bitch in his kennels. The best possible mating is, or should be, none too good for every careful breeder.

The impossibility of keeping suitable mates for all the matrons of a kennel is, of course, the chief objection to owning a stud dog. 
Many fanciers, not only of dogs, but of other kinds of stock, have tried the costly experiment of attempting to maintain a small stud of exceptional quality. They have always failed as breeders, because of the dearth of material for selection. Perfection, even in any one detail, appears so seldom that the breeder must have the greatest freedom in his choice of breeding stock. The greatest freedom is only to be secured without the temptation to breed to one's own stud dogs. However good they may be as individuals, however potent as sires, it is almost always sure that somewhere is a dog who would be a better mate for any given bitch.

It requires the greatest strength of mind not to breed to one's own dog. It is so much more convenient. There are no express charges or stud fees to be paid. One is naturally jealous of his dog's reputation and wants him to have every possible opportunity to sire winning pups.

If one can withstand these temptations, and always be sure that he is honest with himself in selecting the best possible mate for each of his matrons, then there is no objection in the world to his keeping one or forty stud dogs. It is, however, a pretty safe estimate that not one in a hundred fanciers can do so. 


\section{PRACTICAL DOG BREEDING}

It may seem that this advice against keeping a stud dog is diametrically opposed to the advice to found a strain of your own. This is not of necessity the case. It is to be assumed that a breeder will keep trace of the dogs he has bred and sold. These can therefore be surely counted among the available sires from whom a selection can always be made. In fact, a breeder should consider them first, and most men do so. But here too he should guard against partiality. Do not breed to a dog you have bred, simply because you are his breeder, or because he will supply the puppies with a pedigree that will look on paper as if you had established a strain. That way lies the egotistical breeding system that leads to nowhere.

If one has determined to keep a stud and resolved to use him with discretion, two courses are open. He can either breed or he can buy his dog. In either case he should apply rigorous tests, the same as he would apply to any dog he was to mate to his own bitches.

The ideal stud dog should be possessed of quality, and accordingly he will probably be a winner at the bench shows, or in the case of a sporting dog, a proved performer in the field. If he is a champion so much the better, for 


\section{THE STUD DOG}

while the title sometimes only means luck or opportunity, still it is generally evidence of quality above the average of the breed. His sire and dam, and their sires and dams should bear investigation as to type. If possible, the dog should be already proved as a sire of winning puppies. This is the one most valuable test that can be applied to a prospective sire. Naturally, he should be sound and healthy, and he will be at his physical prime when three or four years old.

Being the possessor of such a dog, it is but natural that a fancier should wish to offer his services at stud. This is right and proper, but he should remember that by placing his dog at the disposal of fellow breeders he assumes certain responsibilities. First, it is his duty to see that his dog is kept in the best of good health. A vigorous, healthy dog is obviously a more desirable sire than a weak, sickly one. The foundations of good health, kenneling, food, exercise, and cleanliness, have been discussed at length in the companion volume to this book, "Practical Dog Keeping," and it would be going beyond the limits of our subject to discuss them here. There are, however, a few special points that apply directly to the stud dog. He should have plenty of exercise - 


\section{PRACTICAL DOG BREEDING}

more than is given to the other dogs - and his regular diet should be supplemented with raw, lean, chopped meat. If very heavy demands are made on his vitality, a couple of raw eggs beaten up with a tablespoonful of sherry or port (for a dog the size of a Pointer) may be given him daily.

Authorities differ on the number of bitches a dog may safely be allowed to serve. Some say only twelve a year: others claim a dog can stand service twice a week without injury to his powers. The former seems "unreasonably conservative," except in the case of a very young dog, but the other goes to the other and the more dangerous extreme. A service a week, or three in two weeks seems a reasonable demand. A young dog should not be used as stud before he is ten months old and should be only used sparingly during his first year. After a dog is six years old he should not be used more than twelve or fifteen times a year, and at eight years one can expect his ability to get puppies to become uncertain, though some dogs have proved to be potent as old as ten.

Besides attention to the health and vigor of the stud dog, the owner must assume certain responsibility for visiting matrons. He must provide against any possibility of a mesalliance, 


\section{THE STUD DOG}

and see that she is properly fed and exercised. When she first arrives, if she has come by express, she should be given a run and put in some quiet, comfortable place removed, if possible, from the other inmates of the kennels. Upset by the journey and frightened in a strange place, she needs rest and quiet. She should have all the clean, cool water she wants to drink - she is sure to be thirsty - and she should be fed lightly. The next day she will be ready to be bred.

A "tie" is generally considered evidence of a satisfactory service. There is, however, no foundation of fact for the theory that the duration of the "tie" is any indication of the number of puppies that will be born. Moreover, bitches have proved to be in whelp after a service when there was no "tie" at all, but, in such cases, it is but fair to notify the owner of the bitch of the circumstances.

There is no more provoking trial to a breeder's patience than to have a brood bitch "miss." He is apt to put the blame on the stud dog. This is natural, but unjust. Absolute sterility is uncommon among dogs. Over eighty per cent. of the cases of barrenness are to be found among the bitches. Moreover, a bitch out of condition - too fat is much worse 


\section{PRACTICAL DOG BREEDING}

than too thin - very often fails to have puppies even after an apparently satisfactory mating with a proved sire. In such cases, it is her owner's fault. However, most of the misses are the result of not breeding the bitch at the proper time during her period of heat. Sometimes this is the fault of her owner in not shipping her promptly: sometimes the blame rests with the owner of the stud dog who is careless.

But whatever the cause and whoever is to blame, the owner of the bitch is almost sure to charge the stud dog with the fault. Of this the stud dog's owner may be sure, and, since the reputation of being a sure sire of large litters is a valuable asset to any dog, every precaution ought to be taken to reduce to a minimum the chances of a miss. Careless words from fancier to fancier are often a stud dog's best - or worst - advertisement, and there are some "knocks" no optimism can transpose into "boosts." A reputation as an uncertain sire is one of these.

In advertising a stud dog, discretion is the better part of valor. A few facts soberly stated are better than buncombe and extravagant claims. Our English cousins are usually more circumspect in their kennel advertising than we, but oddly enough there appeared in 


\section{THE STUD DOG}

a recent issue of one of the British kennel papers an advertisement that is a good example of all a stud advertisement should not be:

\section{AT STUD}

The Oldest and Most Consistent Strain of Airedales and the Greatest Sires of the Past Two Years

\section{NOTE---NO OORANGS IN THIS STRAIN}

FACTS. NOT BLUFFS!

Stud Dog's Name (K. C. S. B.

THE MOST PERFEC'T

\section{AIREDALE \\ LIVING}

$£ 130$ refused, winner of 80 firsts and specials defeating many champions. His puppies out this year (we ignore last year's) include , and a puppy shortly to come out who can beat the lot. FEE, FOR A SHORT TIME, 30s. 


\section{PRACTICAL DOG BREEDING}

One does not have to be a walking encyclopedia of Airedale pedigrees and performances to appreciate the questionable taste of such statements, while, had I included the names, any novice in the Airedale fancy could see that despite the bold claim to the contrary, there is more "bluff" than "facts" in the advertisement. But, some one may ask, what has taste got to do with it? - a stud card is not a sonnet. True, but the object of a stud card is to sell the services of your dog. Confidence is an essential, integral part of every sale ever made, and surely confidence is never begotten by statements that the veriest tyro knows to be misleading. On the other hand, one does not have to write a "tombstone advertisement." There is a happy medium.

A good working guide when writing a stud advertisement is to be sure first that you present the essential facts, and let the good word you say for your dog be secondary. There are five facts that should be in every stud advertisement. The dog's name and stud book number, his pedigree for the first two generations, his age, the fee, and the address. In some breeds, his weight or his color also come into the class of the essentials. These are facts that every one who breeds to any dog will 


\section{THE STUD DOG}

want to know, and, if they are presented clearly in the stud card, it saves time in letter writing.

In saying a good word for your own dog it is always well to let a list of his winning puppies or a criticism quoted from a show report in a kennel paper speak in your stead. "Best" and "greatest" are two adjectives that should be struck out of the advertiser's lexicon. You will never get any three fanciers to agree on the "best dog of the breed " or on the "greatest sire." It is silly to claim something that cannot be, except in one case in a thousand, substantiated, and which is sure to create just the impression that one ought to strive to avoid.

The various kennel journals are the best mediums through which a stud dog's services may be offered. This may be supplemented by letters and cards sent to known breeders of your variety. Lists of these can be purchased for two cents a name and are a good investment.

Two little things that, although not strictly in the form of advertising, will prove to be very valuable publicity are Certificates of Service and Whelping Cards. Owners appreciate such attention and they help create confidence and good will. A good form for a certificate is: 
156 PRACTICAL DOG BREEDING

\section{THE NONAME KENNELS}

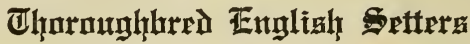

SOUTHERN PINES

NORTH CAROLINA

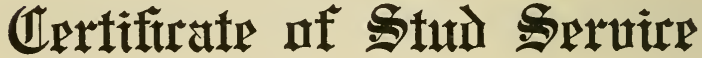

Un fies that on 19_the English Setter bitch property of of , was bred to our English Setter dog__ A.K. K. S. B. No. F. D. S. B. No. , and is due to whelp on or about 19

Arknumlednnment J ceipt of ___dollars, $\$$ , in full payment of the above service.

\section{Witness.}

Onner.

Southern Pines, N. C.,

19

The whelping card, which should be printed on a self-addressed post card may be in this form : 


\section{THE STUD DOG}

\section{THE NONAME KENNELS, SOUTHERN PINES, N. C.}

ON 19_ MY ENGLISH SETTER BITCH A. K. C. S. B. No.

F. D. S. B. No. WHELPED PUPPIES, DOGS AND BITCHES TO YOUR STUD DOG

REMARKS

NAME

ADDRESS

Any local printer can get these up in attractive shape, and at a reasonable cost. Both the certificate of service and the post cards for recording whelping will prove to be a good investment for all kennels that do any considerable business, and it is but little more expensive to gain that decidedly personal touch by having special forms printed with the kennel name and address on them than to buy the stock forms. These are, however, better than none, and are specially available for the small kennel or the breeder with a single stud dog.

Before leaving the subject of the stud dog, it will be well to consider briefly some of those ills that are peculiar to him, and which, accord- 


\section{PRACTICAL DOG BREEDING}

ingly are not treated in general books on dog keeping.

Impotence, or sterility, may be due to a variety of causes, some incurable, others able to be remedied. In many cases either one or both of the testes do not descend to the scrotum. In the former case a dog is usually fertile: in the latter, he is usually impotent, though often able to perform the act of coition. Of course, a dog that has been castrated is absolutely sterile. In other cases, without any apparent reason or cause, the seminal fluid is deficient. This can often be determined by a microscopical examination. Impotence from any of the above causes is almost without exception beyond remedy. A diet of raw meat, supplemented with raw eggs and sherry, is rarely beneficial, but, in the case of a valuable dog, it is certainly worth a fair trial.

Temporary impotence, due to accident or deformity, is amenable to treatment. Fracture of the bone of the penis, which happens occasionally, will mend in a month's time, usually without treatment, but a dog should not be used at stud for two months. When the opening of the prepuce is so constricted as to prevent the penis from protruding, it can be cured 


\section{THE STUD DOG}

by a simple operation. This had, however, best be left to a veterinarian's skill. Some dogs, especially young dogs, and dogs used too often at stud, are temporarily impotent because of the lack of sexual desire. A dose of tincture of cantharides, from three to twenty drops, according to the size of the dog, administered in water two hours before service, will often have the desired effect.

Inflammation of the testicle is usually caused by some accidental injury in the case of young dogs, but in old animals, especially if they have been extensively used at stud for a long time, it may arise from some constitutional cause. The testicles become swollen, and the scrotum is shiny and red. The dog suffers considerable pain and walks and sits down with difficulty. Local relief is sometimes obtained by the use of a hot poultice and sometimes by an ice bag, but the dog should be thoroughly purged and placed on a light diet of milk, thin soups, and dry biscuits.

In some cases the testicle enlarges, without the inflammation and soreness. This condition is nine times out of ten found in old dogs, and unless the enlargement continues and if it does not cause any great discomfort by hanging low 


\section{PRACTICAL DOG BREEDING}

and interfering with the dog's actions, it may be left alone. The only positive cure is castration.

A dog used at stud often develops wartlike growths on the penis. These greyish, hard growths often spread and grow, and should be promptly treated. A wash of two teaspoonfuls of common washing soda in half a pint of water sometimes effects a cure, but, if this fails, use a five per cent. solution of chromic acid, treating only one or two warts at a time. 


\section{CHAPTER IX}

THE BROOD BITCH

7 HE dog breeder's estimation of the brood bitches of his kennels has changed materially in the present generation, swinging back to the opinion held before the era of bench shows and field trials. The first fanciers, who kept their dogs solely as hunting dogs or companions, appreciated nicely the true value of quality in their matrons. In early sporting books such statements as "select always the fairest and the best trailers as dams" are common. Later, the idea became prevalent that "any old bitch with a pedigree is a good brood bitch." To-day, we have returned to the earlier and sounder estimation of the value of the bitch side of a pedigree.

We have already seen that although in the case of the breed at large the stud dog, because of his greater opportunities, is numerically more important, still in the case of the individual 


\section{PRACTICAL DOG BREEDING}

mating this is not so. The two parents are equipotent and of like importance. In fact, to the breeder, the brood bitch, being his own property, while he usually sends her away to an outside dog to be bred, is of paramount importance. A kennel's strength or weakness I speak, of course, of a kennel that is primarily a breeding establishment - can be judged by its matrons. The breeder will, therefore, pay strictest attention to the selection of his brood bitches, and he will always exercise great care of their health and condition.

When a bitch is neither in season, in whelp, nor nursing a litter, she requires no different care from any other inmate of the kennels. To repeat the discussion of all the questions of feeding, kenneling, exercising, and grooming, which have been treated at length in the companion volume of this book, would be out of place here.

Many persons, even many persons who have owned dogs, are, however, peculiarly ignorant of the sexual functions of a bitch. Owners of dogs advertised at public stud often receive bitches to be bred to their dog that evidence no sign of being "in heat," showing that an appreciation of the fact that a bitch is avail- 
able for breeding purposes only at certain times is not common.

CEstrum, or the period of menstruation of the bitch, usually first appears when she is from seven to ten months old. The medium sized breeds usually have their first heat seven or eight months after birth, larger breeds and the very diminutive varieties often delay the period to the tenth month or even to a full year. Once the periods begin they occur with considerable regularity every six months (there are, of course, some individual exceptions to this rule), till a bitch is about eight years old.

From its first indication till its abatement the season of heat lasts three or four weeks. The first sign is a swelling of the external parts, the vulva. This is followed almost directly by a slight mucus discharge which gradually thickens, and is succeeded, in a week's time, by blood. This condition, which will continue for a week or ten days, is again followed by the mucus discharge which gradually disappears, the parts assuming their normal size again. The proper time to breed a bitch, in fact, the only time when she will stand for a $\mathrm{dog}$, is just after the cessation of the flow of blood. This is the only time that she will receive a dog's services, although her condition 


\section{PRACTICAL DOG BREEDING}

from the first of heat sexually excites the male. In sending a bitch away to be bred, since there are but a few days when she is available, it is wise to ship her off at the first signs of heat, thus avoiding disappointment and delay of six months.

During, or just after heat, inflammation of the uterus is sometimes caused by chill, usually the result of giving the bitch a bath. Such attacks may become chronic, appearing at each heat, and the condition is common only in old bitches. The symptoms are dullness and loss of appetite, accompanied by slight fever and followed by loss of flesh and swelling of the abdomen, which is quite hard and painful to the touch. These symptoms increase in severity, ending in a pinkish, offensive discharge. The start of the discharge usually results in a marked improvement in the bitch's condition, but sometimes this discharge fails to come away naturally. In this case the womb is ruptured, and the patient usually dies of acute peritonitis. The bitch should be kept quiet and every effort should be made to make her comfortable by applications of hot linseed poultices, frequently changed, to her abdomen. The vagina should be syringed out with a warm solution of lysol, and her strength should be 


\section{THE BROOD BITCH}

kept up with milk, beef broth, fish, and such other light, nourishing foods as she can take and retain.

Much less dangerous, but far more common is a white mattery discharge after heat. The proper treatment is a thorough syringing night and morning with a solution of ten grains of burnt alum in an ounce of water.

After a bitch has been bred, she needs no special attention during the first month or six weeks of her pregnancy. She should, of course, have plenty of exercise and an abundance of good food. This does not mean that she should be worked all day in the field nor allowed to run her legs off, nor should she be stuffed. If a bitch is properly kept, no change in her daily routine need be made, but it is advisable to see that her bowels are kept open by a weekly dose of castor oil and syrup of buckthorn. Three weeks after service she should be treated for worms. Some fanciers suppose that this will prevent worms in the puppies. It will not, but it is a valuable precautionary measure, since no bitch that is infested with these parasites can properly assimilate her food.

The determination of whether or not a bitch is in whelp is often important. This can best 


\section{PRACTICAL DOG BREEDING}

be accomplished about three weeks after conception. At this time, if she be laid on her back and quieted until she will relax her abdomen, small, roundish bodies can be felt by the fingers manipulating her belly. Often the exact number of the expected family can be foretold. At four weeks the puppies seem to disappear, but any time after the sixth week they can be easily felt moving about, if the hand be gently but firmly pressed against the abdomen. The secretion of milk in the breasts, which occurs even in maiden bitches, six or eight weeks after heat, is no sure sign. Some bitches will exhibit all of the signs, except the motion of the pups, of pregnancy. They increase in size, just as if they were to have a large litter, but at the end of the time of the supposed gestation only a little, watery discharge comes away, and the bitch gradually gets smaller. These cases of false conception are provoking enough, and they are quite common.

Assuming that the service has been effective, the bitch, six weeks after conception, will begin to need a little extra watching and attention. She should be fed three times a day from now on, the best rule being little and often. Her exercise should be kept up, but always within 


\section{THE BROOD BITCH}

reason. Short walks two or three times a day should be the routine. Do not let her run and romp and keep her from all undue excitement. Do not wash her after the seventh week, and do not take her in a motor or on the train. These things are all apt to induce abortion. It is poor policy to be forever dosing a pregnant bitch. The less medicine and the more common sense she has the better it is for her and for her expected offspring.

The bitch's time of gestation is sixty-three days. This, however, is not a hard and fast rule, though reference can always be made to the table in the appendix with the reasonable expectation that it will give approximately the date a bitch will be due. Live, healthy litters have been born on the fifty-eighth day and, at the other extreme, on the seventy-first, but these are extreme exceptions. It is not difficult to read the signs a bitch gives of her coming confinement, and one can usually know within a few hours of when she will whelp. She becomes restless, seeking a quiet place and refusing food. If a box has been prepared for her, as it should be, she will nervously get in and out of it, turning round and round, and nosing and scratching at the bedding. The vulva swells and there is a thick mucus dis- 


\section{PRACTICAL DOG BREEDING}

charge. When her labor pains come on, she will strain and pant, and turn round and lick herself. This is a sure sign that labor is well progressed, and the birth of a pup can be confidently expected in a very short time. During labor, unless something goes radically wrong, the bitch should be left strictly alone.

A proper whelping box, however, is easily prepared and will be a capital investment. This should be square, or nearly so, each side being just long enough for the bitch to be able to lay out at full length. A bit of old carpet lightly tacked at each corner is the best bedding, for second choice, a scanty supply of good wheat straw. A little shelf fastened round the sides of the whelping box, just high enough for a pup to get under it and broad enough to prevent his being crushed in the corner should his mother inadvertently lie on him, is excellent puppy life insurance. Even the most careful of mothers will sometimes kill her babies in a cramped box, or if they are hidden in deep bedding.

The time required for the birth of a litter varies greatly, both with the age of the bitch and her breed and the number of puppies born. A bitch having her first litter must always be expected to require more time than a matron 


\section{THE BROOD BITCH}

who has had two or three. A medium sized bitch who has had several litters will often give birth to two or three puppies within an hour, while a bitch of the same breed having her first litter will hardly do so well in two or three hours' time. The bitches of the larger breeds commonly have big litters and often require all day. If after any pup has been born an interval greater than two hours elapses before the arrival of another, something may be wrong. Examine the bitch. If a bladder - the pups are born in a sack, the fœtal membrane - is protruding, things are probably going well. Matters should be allowed to take their natural course, for it is always a good rule never to interfere until absolutely necessary.

The normal course is for the bitch to rip the fœtal membrane once it is well protruded, and the puppy is then soon delivered. The mother bites the umbilical cord and cleans and dries the puppy. Usually the next pup is by this time nearly born. After three or four youngsters have arrived, there is often an interval of a couple of hours, during which the bitch rests. At this time, some clean, cool water and a little thin oatmeal gruel may be given the bitch.

It is not unusual, especially when the litter 


\section{PRACTICAL DOG BREEDING}

is very numerous, for a bitch to become very exhausted. A little milk with a tablespoonful of brandy will often revive her sufficiently, or it may be necessary to use drug to stimulate the action of the womb. Ergotine is the best of these. It should be administered hypodermically in a dose of from one to three grains, according to the size of the dog, in from ten to forty drops of brandy. Injected under the loose skin under the thighs, the action of this drug is evident in fifteen minutes, and the dose can be repeated, if necessary, in two hours.

Those breeds with particularly large skulls, as English and French Bulldogs and Boston Terriers, often have trouble in whelping, the heads of the puppies being too large to pass the dam's pelvic bones. Toy dogs, quite aside from their more delicate constitutions, sometimes have trouble due to an occasional pup throwing back in size to the larger stock from which the variety has been bred. Another somewhat similar case is when a small bitch has been mated to a dog of a larger breed, as a Fox Terrier bred to a Setter.

Another class of parturition troubles arise from an unnatural position of the puppy at the time of delivery. The normal position for the 
puppy to be born is head foremost with the front legs raised and lying close on each side of the neck. When the hind legs are presented, the pup is usually born easily, but there is some danger of its smothering. Malpresentations of a more serious nature are not common, but they are dangerous. To interfere, which is sometimes necessary, usually means the loss of the pup, which, if not killed, is often maimed. Moreover, unless care be exercised, inflammation may set in, resulting fatally for the dam. Therefore, the discovery of a malpresentation should always be the signal for a hurry call to a reliable veterinarian. If one is not available, prompt action should be taken by the breeder himself, since it is foolish to allow a bitch to waste her energies, which she will probably need to bring forth the other pups.

In all such cases the first object should be to get the puppy into the right position. This failing, to remove it as quickly and easily, and with as little danger and inconvenience to the dam as possible, for her life is then of greatest consequence. If reasonable care be exercised to prevent sudden jerking, and if force is only exerted during the throes, a bitch will stand considerable pulling on the fœtus. Inflamma- 


\section{PRACTICAL DOG BREEDING}

tion, resulting from direct injuries to the bitch herself are dangerous, and it requires a steady and skilful hand, especially when the knife must be used, to manipulate forced deliveries.

A common malpresentation is when the forelegs are turned down and backwards, throwing the shoulder girdle forward, thus forming an obstruction. A blunt pointed hook,an ordinary long handled buttonhook will answer admirably, - should be used to catch the forelegs and lift them into better position. This done, the pup can usually be delivered by the bitch unassisted. Sometimes in head presentation the hind legs are bent forwards up against the belly, causing trouble. Without obstetrical forceps there is little the amateur can do in such cases. It is best to tie a string to the pup's forelegs and to pull firmly at each throe, so as to help pass the hind quarters. Another form of presentation that will sometimes cause trouble is when the front and hind foot appear simultaneously. The fore leg should be pushed in and the hind leg tied with a string or tape. The other hind leg should then be felt for and drawn out (the buttonhook may prove useful here). After securing the second hind leg, the puppy should be delivered by traction. 


\section{THE BROOD BITCH}

There are two malpresentations of the head. In one case, the head is bent forward, the lower jaw pressing against the chest so that the top of the skull is presented. The fotus should, if possible, be pushed back and efforts made to raise the nose either with the finger or a long handled hook inserted in the mouth of the pup. When, on the other hand, the head is bent backwards, presenting the front of the throat, efforts should be made to push the fœtus back and depress the nose. If this fails, the pup can be decapitated, and the body and head delivered separately. In cases where the pup is presented transversely, the back or side appearing, it is seldom possible to turn the pup into a position making delivery possible. The only solution is to cut the body in two and forcibly remove the parts.

Considering the artificiality of their lives, it is remarkable what a small percentage of bitches ever have any trouble whelping. I have gone into parturition troubles at considerable length, for few easily available books treat of them, but the breeder can always console himself by remembering that they are comparatively rare occurrences.

After the litter has been born, if the case has been, as is to be expected, a normal one, 


\section{PRACTICAL DOG BREEDING}

the dam needs but little attention. A good bowl of thin oatmeal gruel and a change of bedding will suffice for her immediate needs. A breeder should curb his very natural desire to examine the new arrivals. Nothing is so disturbing to them and their mother. A nervous dam and a disturbed pup are a pretty poor foundation for good health. Sleep, plenty of sleep, is what the new born babies need most the first two weeks of their lives. Remember that "well begun is half done."

Bitches sometimes display strange idiosyncrasies of the maternal instinct. Some are so devoted to their offspring that they refuse food and will not leave the pups for a moment. Such extreme devotion must be forcibly controlled, and the bitch at least required to take some exercise, even if she cannot be forcibly fed. Other bitches are almost indifferent to their family, and a few go to the extreme of refusing to allow them to suckle. Some bitches have been known to eat their new born pups, and this may develop into a regular habit. Fear is the cause of this, and under more quiet conditions bitches have overcome this strange tendency. A diet of raw, lean meat, prior to whelping is advisable in such cases. It is a preventive measure that must, however, be sup- 
plemented by overcoming the bitch's nervousness.

While nursing her family, a bitch should be well fed. Four meals a day proves very satisfactory. Breakfast of soup and dog biscuits, and the regular kennel dinner in the evening, with milk or gruel at noon and the last thing at night: this makes a highly satisfactory fare. The fact that the puppies will roughly double their weight while they are nursing and that the recuperative processes carried on by the bitch herself are considerable gives some idea of the strain that she must bear. Adequate food is obviously a necessity.

The number of puppies a bitch can raise to the best advantage is a question only to be settled by a consideration of the individual case, remembering at once the size of the bitch and her individual strength. Four is certainly the outside limit for any of the toys. Five is plenty for a dog of medium size like the Terriers. Six is about all that can be reasonably asked even of the largest varieties. It requires fortitude for a breeder to destroy puppies from a carefully selected mating. However, unless a foster mother can be provided for the surplus, it is wisdom so to do. Four to six strong, well nourished, healthy pups will be worth 


\section{PRACTICAL DOG BREEDING}

more at six months than twice that number of sickly, leggy, slab-sided, cow hocked wrecklings. Often it is possible to obtain a foster from the local pound. The dog catchers are very apt to pick up stray bitches when their puppies are born. The points or breeding of the wet nurse have nothing to do with the care she can and will bestow on her adopted family, provided she is sound and healthy. Skin disease is to be particularly guarded against.

The saving of the dam's energies, when she is asked to raise only a reasonable number of puppies, is great, and this should be supplemented by the exercise of the same judgment in the number of times she is bred. Most breeders, since summer puppies are more easily reared, prefer to have their matrons whelp in the early spring. Some go so far as to never breed a bitch in the fall. It is certainly unwise to breed a bitch each time she comes in season. Three litters in two years is enough, and even this should only be asked of a robust bitch.

Whether or not a bitch should be bred at her first season is a debatable question. There is good authority on both sides. Personally, I believe it is a question that cannot always be answered either in the positive affirmative or the absolute negative. If the bitch is strong and 
well developed there is no reason, provided she does not come in before she is nine months old, why she should not be bred without damage to herself or risk to the puppies. However, it is unreasonable to expect to breed sound, healthy pups from a weak, immature bitch.

Even a healthy bitch nursing a rational number of pups may sometimes have a scanty supply of milk. She must be given raw, lean meat and plenty of oatmeal gruel and fresh milk. The secretion should be stimulated by massaging the breasts. On the other hand, some bitches have an excessive supply of milk, evidenced by swelling of the breast, which becomes hard and painful. The milk should be drawn off night and morning, and a laxative dose of castor oil and syrup of buckthorn administered. The diet should consist of dry food - stale bread and dog biscuits are capital.

The teats of a nursing bitch sometimes become dry and cracked. The soreness is great, and a bitch, because of the pain, will not allow the pups to suckle. The teats should be washed with warm water night and morning and then rubbed with a little boracic acid ointment. In fact, even if there be no soreness, it is well to wash the nipples twice a day with a solution of boracic acid. 
Weaning the puppies can be left to nature. At five weeks old they will usually start lapping a little warm, sweetened milk. At six weeks, their mother should only be with them at night. At seven weeks they should be shifting for themselves.

After the puppies are weaned, the bitch should be given a good purge and allowed a week of rest cure with three good meals a day. After this she should be treated for worms, and then put back on the regular kennel fare and routine. It may be advisable to give her a dose of cod liver oil tonic morning and night for a couple of weeks. The more promptly she can be restored to normal conditions the better it will be for her, and a breeder will find that her care will be time and pains well invested. 


\section{CHAPTER X}

THE PUPPIES



Y their puppies you can judge the success of dog fanciers, for, although there are large kennels that cut a wide swath in the awards at the bench shows and field trials, still, unless they are producing a reasonable number of home bred winners, they are principally important in the development of the thoroughbred dog as furnishers of incentive for the true breeders. Their example of prizes won is stimulating; their financial support is even more valuable; but, as factors in the improvement of the variety in which they are interested, they are, it is to be regretted, often ne'gligible.

Puppies, better puppies than ever before graced a bench or pointed a covey, are the goal of the dog breeder's ambition. Toward this end he always works. It seems strange then that, as a breeder, his work is finished before the puppies are born. The only point he 


\section{PRACTICAL DOG BREEDING}

touches directly in the breeding of better puppies is in his selection. It is, of course, his will that determines which two of many possible individuals shall be mated, in other words, which units of heredity shall be combined. This is, as we have seen, a difficult and complicated task, and to make the best selection a breeder needs every help he can secure. Hence the great importance of a thorough knowledge of the history and points of the variety being bred and a sound understanding of the principles of heredity and variation. It is ignorance of these things, ably supplemented by carelessness and catch-penny methods, that makes "well bred bad dogs" a drug on the market.

Despite the fact, however, that the trend of modern biologic thought is to lighten the emphasis formerly placed upon the inheritance of acquired characteristics and to discount largely the influence of environment on physical structure, still the practical breeder of dogs is very vitally interested in the proper rearing of his home bred puppies. The most perfect litter of exceptional individuals ever whelped must be raised to have any value. The good proverbially die young, and to hear fanciers talk one gets the idea that the pick pup of every lit- 


\section{THE PUPPIES}

ter ever whelped is invariably buried during infancy.

From every point of view, the first six months of a dog's life are the most important and critical in its individual development, and the first day is more important in inverted ratio than the two hundredth. Few fanciers seem to appreciate this. They usually consider that puppies are safest while nursing. In so much that they are less trouble and are less interfered with, this is in a measure true. The vast number of pups that die before their eyes are open, however, shows that this condition is more apparent than real. In raising a valuable litter then, a fancier should start the moment they are born. Eat, sleep, and grow: this is the life of the puppies during the first two weeks of their existence. Every effort must be made to make this life as ideal as is possible. A bad beginning never makes a good ending in the rearing of young animals.

When a puppy is born, its mother will attend to its first toilet. However, since damp and chill are potent enemies of the young life, it will be wise to take it from its mother, when she has finished with it, dry it thoroughly and wrap it in warm flannel rags, putting it in a 


\section{PRACTICAL DOG BREEDING}

dry, warm place. The mother will be so engaged that she will not be disturbed and the whole family can be re-united after the last of the litter has been born. Since the navel cord is sometimes the seat of an infection that is fatal, and prevention being very much better than cure, it is well to wash off the cord with a little tepid water in which is a mild solution of some good disinfectant, peroxide of hydrogen or lysol are excellent, and to dust it with boracic acid powder.

Many fanciers have had experience with an apparently mysterious and almost universally fatal disease popularly called the squeaks. Puppies three or four days old suddenly lose their appetites, become nervous and fidgety, and are in apparent pain. They whine and squeak continually, from which symptom the disease has received its name. The abdomen swells at first and is hard to the touch, but the puppies eventually die, stretched out on their bellies with a flat, crushed look. The immediate cause is to be found in the bitch's milk, which, if drawn off, will be seen to be greenish and stringy, with a strong, sourish odor.

The final cause is intimately associated with the condition of the dam prior to whelping. It is a disease peculiar to cramped quarters, and 


\section{THE PUPPIES}

the best means of prevention are attention to the bitch during her pregnancy. She must have plenty of exercise, and her bowels must be kept open. Some fanciers make a practice of milking a bitch after she has whelped and before the pups have suckled. This is advisable, since every possible preventive measure should be employed, there being no known cure for the disease once it has attacked the offspring.

If for any reason the dam cannot nurse her own puppies and a foster cannot be procured, it is quite possible to raise them by hand. This is an irksome task, but not difficult. The pups will suck from an ordinary nursing bottle, but the rubber nipple had best be substituted by one made of soft leather - an old glove answers admirably - in the end of which several holes have been pricked with a large pin. This leather nipple must be stuffed with a bit of sponge to give it form, for a pup in nursing wraps its tongue round the nipple. The nipples and bottles should, of course, be kept clean, boiling them out after each feeding.

A bitch's milk, contrary to popular opinion, is stronger than a cow's. The following analysis by A. J. Sewell, M.R.C.V.S., the well known English veterinarian, shows this difference: 


\section{PRACTICAL DOG BREEDING}

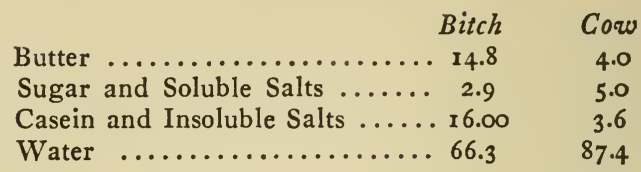

A bitch's milk, it appears, is about three times as concentrated as cow's milk, yet many fanciers dilute the latter when feeding pups. This is, of course, the exact reverse of the proper method. A fairly close approximation of bitch's milk can be prepared by taking a pint of cow's milk, adding to it four tablespoonfuls of cream, a heaping teaspoonful of either Mellen's or Eskay's baby foods, and six ounces of water. The prepared baby food should be mixed thoroughly with the water till a paste is made, and then added to the milk and cream and the whole brought to a boil, feeding when it has cooled to blood heat.

A day's rations may be prepared at a time, if kept tightly corked in clean bottles in the ice chest, and warmed by putting the nursing bottle in hot water just before feeding. Besides the obvious advantage of feeding artificial milk as close as possible to the composition of the pup's natural diet, the more concentrated food has the further advantage of furnishing adequate nourishment without the danger of overloading the small stomach of the young pup. Each 


\section{THE PUPPIES}

pup should be allowed to suck the bottle ten minutes, and they will have to be fed every three hours, day and night. At three weeks old the puppies will only require food every four hours, but they must be allowed to suck for fifteen minutes.

At five or six weeks the puppies should naturally begin the weaning process. By the time they are two months old they should be entirely independent of their mother. It is, however, best to leave this entirely to nature. Do not force matters. Their mother's milk is the best food pups can have, and so long as she will nurse them, they stauld be allowed this advantage. The arrival of the youngsters' first teeth will soon enough force the dam to leave off nursing them.

The dog, like most mammals, has two sets of teeth. The first set, the milk teeth, are temporary: the second are permanent. There are twenty-eight milk teeth, and the permanent set, varying according to the breed, contains fortytwo or forty-four. There are three different kinds of teeth: the incisors, twelve in number in each set, are in the front of the mouth and used for cutting and tearing: just behind the incisors are the canines or tusks, four in number: in the back of the mouth are the molars, twelve in 


\section{PRACTICAL DOG BREEDING}

the milk set and seven on each lower jaw and six on each upper in the permanent set, heavy, strong teeth, used for crushing and grinding. Some short faced breeds, as Bulldogs, have only five upper and six lower molars in each jaw.

Usually puppies experience little or no trouble in cutting their milk teeth. The larger breeds cut these teeth earlier than the smaller, the center molar in the lower jaw usually appearing first about three weeks after birth. The upper incisors next appear, followed by the lower incisors and the tusks, after which the two lower molars will come through and then the upper ones, the front upper molar being the last of the milk set to make its appearance.

The process of dentation will take about two weeks, so a puppy of the larger breeds should be equipped with a set of temporary teeth by the time it is five weeks old, while pups of the smaller breeds will be a few days later. Bitch puppies generally cut their teeth a few days earlier than their brothers, and summer puppies may have their teeth a little earlier than winter pups of the same variety. This set of teeth is very soft, and by the time a pup is four months old the sharp edges will be worn 
smooth. This, together with the fact that the teeth are not set close and grow farther apart as the pup's jaw grows, furnishes a rough index to the age of the youngster.

At about four months old, a puppy begins to get its permanent set of teeth. The center upper incisors will be loose or out about this time, and the fourth upper molar is beginning to put in an appearance. The other upper incisors and then the lower ones are replaced and the permanent tusks begin to show through the gums. The back molars appear next and then the more forward ones, the upper teeth appearing earlier than the lower, the opposite of the order in the temporary set.

The teeth do not follow any set and regular order, but by the time a St. Bernard, a Great Dane, or a Mastiff is five months old he should have a complete set of permanent teeth. The Terriers and medium sized dogs are usually two or three weeks later, and a toy may not be through teething till seven or even eight months. During the cutting of these permanent teeth it pays to watch a puppy's mouth. One of the permanent teeth may come up beside a temporary one without forcing it out. If neglected, this will cause no end of pain and inconvenience, and, if long neglected, may even 


\section{PRACTICAL DOG BREEDING}

result in a twisting of the permanent teeth. It is a simple thing to look into a pup's mouth every few days during the teething period and to draw any loose teeth of the baby set.

A puppy is often upset during the cutting of the permanent teeth. Eczema sometimes breaks out and the youngster's digestive tract is more than apt to be disarranged. Give a pup a thorough worming when he is three months old. It is a perfectly safe supposition that a puppy has worms, and it is the best insurance against stomach disorder, bowel troubles, and rickets to institute and follow a regular course of vermifuge. Three months is a good age to administer the first dose, and repeat it every three months till a dog is a year and a half old, after that at least twice a year.

Any of the vermifuges placed on the market by reliable firms will be found to be very effective, if the directions of the manufacturers are carefully followed. It is always advisable to do well what is worth doing at all, and the treatment should be repeated two or three days after the first dose. -Thorough treatment for worms will forestall most of the teething troubles, but if the pup is upset, put him on a light diet and administer a dose of castor oil and syrup of buckthorn. 
Rickets is a disease peculiar to puppies, and, if the youngster gets through his teething, he is very apt to escape all possibility of this trouble. Few cases appear, and then only as a legacy of distemper, after a dog is six months of age. The symptoms cannot be mistaken. The joints, especially those of the legs, swell; the forelegs are bowed and the hind legs are cowhocked. Usually there is involuntary twitching and shaking, the pup is thin and pot bellied, suffers considerable pain, and is altogether a miserable, pathetic object. The cause is worms, aggravated by improper food, lack of exercise, foul air, dampness, and lack of light and air. In extreme cases it is kindest and wisest to put the sufferer mercifully out of the way. If a cure is attempted - permanent cure is seldom achieved - the puppy must be treated heroically for worms and then well fed, well housed, and well exercised. Fowler's solution of arsenic, or better still, cod liver oil tonic, after the formula recommended in the companion volume to this book, is valuable.

Many puppies have fits. Sometimes these occur during the cutting of the second teeth, but they are usually the result of worms with heat or super-excitement furnishing the immediate cause. The youngster, who has appar- 


\section{PRACTICAL DOG BREEDING}

ently been quite well, suddenly crumples up, rolls about, kicking and champing its jaws, and frothing at the mouth. In a few seconds it will stagger to its feet, look about in a dazed manner, and then rush off, running round in circles, barking excitedly. Attack may follow attack in rapid succession and with increasing severity till the puppy may die of exhaustion.

First and foremost, one must remember that fits, as evidenced by these symptoms, have nothing whatever to do with rabies. Thousands of innocent dogs are slaughtered each year and hundreds of people are scared to distraction through this very silly mistake. The bite of a dog in a fit is absolutely harmless, and one can secure him without any fear. This should be done, and he must be restrained from hurting himself in his frenzies. A sponge or large cloth, soaked in cold water, should be soused on his head, and he should be kept quiet in a dark room. Talk to him and pet him gently. Do whatever you can to quiet him. After the fit has disappeared, the dog should be kept on a light diet of milk and thin broth for a couple of days and then treated for worms.

There are three minor operations that some breeders are called upon to perform upon their dogs. 


\section{THE PUPPIES}

The terriers, except the Scottish Terrier, and the spaniels, except the Irish Water Spaniel, are docked. This is best done when the puppy is four or five days old. The skin should be drawn down away from the body as far as possible, so it will be able to grow over and cover the stump of the bone, and the tail cut off clean with a pair of scissors. It is best to keep the pups away from the mother for half an hour or more, until the active bleeding has stopped. This, however, is seldom serious, and it can be readily checked by an application of tincture of perchloride of iron. It is not a bad plan to wash off the wound with a mild solution of disinfectant. It is customary to leave about three-fifths of a Fox Terrier's tail and something more than half of the tails of the other Terriers. The sporting Spaniels have a little less than half of their tails left and the toys about a third.

Cropping is not quite so easy, but the employment of the steel clips, sold by kennel supply houses for this purpose, makes it a surer and simpler operation than formerly. The clips should be fastened securely to the ear in the correct position, and the part of the ear outside the metal cut out quickly and cleanly with a sharp razor. Cocaine is sometimes used as a 
local anesthetic, but this is hardly necessary, for the pain is very slight. Cropping had best be done when a pup is nine or ten months old, and the proper training of the ear after cut is all-important, if a correct carriage is to be induced. It is at this point that the amateur generally fails dismally, and he should, if possible, receive a few practical lessons from a competent man, or else send his dogs to such a one to be cropped. Surgeon's plaster, wax, and even plaster of Paris are employed to fasten the ears back across the skull, so that when released they shall stand smartly erect.

Puppies are sometimes born with extra claws, dew claws, on the inside of their legs. These whether they be on the front or back legs, should be removed four or five days after birth, by cutting them off clean, close to the leg, with sharp scissors. This is an almost painless and bloodless operation.

The troubles of puppyhood are almost without exception the result of improper quarters, dirt, poor or badly selected food, or worms. With a very little reasonable attention, there is not a reason in the world why the average pup should not be " disgustingly well." Growing youngsters demand room and light and fresh air. They must have adequate food. They 
cannot thrive if infested with worms. Remember these things and the problem of raising puppies successfully is solved for you.

It is, however, true that no matter how roomy and light your kennels be, nor how large their runs, nor how careful you are of what goes into the pups' stomachs: they will do better on a farm. This being so, it is well, if possible, to make an effort to find reliable persons with whom you can board your youngsters between five and eight months of age. This English custom, and it is a great factor in the success of the British kennels, is one that is based on years of experience, and we in America should make every effort to establish it in this country. It will be an important factor in the rearing of better puppies. 


\section{PRACTICAL DOG BREEDING}

\section{Dog Breeding Calculator Showing}

\begin{tabular}{|c|c|c|c|c|c|c|c|c|c|c|c|}
\hline JAN. & MAR. & FEB. & APR. & MAR. & $\mathrm{MAY}_{\mathrm{A}}$ & APR. & JUNE & MAY & JULY & JUNE & Auc \\
\hline ș & $\frac{\pi}{5}$ & క్ & $\frac{\pi}{ \pm}$ & క్ & $\frac{8}{5}$ & ริ & $\frac{\mathbb{D}}{\Delta}$ & $\begin{array}{l}\text { ช } \\
\text { న్ } \\
\text { ปे }\end{array}$ & $\frac{R}{5}$ & 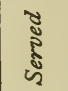 & $\frac{n}{3}$ \\
\hline I & 5 & I & 5 & I & 3 & I & 3 & I & 3 & I & 3 \\
\hline 2 & 6 & 2 & 6 & 2 & 4 & 2 & 4 & 2 & 4 & 2 & 4 \\
\hline 3 & 7 & 3 & 7 & 3 & 5 & 3 & 5 & 3 & 5 & 3 & 5 \\
\hline 4 & 8 & 4 & 8 & 4 & 6 & 4 & 6 & 4 & 6 & 4 & 6 \\
\hline 5 & 9 & 5 & 9 & 5 & 7 & 5 & 7 & 5 & 7 & 5 & 7 \\
\hline 6 & 10 & 6 & 10 & 6 & 8 & 6 & 8 & 6 & 8 & 6 & 8 \\
\hline 7 & I I & 7 & II & 7 & 9 & 7 & 9 & 7 & 9 & 7 & 9 \\
\hline 8 & 12 & 8 & I2 & 8 & 10 & 8 & 10 & 8 & 10 & 8 & I0 \\
\hline 9 & 13 & 9 & 13 & 9 & II & 9 & II & 9 & II & 9 & II \\
\hline 10 & I4 & I0 & I4 & 10 & 12 & IO & 12 & I0 & 12 & IO & 12 \\
\hline II & 15 & II & 15 & II & 13 & II & 13 & II & 13 & II & 13 \\
\hline 12 & 16 & 12 & I6 & I2 & 14 & 12 & I4 & 12 & 14 & 12 & I4 \\
\hline 13 & I7 & 13 & I7 & I3 & 15 & 13 & 15 & I3 & I5 & I3 & I5 \\
\hline 14 & I 8 & 14 & 18 & 14 & 16 & 14 & I6 & 14 & 16 & 14 & I6 \\
\hline 15 & 19 & I5 & 19 & 15 & I7 & r5 & I7 & I5 & 17 & 15 & I7 \\
\hline I6 & 20 & I6 & 20 & 16 & 18 & I6 & 18 & I6 & 18 & 16 & 18 \\
\hline 17 & 21 & 17 & $2 I$ & 17 & 19 & I7 & 19 & I7 & I9 & I7 & I9 \\
\hline 18 & 22 & 18 & 22 & 18 & 20 & I8 & 20 & 18 & 20 & 18 & 20 \\
\hline 19 & 23 & 19 & 23 & 19 & $2 I$ & 19 & 21 & 19 & $2 I$ & I9 & 21 \\
\hline 20 & 24 & 20 & 24 & 20 & 22 & 20 & 22 & 20 & 22 & 20 & 22 \\
\hline 2 I & 25 & 21 & 25 & $2 I$ & 23 & 21 & 23 & 2 I & 23 & $2 \mathrm{I}$ & 23 \\
\hline 22 & 26 & 22 & 26 & 22 & 24 & 22 & 24 & 22 & 24 & 22 & 24 \\
\hline 23 & 27 & 23 & 27 & 23 & 25 & 23 & 25 & 23 & 25 & 23 & 25 \\
\hline 24 & 28 & 24 & 28 & 24 & 26 & 24 & 26 & 24 & 26 & 24 & 26 \\
\hline 25 & 29 & 25 & 29 & 25 & 27 & 25 & 27 & 25 & 27 & 25 & 27 \\
\hline 26 & 30 & 26 & 30 & 26 & 28 & 26 & 28 & 26 & 28 & 26 & 28 \\
\hline 27 & $3 I$ & 27 & MAYI & 27 & 29 & 27 & 29 & 27 & 29 & 27 & 29 \\
\hline 28 & APR, I & 28 & 2 & 28 & 30 & 28 & 30 & 28 & 30 & 28 & 30 \\
\hline 29 & 2 & & & 29 & 31 & 29 & July r & 29 & $3 I$ & 29 & 31 \\
\hline 30 & 3 & & & 30 & June I & 30 & 2 & 30 & Aug.I & 30 & Sep. \\
\hline $3 I$ & 4 & & & $3 I$ & 2 & & & $3 I$ & 2 & & \\
\hline
\end{tabular}




\section{Date Due to Whelp After Service.}
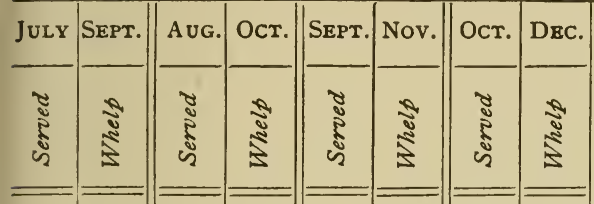

\begin{tabular}{|l|l}
\hline Nov. JaN. \\
\hline
\end{tabular}

DEC. FEB.

\begin{tabular}{|c|c|c|c|c|c|c|c|c|c|c|c|}
\hline I & 2 & I & 3 & I & 3 & I & 3 & I & 3 & I & 2 \\
\hline 2 & 3 & 2 & 4 & 2 & 4 & 2 & 4 & 2 & 4 & 2 & 3 \\
\hline 3 & 4 & 3 & 5 & 3 & 5 & 3 & 5 & 3 & 5 & 3 & 4 \\
\hline 4 & 5 & 4 & 6 & 4 & 6 & 4 & 6 & 4 & 6 & 4 & 5 \\
\hline 5 & 6 & 5 & 7 & 5 & 7 & 5 & 7 & 5 & 7 & 5 & 6 \\
\hline 6 & 7 & 6 & 8 & 6 & 8 & 6 & 8 & 6 & 8 & 6 & 7 \\
\hline 7 & 8 & 7 & 9 & 7 & 9 & 7 & 9 & 7 & 9 & 7 & 8 \\
\hline 8 & 9 & 8 & IO & 8 & I0 & 8 & 10 & 8 & I0 & 8 & 9 \\
\hline 9 & I0 & 9 & II & 9 & II & 9 & II & 9 & II & 9 & IO \\
\hline 10 & II & IO & 12 & 10 & 12 & IO & I2 & IO & 12 & I0 & II \\
\hline I I & 12 & II & 13 & II & 13 & II & I3 & II & I3 & II & 12 \\
\hline 12 & I3 & 12 & 14 & 12 & 14 & 12 & 14 & I2 & I4 & 12 & 13 \\
\hline 13 & 14 & 13 & 15 & 13 & I5 & 13 & 15 & 13 & I5 & 13 & 14 \\
\hline 14 & I5 & $\mathrm{I}_{4}$ & 16 & 14 & I6 & I4 & I6 & I4 & I6 & 14 & 15 \\
\hline 15 & I6 & I5 & I7 & I5 & I7 & I5 & I 7 & 15 & I7 & I5 & I6 \\
\hline 16 & I7 & 16 & 18 & I6 & 18 & I6 & I8 & I6 & I8 & 16 & 17 \\
\hline 17 & 18 & I7 & I9 & 17 & I9 & I7 & I9 & I7 & I9 & I7 & 18 \\
\hline I 8 & I9 & 18 & 20 & I8 & 20 & I8 & 20 & 18 & 20 & 18 & 19 \\
\hline 19 & 20 & I9 & 21 & I9 & $2 I$ & 19 & $2 \mathrm{I}$ & I9 & $2 \mathrm{I}$ & I9 & 20 \\
\hline 20 & 21 & 20 & 22 & 20 & 22 & 20 & 22 & 20 & 22 & 20 & 21 \\
\hline $2 \mathrm{I}$ & 22 & 21 & 23 & $2 \mathrm{I}$ & 23 & $2 \mathrm{I}$ & 23 & $2 \mathrm{I}$ & 23 & $2 I$ & 22 \\
\hline 22 & 23 & 22 & 24 & 22 & 24 & 22 & 24 & 22 & 24 & 22 & 23 \\
\hline 23 & 24 & 23 & 25 & 23 & 25 & 23 & 25 & 23 & 25 & 23 & 24 \\
\hline 24 & 25 & 24 & 26 & 24 & 26 & 24 & 26 & 24 & 26 & 24 & 25 \\
\hline 25 & 26 & 25 & 27 & 25 & 27 & 25 & 27 & 25 & 27 & 25 & 26 \\
\hline 26 & 27 & 26 & 28 & 26 & 28 & 26 & 28 & 26 & 28 & 26 & 27 \\
\hline 27 & 28 & 27 & 29 & 27 & 29 & 27 & 29 & 27 & 29 & 27 & 28 \\
\hline 28 & 29 & 28 & 30 & 28 & 30 & 28 & 30 & 28 & 30 & 28 & Mar.I \\
\hline 29 & 30 & 29 & 31 & 29 & Dec. I & 29 & $3 I$ & 29 & $3 I$ & 29 & 2 \\
\hline 30 & Oct. I & 30 & Nov. I & 30 & 2 & 30 & JAN. I & 30 & Feb.I & 30 & 3 \\
\hline 31 & 2 & 31 & 2 & 1 & & $3 I$ & 2 & & & $3 I$ & 4 \\
\hline
\end{tabular}





\section{BIBLIOGRAPHY}

The following list of books has been prepared with the view of enabling those breeders who wish to extend their knowledge of the principles and practice of breeding to do so in the most economical and effective manner. In general, the books mentioned are the standard works on the subjects they treat, but an effort is made only to include those most available to American readers. Because of the lack of information on books treating of the histories and points of the various breeds, a short list of the most important of these is included.

Evolution.

Charles Darwin's “The Origin of Species," “The Descent of Man," and "Animals and Plants under Domestication" (in the order named) make a splendid introduction to this study, and can be followed by A. R. Wallace's "Darwinism," Romane's "Darwin and After Darwin," and Weismann's "The Evolution Theory."

REPRODUCTION.

E. B. Wilson's "The Cell," is the standard work on the cell, and will supplement the elementary facts found in any good text-book on Physiology.

VARIATION.

H. M. Vernon's "Variation in Animals and Plants," contains many forceful examples of the different types of variation, while for a statistical study the best books are F. Galton, "Natural Inheritance," and K. Pearson, "The Grammar of Science." For mutations one should read, H. de Vries, "Species and Varieties," and "The Mutation Theory." HEREDITY.

J. A. Thompson's "Heredity," is a standard work - the sections dealing with the germ plasm theory are especially" 


\section{PRACTICAL DOG BREEDING}

good - and G. Archdall Reid's "The Laws of Heredity," is capital treatment of heredity in man.

SELECTION (Breeding).

By far the best work I know for practical breeders is "Principles of Breeding," by Eugene Davenport - a clear and complete exposition of the scientific and practical material. More directly treating of the problems of dog breeding is C. J. Davies' "Breeding to Type." "The Rational Service," by "Great Dane," and "The Management of the Stud Dog and Brood Bitch," by Theo. Marples are valuable little books.

General Works on Dogs.

The standard American work treating the histories and points of the various breeds is James Watson's "Book of the Dog," a popular one volume edition of which is now published, containing all the text, but only part of the illustrations of the original two volume edition. "Modern Dogs," in four volumes, two devoted to sporting dogs, one to terriers, and one to non-sporting breeds, by Rawdon B. Lee is a well written, authentic work, and "The Twentieth Century Dog" (two volumes, one sporting; one non-sporting) is a remarkably valuable compilation of the opinions of many experienced owners. "The Kennel Encyclopedia," edited by J. Sidney Turner, is a splendid work of reference, while Count Henri de Bylandt's "Dogs of All Nations" (2 vols.) is a profusely illustrated work giving, in four languages (English, French, German, and Dutch) the official standards of all known breeds, many of which are not even mentioned in the English and American works.

The following is a list of the most important monographs on the more popular breeds. Those books published in America are marked with a star (*).

SPORTING DoGs.

* "The Sporting Dog," Joseph A. Graham.

"The Bloodhound," Edwin Brough.

"Bloodhounds," Major E. H. Richardson.

"Scotch Deerhounds and their Masters," George Cupples. * "The Borzoi" (Russian Wolfhound), Joseph Thomas.

* "Horse and Hound" (Foxhounds), General Roger Williams, M.F.H. 
* "The Foxhound," General Roger Williams, M.F.H.

* "The American Fox Hound," Haiden C. Trigg, M.F.H. * "The Beagle," edited by Reno B. Cole.

"The Greyhound," Dalziel, Maxtee, and Rixon.

"Sporting Spaniels," Cane and Phillips.

* "The Cocker Spaniel," Eugene Glass.

* "The Spaniel and its Training," F. H. Mercer.

"The Clumber Spaniel," James Farrow.

"The Pointer and his Predecessors," William Arkwright. TERRIERs.

"Terriers," edited by Harding Cox.

"The Airedale Terrier," Holland Buckley.

* "The Airedale," Williams Haynes.

"The Airedale Terrier," F. M. Jowett.

* "All About Airedales," E. M. Palmer.

* "The Bull Terrier," Williams Haynes.

"The Perfect Fox Terrier," Sidney Castle.

"The Fox Terrier," Hugh Dalziel, revised by J. Maxtee.

* "The Fox Terrier," Williams Haynes.

"The Fox Terrier," Rawdon B. Lee.

"The Scottish Terrier," C. J. Davies.

"The Scottish Terrier," W. L. McCandlish, with a chapter on "The West Highland White Terrier," by B. W. Powlett.

* "Scottish and Irish Terriers," Williams Haynes.

"The Irish Terrier," F. M. Jowett.

"The West Highland White Terrier," Holland Buckley. Non-SPORTING Dogs.

"The Great Dane," Frederick Becker.

"Great Danes, Past and Present," Morrell Mackenzie.

"The Collie," Hugh Dalziel, revised by J. Maxtee.

"Show Collies," H. E. Packwood.

* "The Useful Collie," W. A. Sargent.

"The Perfect Bulldog," Hay Hutchison.

"Show Bulldogs," Sidney H. Deacon.

"Bulldogs and Bulldog Men," H. St. John Cooper.

* "The Boston Terrier," Varnum Mott, M.D., revised by Williams Haynes.

* "The Boston Terrier," Edward Axtell.

"The Whippet and Race Dog," Freeman Lloyd. 


\section{PRACTICAL DOG BREEDING}

"Manual of Toy Dogs," Mrs. Leslie Williams.

"Toy Dogs," Mrs. Handley Spicer.

"English Toy Spaniels," Mrs. Lillian Raymond-Mallock.

"English Toy Spaniels," the Hon. Mrs. Lytton.

"Show Pomeranians," Miss L. Ives.

"The Yorkshire Terrier," "Our Dogs." 


\section{INDEX}





\section{INDEX}

Abortion, tendency of some bitches to, 52; causes and prevention of, $\mathbf{1} 67$.

Acquired characteristics, an external cause of variation, 60 ; defined, $83-84$; less belief in inheritance of than formerly, 85.

Advertising a stud dog, 152 seq.

Airedale Terrier, I8, 21, 26, 60, 78, I00, II2, I13, I16, I43, I53. Agricultural stations, practical work in breeding done by, 14

15.

American bred dogs, beaten by importations, 29 .

Ancestral heredity, law of, 90-92; a guide in breeding, roo.

Artificial selection, compared with natural, 30 seq.; definite limits to, 55 .

Atavism, breeders' hazy ideas of, 16 ; observed by dog breeders, 58 ; related to inheritance, 59 .

Batson, quoted, II.

Beagle, 34, 35 .

Bibliography, $197 \mathrm{seq}$.

Biologists, studies in practical breeding, 14-15; agree on evolution, 33 ; example of help from, 124.

Blindness, fault to be shunned, ro3; a result of continued inbreeding, $\mathbf{r} 33$.

Books on dogs, valuable to breeder, 27 ; list of, $198 \mathrm{seq}$.

Boston Terrier, 18, 48, 54, 109, 170.

Breeding systems, 126 seq.; every breeder has his own, 126; six basic, 127 ; the figure, $135-137$; the alternate generation, 137 ; a new, 140 seq.; the trust-to-luck, 16, 25, 128; the fashionable, r29-130; the egotistical, 130,148 ; see also inbreeding, out breeding, line breeding.

Brood bitch, a valuable, 140 ; care prior to service, 150 ; proper condition for service, I5I; modern high regard for, $16 \mathrm{I}$; 
period of heat, 163 ; period of gestation, $167, \mathbf{1 8 2}$; care at time of whelping, 170; care when nursing, 175; how often to breed, $\mathbf{1 7 6 .}$

Castration, 158 .

Cells, whole body a colony of, 35 ; structure of, 36-37; division, 37 ; the germ, $38-39$; reduction in germ, 45 seq.

Champion, bred in first litter, 19; his breeder honored, 29; must be sound, 51 ; fetish worship of, 85 ; a strain of, 93; is object of breeder's operations, 107; statistics of breeding in two breeds, II3-II4; Airedale studied statistically, II7-I21; not always best sire, I45.

Characteristics, individual, transmission of, 42 ; intensified by inbreeding, 99.

Chow Chows, 79, roo.

Coat, variation in, 52 ; affected by climate, 60 ; Mendelian inheritance of in Fox Terriers, 79.

Collie, 5I, I I 5-I 16 .

Color, studies in coat and eye, 78 ; of Boston Terriers, I08; of eyes and coats probably Mendelian, 12I-122; rule for breeding for, 123 .

Condee, Ralph W., quoted on Airedale bloodlines, roo-ror ; family tree of Airedales prepared by, $1 \mathbf{I} 7$.

Cropping, r9r.

Cross-breeding; futile without variation, 49 ; only could produce some results, 53 ; by Mendel, 75 .

Cunningham, Duncan, on Skye Terrier standard, 20.

Dam, as important as sire, 83,99 ; the theoretically ideal, I2I ; importance of in figure system of breeding, 135; valuable when excelling in her breed's weak points, r40; old opinion of importance of, I6r; care during pregnancy, r65; care at whelping, r70; perversion of maternal instincts, I74.

Darling, Dr. C. G., on eye color, 78 .

Darwin, books best known to fanciers, 15 ; theory of natural selection, $30 \mathrm{seq}$.; case of telegony cited by, 56 ; on deterioration of dogs in India, 59. 
Davenport, Professor; canvass among dog fanciers made by,

57; studies in trotting horse pedigrees, II 6-II7.

Davies, C. J., on figure system of breeding, $135 \mathrm{seq}$.

Deafness, a fault to be shunned, ro3.

Determinants, see Factors of Inheritance.

De Vries, on mutations, 54; on Mendelian inheritance, 73. Dew claws, removal of, rg2.

Distemper, a cause of rickets, 189 .

Docking, r $9 \mathrm{r}$.

"Dog Book," quoted, 22.

Dog breeder, so-called scientific, 15 ; has a comparatively easy task, 17 ; necessary equipment of, 19 seq., 144 ; requirements for success as, 26-28, 144; rewards of, 29; must know fundamentals of genetics, $35,107,143$; a spectator of heredity and variation, 88 ; "eye for livestock" an asset of, 97 ; is a true sportsman, 108; his best friend, II 5 .

Dog breeding, a sport, 14 ; true object of, 18 ; puppies are proof of success in, ro7.

Dominance in Mendelian inheritance, 76 .

Drag of the race, see Regression.

English Bulldog, 54, 58, 92, 99, 170.

Evolution, Darwin's theory of, 30 seq.; belief in, 33 .

Ewart, Professor, experiments breeding horse and quagga, 57.

Factors of inheritance, combined in sexual reproduction, 43; different combinations assured by reduction, 46; remain pure when crossed, 80; complete set in each parent, 82. Faults, breed's prevailing, 99; differentiated from defects, ro3; inbred, hard to remove, 133.

Fertility, important to breeders, 52 ; cannot always be maintained, 94; impaired by continued inbreeding, 133 .

Fertilization, process of described, 38 seq.; in plants, 68. Fits, 189.

Fœtal membrane, puppies born in, $\mathbf{x} 69$.

Food, effect of in natural selection, 33; proper for a stud dog, I 50; proper for a nursing bitch, 175, 177; artificial for puppies, 184.

Foster mother, 176 . 
Fox Terriers, 28, 53, 54, 56, 64, 65, 72, 92, 95, 116, х70. French Bulldogs, 35, 54, 170.

Galton, contributor to theory of heredity, 42 ; statistical studies in inheritance, 70-7I; law of ancestral heredity, 90 seq.

Genetics, recent advances in, I3; popular interest in, $\mathbf{1 4}_{4}$; knowledge of, necessary to breeder, 35, 107, 143 .

Germ plasm, theory explained, $4 \mathrm{I}$ seq.; unchanged in pure line, 69 ; nature of, in hybrids, 81 ; of sire and dam equipotent, 99.

Gesner, Conrad, quoted, ro5.

Gestation, duration of, 167; table of, 194-195.

Gordon Setter, 35.

Great Dane, 96, $x 87$.

Hagedoorn, A. L., experiments in color breeding, 78, 122. Harris, Arthur, quoted, 33.

Heat, see OEstrum.

Heredity, law of, 30 ; basis of selection, 34 ; an exception to, seems ridiculous, 35 ; makes selection effective, 35 ; secret of, lies in germ cells, 40; early theory of, 40; Weismann's theory of, $4 \mathrm{I}$ seq.; pure line, $68 \mathrm{seq} . ;$ Mendelian, 73 seq.; mistaken conceptions of, 85 ; dog breeder a spectator of, 88; law of ancestral, 90 ; advantages of mathematical study of, 94 ; of individual magnified by inbreeding, 133 .

Heredity, Journal of, quoted, $\mathbf{2 2}$.

Histories of breeds, carefully recorded, I8; important to breeders, 2 I; part of breeder's equipment, 27 .

Hocks, cow, a fault, ro3.

Hybrid, in Mendel's experiments, 75 ; the germ plasm of, $8 \mathbf{I}$.

Impotence, important to breeders, 52 ; see also Sterility.

Inbreeding, prepotency of, 99; defined and studied statistically, Iro seq.; as a breeding system, I3I; the uses of, I32; a double edged sword, I33.

Indian Kennel Club, 59.

Irish Terrier, 23-25; 56.

Irish Water Spaniel, rgr. 


\section{INDEX}

Johannsen, Professor, experiments in pure line breeding, 68 seq.

Judges, responsible for type, 19-20; as owners of stud dogs, 146.

Labor, signs of, 168; duration of, 169 .

Lang, A., on breeding for coat color, 122 .

Line breeding, confused with inbreeding, II2, 13I; statistically studied, Ir 3 ; most effective in breeding champi-

ons, Ir 5 ; uses of, I34; modifications of, 135, 137 .

Little, C. C., studies in coat color of Pointers, 78, 122.

McConnell, F. H., quoted on example of supposed telegony, 56 . Malformations, a result of inbreeding, 133 .

Malpresentations, I70 seq.

Mastiff, 187 .

Maternal instinct, perversions of, $\mathbf{1 7 4}$.

Mendel, experiments in cross-breeding, $74 \mathrm{seq}$.

Mendelian inheritance, breeders' hazy notion of, 16; nature of, 73 ; in dogs, 78-79; 121 seq.; results expected from, 80.

Milk, faulty supply chronic with some bitches, 52 ; in breasts during pregnancy, 166 ; treatment for scanty supply, 177 ; cause of "squeaks," r82; bitch's and cow's analyzed and compared, 184 .

Muss-Arnolt, G., on "canine prostitution," 16.

Mutation, defined, 54; not common in dogs, 64 .

Natural selection, compared with artificial selection, $30 \mathrm{seq}$. Navel cord, bitch severs, 169; seat of infection, 182.

Newcastle, Duchess of, her strain, 28.

Nucleus, in each cell, 36 ; behavior in cell division, 37 ; behavior in fertilization, 39 ; reduction of, 45 .

CEstrum, period of described, $163 \mathrm{seq}$.

Old English Sheepdog, 55.

Otterhound, 2r.

Out-breeding, statistics of, $\mathrm{II}_{3}$; results as a fear of inbreeding, ${ }_{3} 8$; seldom possible and not effective, 138 . Ovum, described, 38 ; fertilized, 39 ; reduction of, 45 . 
Packwood, H. E., on Collie pedigrees, II5 seq.; quoted on trust-to-luck breeding, 128 .

Parturition troubles, $170 \mathrm{seq}$.

Pasterns, weak, a bad fault, ro3.

Pearson, correction of Galton's law, 90 .

Pedigree, true meaning of, 22-25; another example, 26; importance of in understanding regression, $7 \mathrm{I}$; how to use in selection, 103 ; studies invaluable to breeders, Iro;

Raper quoted on, 129 .

Penis, fracture of bone of, 158 ; prevented from passing prepuce opening, 158 ; growths on, 160.

Pointer, 5I, 78, 84, I00, II6, 122.

Points, knowledge of, necessary, 96; following Mendelian inheritance, I2I seq.; balancing of, in mating dangerous,

I4I.

Pomeranian, II6.

"Practical Dog Keeping," companion volume, 149, 162.

Predominance of strains and individuals, 99 .

Pregnancy, care of bitch during, 165,183 ; determination of, I66; period of, 167 ; table of duration, 194-195.

Prenatal impressions, as cause of variation, $57 \mathrm{seq}$.

Prepuce, too small opening of, 158.

Previous sire, effect of, see Telegony.

Protoplasm, a part of all cells, 36; behavior in reduction, 45 . Puppies, less numerous in wild dogs, 59; easy to train setter, 84 ; dog gets more than a bitch produces, r02; are proof of successful breeding, 107, 179; malpresentation of, 170 seq.; care of, at birth, $174,18 \mathrm{I}$; number a bitch can raise, 175; good care necessary, 180; artificial feeding of, 184; teething, 185 seq. 189 ; rickets in, 189 ; special illnesses of, 192; putting out to walk, 193 .

Pure line, breeding experiments in, $68 \mathrm{seq}$.

Rabies, not to be confused with fits, 190 .

Race average, offspring closer to, than exceptional parents, $7 \mathrm{I}$; advantages of strain raised above, 94 .

Raper, George, quoted on pedigree, I29.

Regression, principle of demonstrated, 70 seq.; what it means to a breeder, 90; object of selection is to overcome, 96; against a belief in alternate generation breeding system, 137 ; how to make an ally of, 139 . 
Reproduction, mechanical side of, 35 seq.; bisexual, 38 ; asexual, 70.

Reversion, part of heredity rather than of variation, 58 .

Rickets, r89.

St. Bernard, $\mathbf{1 8 7}$.

Schipperke, 55 .

Scottish Terrier, 97, 100, I I2-II3, I16, I35, I43, I91.

Screw tail, originally a mutation, 54 .

Segregation, Mendelian ratio of, 76 ; fundamental part of all Mendelian inheritance, 77 .

Selection, kind, formerly practiced, 25 ; artificial and natural, 30 seq.; breeder's work is, $34, \mathbf{1 8 0}$; fruitless in pure line breeding, 70; solution of problems of, 89 ; the true object of, 89 , ro4; accomplishments possible by, 92 ; six generations of, will fix a character, 94; adverse, sometimes forced on breeder, 95; limits of, 95 ; able to change type, 96; rational principles of, $96 \mathrm{seq} . ;$ good rule for, 102 ; how to use a pedigree in, ro3; abandoned in trustto-luck breeding, 128; perverted in fashionable breeding, 129; of sire, r45; of dam, r40, r6r.

Service, care of bitch before, $15 \mathrm{I}$; certificate of, 156 ; proper time for, 163 .

Setter, 84, 92, Ir6, 156, r70.

Sewell, Dr. A. J., on composition of bitch's milk, 183 .

Shyness, to be avoided in breeding stock, $5 \mathrm{I}$.

Sire, not more important than dam, 83, 99; great improvement has come from few great, ror; great effect on breed of popular, IO2; importance of exceptional sires, II7; not necessarily famous for his daughters, 120; breeding a bitch to her sire's, 127; selection of, 145 seq.

Size, limit reached in some breeds, 96.

Skye Terrier, 20.

Spaniels, 40, 79, 19 r.

Squeaks, 182 .

Stamina, cannot always be maintained, 95 ; impaired by in and inbreeding, 133 .

Standard, knowledge of, necessary, 19; could well be more specific, 20; new English Fox Terrier, 53. 
Statistics, of telegony, 57 ; of variation in human height, 70 ; of champions, II3-114; of Airedale breeding, II7-121. Sterility, a result of inbreeding, 133 ; a cure for, 158 ; temporary, 158 ; lack of sexual desire results in, 159 .

Stock breeders, more scientific than dog breeders, 15; believe in prenatal impressions, 58 .

Strain, knowledge of important, 99; some are prepotent, roo; recognized by dog breeders, 115 ; of winners in Collies and Airedales, II6-I2I; a breeder's own, importance of establishing, 19; chief advantage of, 25; the Duchess of Newcastle's, 28; Warren, 56; an ally against regression, 73 ; several famous, 92 ; establishment of, is best breeding system, $\mathbf{x} 39$.

Stud Book, records success of small breeder, 28; furnishes measure of breeding success, 107; typographical errors in, 108.

Stud dog, great show dog not always a great, ror; objections to keeping a stud dog, $145 \mathrm{seq}$.; the ideal, r 48 ; feeding, I50; number of bitches should serve, I5O; advertising, r52 seq.; peculiar ills of, 157 .

Taylor, Major, studies in bird dog pedigrees, 116 .

Teats, sore, $\mathbf{1 7 7}$.

Teething, time of, 185 seq.; troubles during, 188.

Telegony, breeder's hazy ideas about, 15 ; evidence pro and con, 55; Ewart's experiments in, 57; Davenport's statistics about, 57 .

Testicles, inflammation of, $\mathbf{1 5 9}$.

Tie, evidence of service, $15 \mathrm{I}$.

Toy Spaniels, 52.

Type, changed by selection, 96 ; changed by judges, 98 .

Use and disuse, effect of, on breeding stock, 84 .

Uterus, inflammation of, during heat, 164 ; injuries to, in forced deliveries, $\mathbf{1 7 2 .}$

Variation, law of, 30 ; basis of selection, 34 ; secret of, in germ cells, 40 ; reduction a cause of, 46 ; reason for shows and trials, 48 ; correlated, 50 ; of form and function, $5 \mathrm{I}$; quantitative and qualitative, 52 ; continuous and discontinu- 
ous, 52 ; internal causes of, 55 seq.; external forces causing, $59 \mathrm{seq}$.; mathematical nature of, 62 ; normal, 63 ; in pure line, 69; breeder a spectator of, 88 ; always present, 93 ; mathematical study of, 93 ; not to be reduced by selection, 95 .

Vermifuges, 188 .

Watson, James, example from on true meaning of pedigree, 22 seq.

Watson, J. A. S., on normal variation, 62.

Weaning, best left to nature, $\mathbf{r} 78$; when to start, 185 .

Weismann, theory of heredity, $4 \mathrm{r}$ seq.

Whelping, certificate of, 157 ; box for, 167 ; time required for, I 68 ; care of bitch during, r70; malpresentation of pups in, $17 \mathrm{r}$.

Woodward, Earle J., on Airedale strains, Ir7.

Worms, in brood bitches, 165 ; in pups, 188, 193. 



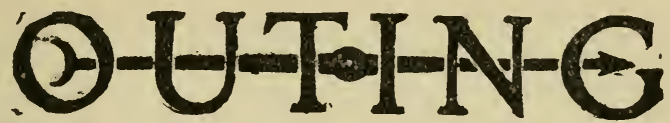

\section{HANDBOOKS The textbooks for out- door work and play}

a Each book deals with a separate subject and deals with it thoroughly. If you want to know anything about Airedales an OUTING HANDBOOK gives you all you want. If it's Apple Growing, another OUTING HANDBOOK meets your need. The Fisherman, the Camper, the Poultry-raiser, the Automobilist, the Horseman, all varieties of out-door enthusiasts, will find separate volumes for their separate interests. There is no waste space.

a The series is based on the plan of one subject to a book and each book complete. The authors are experts. Each book has been specially prepared for this series and all are published in uniform style, flexible cloth binding.

व Two hundred titles are projected. The series covers all phases wi cutdoor life, from bee-keeping to big-game shooting. Among the bocks now ready or in preparation are those described on the following pages.

PIICE SEVENTY CENTS PER VOL. NET, POSTAGE 5c. EXTRA THE NUMBERS MAKE ORDERING EASY.

1. EXERCISE AND HEALTH, by Dr. Woods Huichinson. Dr. Hutchinson takes the common-sense view that the greatest problem in exercise for most of us is to get enough of the right kind. The greatest error in exercise is not to take enough, and the greatest danger in athletics is in giving them up. He writes in a direct matter-of-fact manner with an avoidance of medical terms, and a strong emphasis on the rational, all-round manner of living that is best calculated to bring a man to a ripe old age with little illness or consciousness of bodily weakness.




2. CAMP COOKERY, by Horace Kephart. "The less a man carries in his pack the more he must carry in his head," says Mr. Kephart. This book tells what a man should carry in both pack and head. Every step is traced-the selection of provisions and utensils, with the kind and quantity of each, the preparation of game, the building of fires, the cooking of every conceivable kind of food that the camp outfit or woods, fields or streams may provideeven to the making of desserts. Every recipe is the result of hard practice and long experience.

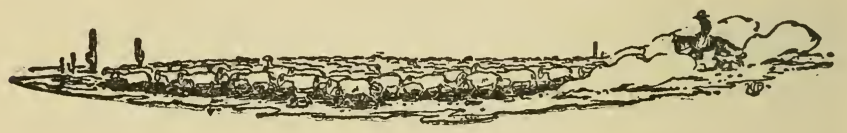

\section{BACKWOODS SURGERY AND MEDICINE,}

by Charles S. Moody, M. D. A handy book for the prudent lover of the woods who doesn't expect to be ill but believes in being on the safe side. Common-sense methods for the treatment of the ordinary wounds and accidents are described-setting a broken limb, reducing a dislocation, caring for burns, cuts, etc. Practical remedies for camp diseases are recommended, as well as the ordinary indications of the most probable ailments. Includes a list of the necessary medical and surgical supplies.

4. APPLE GROWING, by M. C. Burritt. The various problems confronting the apple grower, from the preparation of the soil and the planting of the trees to the marketing of the fruit, are discussed in detail by the author. Chapter headings are:-The Outlook for the Growing of Apples-Planning for the OrchardPlanting and Growing the Orchard-Pruning the Trees-Cultivation and Cover Cropping-Manuring and Fertilizing-Insects and Diseases Affecting the Apple-The Principles and Practice of Spraying -Harvesting and Storing-Markets and Marketing-Some Hints ou Renovating Old Orchards-The Cost of Growing Apples.

\section{THE AIREDALE, by Williams Haynes. The} book opens with a short chapter on the origin and development of the Airedale, as a distinctive breed. The author then takes up tho problems of type as bearing on the selection of the dog, breeding, training and use. The book is designed for the non-professional dog fancier, who wishes common sense advice which does not involve elaborate preparations or expenditure. Chapters are included on the care of the dog in the kennel and simple remedies for ordinary diseases. 
6. THE AUTOMOBILE-Its Selection, Care and Use, by Robert Sloss. This is a plain, practical discussion of the things that every man needs to know if he is to buy the right car and get the most out of it. The various details of operation and care are given in simple, intelligent terms. From it the car owner can easily learn the mecharisin of his metor and the art of locating motor trouble, as well as how to use his car for the greatest pleasure. A chapter is included on building garages.

\section{FISHING KITS AND EQUIPMENT, by} Samuel G. Camp. A complete guide to the angler buying a new outfit. Every detail of the fishing kit of the freshwater angler is described, from rodtip to creel, and clothing. Special emphasis is laid on outfitting for fly fishing, but full instruction is also given to the man who wants to catch pickerel, pike, muskellunge, lake-trout, bass and other freshwater game fishes. Prices are quoted for all articles recommended and the approved method of selecting and testing the various rods, lines, leadere, etc., is described.

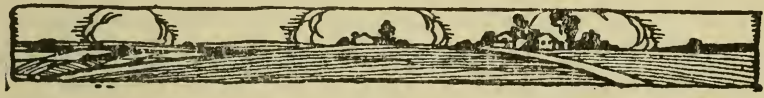

\section{THE FINE ART OF FISHING, by Samuel G.}

Camp. Combine the pleasure of catching fish with the gratification of following the sport in the most approved manner. The suggestions offered are helpful to beginner and expert anglers. The range of fish and fishing conditions covercd is wide and includes such subjects as "Casting Fine and Far Off," "Strip-Casting for Bass," "Fishing for Mountain Trout" and "Autumn Fishing for Lake Trout." The book is pervaded with a spirit of love for the streamside and the ont-doors generally which the genuine angler will appreciate. A companion book to "Fishing Kits and Equipment." The advice on outfitting 80 capably given in that book is supplemented in this later work by equally valuable information on how to use the equipment.

\section{THE HORSE-Its Breeding, Care and Use, by} David Buffum. Mr. Buffum takes up the common, every-day problems of the ordinary horse-users, such as feeding, shoeing, simple home remedies, breaking and the cure for varions equine vices. An important chapter is that tracing the influx of Arabian blood into the English and American horses and its value and limitations. Chapters are included on draft-horses, carriago horses, and the development of the two-minute trotter. It is distinctly a sensible book for the sensible man who wishes to know how he can improve his horses and his horsemanship at the same time. 
10. THE MOTOR BOAT-Its Selection, Care and Use, by H. W. Slauson. The intending purchaser is advised as to the type of motor boat best suited to his particular needs and how to keep it in running condition after purchased. The chapter headings are : Kinds and Uses of Motor Boats-When the Motor Balks-Speeding of the Motor Boat-Getting More Power from a New Motor-How to Install a Marine Power Plant-AccessoriesCovers, Canopies and Tops - Camping and Cruising-The Boathouse.

11. OUTDOOR SIGNALLING, by Elbert Wells. Mr. Wells has perfected a method of signalling by means of wigwag, light, smoke, or whistle which is as simple as it is effective. The fundamental principle can bo learned in ten minutes and its application is far easier than that of any other code now in use. It permits also the use of cipher and can be adapted to almost any imaginable conditions of weather, light, or topography.

\section{TRACKS AND TRACKING, by Josef Brunner.} Atter twenty years of patient study and practical experience, Mr. Brunner can, from his intimate knowledge, speak with authority on this subject. "Tracks and Tracking" shows how to follow intelligently cven the most intricate animal or bird tracks. It teaches how to interpret tracks of wild game and decipher the many tell-tale signs of the chase that would otherwise pass unnoticed. It proves how it is possible to tell from the footprints the name, sex, speed, direction, whether and how wounded, and many other things about wi.d animals and birds. All material has been gathered first hand; the drawings and half-tones from photographs form an important part of the work.

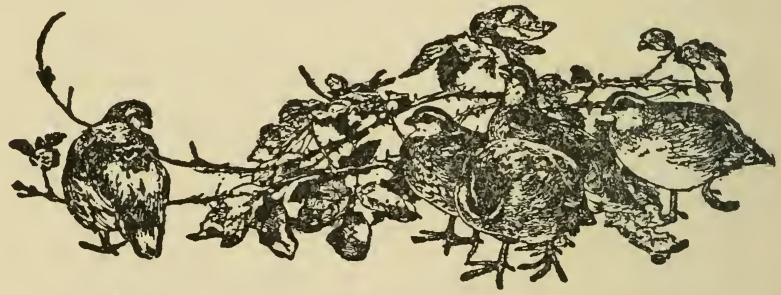

13. WING AND TRAP-SHOOTING, by Charles Askins. Contains a full discussion of the various methods, such as snap-shooting, swing and half-swing, discusses the flight of birds with reference to the gunner's problem of lead and range and makes special application of the various points to the different birds commonly shot in this country. A chapter is included on trap shooting and the book closes with a forceful and common-sense presentation of the etiquette of the field. 


\section{PROFITABLE BREEDS OF POULTRY, by}

Arthur S. Wheeler. Mr. Wheeler discusses from personal experience the best-known general purpose breeds. Advice is given from the standpoint of the man who desires results in eggs and stock rather than in specimens for exhibition. In addition to a careful analysis of stock-good and bad-and some conclusions regarding housing and management, the author writes in detail regarding Plymouth Rocks, Wyandottes, Orpingtons, Rhode Island Reds, Mediterraneans and the Cornish.

\section{RIFLES AND RIFLE SHOOTING, by Charles}

Askins. A practical manual describing various makes and mechanisms, in addition to discussing in detail the range and limitations in the use of the rifle. Treats on the every style and make of rifle as well as their use. Every type of rifle is discussed so that the book is complete in every detail.

\section{SPORTING FIREARMS, by Horace Kephart.} This book is the result of painstaking tests and experiments. Practically nothing is taken for granted. Part I deals with the rifle, and Part II with the shotgun. The man seeking guidance in the selection and use of small firearms, as well as the advanced student of the subject, will receive an unusual amount of assistance from this work. The chapter headings are: Rifles and Arnmunition-The Flight of Bullets-Killing Power-Rifle Mechanism and MaterialsRifle Sights-Triggers and Stocks-Care of Rifle-Shot Patterns and Penetration-Gauges and Weights-Mechanism and Build of Shotguns.

\section{THE YACHTSMAN'S HANDBOOK, by Herbert}

L. Stone. The author and compiler of this work is the editor of "Yachting." He treats in simple language of the many problems confronting the amateur sailor and motor boatman. Handling ground tackle, handling lines, taking soundings, the use of the lead line, care and use of sails, yachting etiquette, are all given careful attention. Some light is thrown upon the operation of the gasoline motor, and suggestions are made for the avoidance of engine troubles.

\section{SCOTTISH AND IRISH TERRIERS, by Wil-} liams Haynes. This is a companion book to "The Airedale," and deals with the history and development of both breeds. For the owner of the dog, valuable information is given as to the use of the terriers, their treatment in health, their treatment when sick, the principles of dog breeding, and dog shows and rules. 
19. NAVIGATION FOR THE AMATEUR, by Capt. E. T. Morton. A short treatise on the simpler methods of find ing position at sea by the observation of the sun's altitude and the use of the sextant and chronometer. It is arranged especially for yachtsmen and amateurs who wish to know the simpler formulae for the necessary navigation involved in taking a boat anywhere of shore. Illustrated with drawings. Chapter headings: Fundamenta] Terms--Time-The Sumner Line-The Day's Work, Equal Altitude, and Ex-Meridian Sights-Hints on Taking Observations.

\section{OUTDOOR PHOTOGRAPHY, by Julian A.} Dimock. A solution of all the problems in camera work out-of doors. The various subjects dealt with are: The Camera-Lens and Plates-Light and Exposure-Development-Prints and PrintingComposition-Landscapes-Figure Work-Speed Photography-The Leaping Tarpon-Sea Pictures-In the Good Old Winter TimeWild Life.

\section{PACKING AND PORTAGING, by Dillon} Wallace. Mr. Wallace has brought together in one volume all the valuable information on the different ways of making and carry. ing the different kinds of packs. The ground covered ranges from man-paoking to horse-packing, from the use of the tump line to throwing the diamond hitch.

22. THE BULL TERRIER, by Williams Haynes. This is a companion book to "The Airedale" and "Scottish and Irish Terriers" by the same author. Its greatest usefulness is as a guide to the dog owner who wishes to be his own kennel manager. A full account of the development of the breed is given with a description of best types and standards. Recommendations for the care of the dog in health or sickness are included. The chapter head. cover such matters as:- The Bull Terrier's History-Training the Bull Terrier-The Terrier in Health-Kenneling-Diseases.

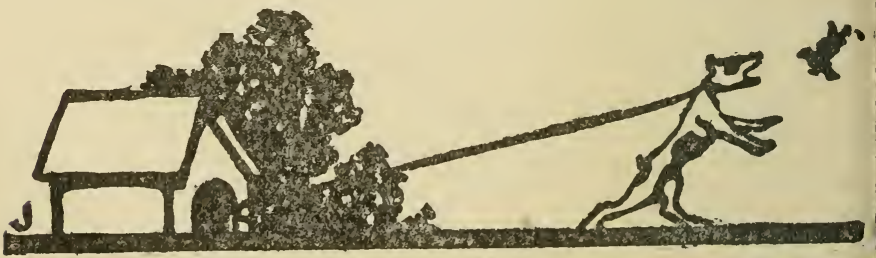


27. ICE BOATING, by H. L. Stone. Ilustrated n diagrams. Here have been brought together all the available formation on the organization and history of ice-boating, the bu ing of the various types of ice yachts, from the small 15 footer the 600 -foot racer, together with detailed plans and specificatic Full information is also given to meet the needs of those who w to be able to build and sail their own boats but are handicapped the lack of proper knowledge as to just the points described in $t$ volume.

\section{MODERN GOLF, by Harold H. Hilton.} Hilton is the only man who has ever held the amateur champi ship of Great Britain and the United States in the same year. addition to this, he has, for years, been recognized as one of most intelligent, steady players of the game in England. This bc is a product of his advanced thought and experience and gives 1 reader sound advice, not so much on the mere swinging of the cli as in the actual playing of the game, with all the factors that en into it. He discusses the use of wooden clubs, the choice of clu the art of approaching, tournament play as a distinct thing in its! and kindred subjects.

\section{INTENSIVE FARMING, by L. C. Corbe} A discussion of the meaning, method and value of intensive methc in agriculture. This book is designed for the convenience of pr tical farmers who find themselves under the necessity of making: living out of high-priced land.

\section{PRACTICAL DOG BREEDING, by Williar}

Haynes. This is a companion volume to PRACTICAL DC KEEPING, described below. It goes at length into the func mental questions of breeding, such as selection of types on bo sides, the perpetuation of desirable, and the elimination of undes able, qualities, the value of prepotency in building up a desir breed, etc. The arguments are illustrated with instances of wh has been accomplished, both good and bad, in the case of we known breeds.

\section{PRACTICAL DOG KEEPING, by Willian}

Haynes. Mr. Haynes is well known to the readers of the OUTIN HANDBOOKS as the author of books on the terriers. His nf book is somewhat more ambitious in that it carries him into $t$. general field of selection of breeds, the buying and selling of dof the care of dogs in kennels, handling in bench shows and field tria and at considerable length into such subjects as food and feedin exercise and grooming, disease, etc. 


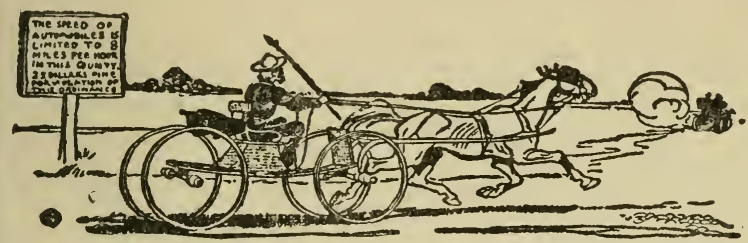

\section{PRACTICAL TREE PLANTING, by C. R.} ttis. The author, who is the New York State Forester, takes up general subject of reforesting, covering nature's method and the ctical methods of broadcast seed-sowing, seed spot planting, sery practice, etc. The various species are described and their ptability to varying conditions indicated. Results of reforesting shown and instructions are given for the planting of windaks and shade trees.

\section{AMATEUR RODMAKING, by Perry D. Frazer.} ustrated. A practical manual for all those who want to mako ir own rod and fittings. It contains a review of fishing rod hisy, a discussion of materials, a list of the tools needed, description the method to be followed in making all kinds of rods, including casting, bait-fishing, salmon, etc., with full instructions for windi, varnishing, etc.

\section{PISTOL AND REVOLVER SHOOTING, byA. L.} Himmelwright. A new and revised edition of a work that has ady achieved prominence as an accepted authority on the use of hand gun. Full instructions are given in the use of both revolver target pistol, including shooting position, grip, position of arm, etc. book is thoroughly illustrated with diagrams and photographs includes the rules of the United States Revolver Association a list of the records made both here and abroad.

\section{PIGEON RAISING, by Alice MacLeod. This} book for both fancier and market breeder. Full descriptions given of the construction of houses, the care of the birds, preation for market, and shipment. Descriptions of the various eds with their markings and characteristics are given. Illustrated a photographs and diagrams.

\section{FISHING TACKLE, by Perry D. Frazer. I1-} trated. The subtitle is descriptive. "Mints for Beginners in Selection, Care, and Use of Rods, Reels, Liues, etc." It tells all fisherman needs to know about making and overhauling his de during the closed season and gives full instructions for tourient casting and fly-casting. Chapters are included on cases and ders for the care of tackle when nut in use. 


\section{AUTOMOBILE OPERATION, by A.}

Brennan, Jr. Illustrated. Tells the plain truth about the li things that every motorist wants to know about his own car. you want to cure ignition troubles? Overhaul and adjust y! carbureter? Keep your transmission in order? Get the maxim wear out of your tires? Do any other of the hundred and things that are necessary for the greatest use and enjoyment of $y$ car? Then you will find this book useful.

38. THE FOX HOUND, by Roger D. Williar Author of "Horse and Hound". Illustrated. The autho: the foremost authority on fox hunting and foxhounds in Amer: For years he has kept the foxhound studbook, and is the final sou of information on all disputed points relating to this breed. book discusses types, methods of training, kenneling, diseases a all the other practical points relating to the use and care of hound. An appendix is added containing the rules and regulati of hound field trials.

39. SALT WATER GAME FISHING, by Char F. Holder. Mr. Holder covers the whole field of his sub; devoting a chapter each to such fish as the tuna, the tarpon, ami jack, the sail fish, the yellow-tail, the king fish, the barracuda, sea bass and the small game fishes of Florida, Porto Rico, the Pac Coast, Hawaii, and the Philippines. The habits and habitats of fish are described, together with the methods and tackle for tak them. The book concludes with an account of the developm and rules of the American Sea Angling Clubs. Illustrated.

40. WINTER CAMPING, by Warwick S. Carpent $A$ book that meets the increasing interest in outdoor life in the $c$ weather. Mr. Carpenter discusses such subjects as shelter equipme clothing, food, snowshoeing, skiing, and winter hunting, wild life winter woods, care of frost bite, etc. It is based on much actual perience in winter camping and is fully illustrated with work photographs.

41. LEARNING TO SWIM, by L. DeB. Handle Illnstrated. Mr. Handley takes up the problem from the standpo of the person of any sex or age who cannot swim a stroke. Step step he unfolds the various stages, floating, the side stroke, $t$ crawl, the trudgeon, the breast stroke, swimming on the back, e concluding with a chapter on speed swimming and training for $\mathbf{x}$ ing. It covers the whole field of natation in a clear, simple manx with photographs showing each stroke in detail.

42. BOAT AND CANOE BUILDING, by Vic Slocum. All of us like to think we could build a boat if we 1 to. Mr. Slocum tells us how to do it. Designs are given for various types of canoes as well as full descriptions for preparing material and putting it together. Small dories and lapstreak bc cee also includes 


\section{PRACTICAL PROSPECTING, by Charles}

Johnson Post. Illustrated. Did you ever wonder what orebearing rock looked like? Did you ever want to know how to test it for the various minerals? Would you be interested in lcarning how to put together a rough and ready outfit that would do all the work of the more expensive kits? This book covers all these points and more. It is a valuable companion for a walking trip through the hills. It telis you not only where minerals are found and how, but also where you need not expect to find them.

\section{BOXING, by D. C. Hutchison. Practical in-} struction for men who wish to learn the first steps in the manly art. Mr. Hutchison writes from long personal experience as an amateur boxer and as a trainer of other amateurs. His instructions are accompanied with full diagrams showing the approved blows and guards. He also gives full directions for training for condition without danger of going stale from overtraining. It is essentially a book for the amateur who boxes for sport and exercise.

\section{TENNIS TACTICS, by Raymond D. Little.} Out of his store of experience as a successful tennis player, Mr. Little has written this practical guide for those who wish to know how real tennis is played. He tells the reader when and how to take the net, discusses the relative merits of the back-court and volleying game and how their proper balance may be achieved; analyzes and appraises the twist service, shows the fundamental necessities of successful doubles play.

\section{THE AUXILIARY YACHT, by H. L. Stone.} Combines information on the installation of power in a boat that was not designed especially for it with the features desirable in degigning a boat for this double use. Deals with the peculiar properties of the auxiliary, its advantages and disadvantages, the handling of the boat under sail and power, etc. Does not go into detail on engine construction but gives the approximate power needed for different boats and the calculations necessary to find this figure.

\section{TAXIDERMY, by Leon L. Pray. Illustrated with} diagrams. Being a practical taxidermist, the author at once goes into the question of selection of tools and materials for the various stages of skinning, stuffing and mounting. The subjects whose handling is described are, for the most part, the every-day ones, such as ordinary birds, small inammals, etc., although adequate instructions are included for mounting big game specimens, as well as the pre liminary care of skins in hot climates. Full diagrams accompany the text. 


\section{THE CANOE-ITS SELECTION, CARE AND} USE, by Robert E. Pinkerton. Illustrated with photographs With proper use the canoe is one of the safests crafts that floats Mr. Pinkerton tells how that state of safety may be obtained. He gives full instructions for the selection of the right canoe for each particular purpose or set of conditions. Then he tells how it should be used in order to secure the maximum of safety, comfort and use fulness. His own lesson was learned among the Indians of Canada where paddling is a high art, and the use of the canoe almost a much a matter of course as the wearing of moccasine.

\section{HORSE PACKING, by Charles J. Post} Illustrated with diagrams. This is a complete description of the hitches, knots, and apparatus used in making and carrying loads of various kinds on horseback. Its basis is the methods followed in the West and in the American Army. The diagrams are full and detailed giving the various hitches and knots at each of the important stages so that even the novice can follow and use them. It is the only book ever published on this subject of which this could be said Full description is given of the ideal paok animal, as well as a cata logue of the diseases and injuries to which such animals are subject

\section{RAINY DAY IN CAMP, by C. H. Claudy} Illustrated. What do you do when you are stormbound in the camp and time hangs heavy on your hands? This book gives a long list of games that you can play and the rules that govern them. It alsc describes various improvised indoor occupations appropriate tc camp life. If you have it in your dufflo bag you need not fear the approach of threatening clouds.

\section{WALKING OUTFITS, by C. P. Fordyce} Mlustrated. Every year tho adherents of "hiking" in this country grow in numbers and enthusiasm. It is an old art and a valuable one. But something more than a pair of legs is necessary to makt the walking trip a success. You must wear the right shoes and thr right clothes. You must carry with you the right kind of sleeping and cooking outfit. Mr. Fordyce gives the concentrated experience of many years on highway and trail.

\section{LEARNING TO SKATE. by J. F. Verne} Illustrated. Half the fun of skating is in knowing how to do $i$ with the least effort. Nothing is so easy when you know howso hard when you don't. This book describes the process in detai from the firet day on the ice to the highest development o speed and fancy skating. The author is familiar with the lates developments in Europe where figuro skating has been carried t" a much higher point than in America. 






\section{LIBRARY OF CONGRESS \\ |||||||||||||||||||||||||||||}

